\title{
Paulus in seiner Welt
}

Nach der Darstellung des Diasporajudentums in der hellenistischen Welt als Ausgangskultur kommt im Folgenden Paulus als zentraler Akteur innerhalb des kulturellen Transfers in den Fokus. Als Akteur in einem kulturellen Transfer bleibt er - wie alle daran Beteiligten - nicht unverändert, sondern wird von den Prozessen berührt und beeinflusst.

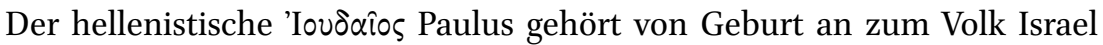
und ist in dessen Traditionen aufgewachsen, erzogen und verwurzelt. Das hellenistische Judentum ist also sein Orientierungssystem. Zugleich ist Paulus auch zutiefst geprägt von seinem nicht jüdischen Umfeld, mit dem er sich aktiv auseinandersetzt. Dies drückt sich allein schon in der Sprache aus, die er verwendet.

Wie bereits diskutiert, sind Sprache und Kultur eng miteinander verbunden. Zudem sind sämtliche uns überlieferten zeitgenössischen Quellen zu Paulus selbst sprachlicher Art, sodass man sich auch nur über Sprache an Paulus annähern kann. Die Zeugnisse, aufgrund derer wir die Verflechtungen des Paulus mit seiner Umwelt nachvollziehen können, sind sprachlich. Seine überlieferten Perspektiven kreuzen sich mittels Sprache mit denen seiner Adressatenschaft. Sprache ist folglich sehr zentral für das paulinische Vermittlungsgeschehen. Entsprechend werden im ersten Teil dieses Kapitels zunächst diverse Aspekte paulinischer Sprache thematisiert.

Daran schliesst eine Diskussion an über das Medium, mit dessen Hilfe Paulus - wiederum sprachlich - kommuniziert: seine Briefe. Die Briefe sind ein Teil des paulinischen Vermittelns. Sie ermöglichen es, dass Menschen, deren Wege sich bereits gekreuzt haben, weiterhin in Kontakt bleiben oder dass überhaupt ein solcher entsteht (Röm). Entsprechend kommt ihnen grosse Bedeutung zu. Sie weben die Fäden weiter, die Paulus in seinen Besuchen vor Ort gesponnen hat. Zugleich sind sie aber nur ein Teil des Vermittlungsgeschehens. Für die Entstehung von Verflechtungen zwischen der Ausgangsund der Zielkultur sowie für die Vermittlung des kulturellen Artefakts sind schliesslich auch die paulinischen Besuche, seine Begegnungen mit den Menschen vor Ort, aber ebenso das Wirken der Mitarbeitenden des Paulus von herausragender Bedeutung. Möglicherweise spielen die Briefe neben diesen anderen Faktoren und Gelegenheiten der Begegnung und Kommunikation in der historischen Realität sogar eine untergeordnete Rolle. Aber die Briefe sind die einzigen überlieferten zeitgenössischen Zeugnisse, weshalb ihnen aus 
der Retrospektive als Medium im Vermittlergeschehen eine so zentrale Rolle zukommt.

Dieselben Briefe sind zugleich auch die Quellen, über die sich die Selbstdarstellung des Paulus hinsichtlich seiner Identität und seiner Rolle als Vermittler erschliessen lässt. Dies wird das Thema des dritten Abschnitts dieses Kapitels sein.

\subsection{Welche Sprachen spricht Paulus?}

Paulus' Erfahrung von Sprache ist die eines hellenistischen 'Iovőaios. In seinen Briefen greift er häufig auf das schriftliche Herzstück seines angestammten Orientierungssystems, die Septuaginta, zurück, die er wahrscheinlich auswendig zitiert oder auch frei interpretiert und neu kombiniert. ${ }^{1}$ Die Septuaginta als griechische Übersetzung der Hebräischen Bibel ist selbst ein herausragendes Produkt eines intensiven Akkulturationsprozesses und Manifest einer normierten Sprachwelt. ${ }^{2}$ Die Freiheit, mit welcher Paulus zitiert, weist deutlich auf die Mündlichkeit des paulinischen Kontexts hin. ${ }^{3}$ Paulusbriefe lassen auch insgesamt eine Nähe zur gesprochenen Sprache erkennen. So nennt Marius Reiser als Merkmale gesprochener Sprache bei Paulus neben Gedankensprüngen und verkürzten Formulierungen insbesondere das gehäufte Vorkommen von Anakoluthen, Ellipsen und Parenthesen, die sich „aus der sukzessiven und assoziativen Denkweise" in der freien Rede ergeben. ${ }^{4}$ Paulus

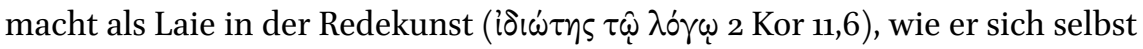
bezeichnet, kaum literarische Ambitionen geltend. Trotzdem setzt er bisweilen rhetorische Stilfiguren wirkungsvoll ein: das Polysyndeton (Röm 8,35.38-39; 9,4; 1 Kor 1,30), die Klimax (gradatio; Röm 5,3-5; 8,30), das Wortspiel und die Paronomasie (z. B. Röm 1,29.31; 12,3; 2 Kor 6,10; Phil 3,2-3), und in Röm 12,15 „sind Homoiarkton (Wortanfangsalliteration), Polyptoton (Gleichklang der Flexionsformen) verbunden“. ${ }^{5}$ Ein Beispiel für die häufigen Verbindungen von

1 Paulus weist diesbezüglich grosse Freiheit auf. Vgl. dazu die Abschnitte „Ergebnisse und Schlussfolgerungen“ und „Vergleich mit der zeitgenössischen Zitierpraxis“ bei Dietrich-Alex Koch, Die Schrift als Zeuge des Evangeliums: Untersuchungen zur Verwendung und zum Verständnis der Schrift bei Paulus, BHTh 69 (Tübingen 1986), 186-190; hier: 190-198.

2 Vgl. dazu K. Usener, „Die Septuaginta im Horizont des Hellenismus. Ihre Entwicklung, ihr Charakter und ihre sprachlich-kulturelle Position“, in: Kreuzer et al., Im Brennpunkt: Die Septuaginta, Bd. 2, 8-118.

3 Vgl.J. A. Loubser, „Orality and Literacy in the New Pauline Epistles: Some New Hermeneutical Implications", in: Neotest. 29, Nr. 1 (1995), 61-74, hier: 65.

4 Vgl. Reiser, Sprache und literarische Formen des Neuen Testaments, 72-73, Zitat: 72.

5 Ebd., 74. 
Anaphern und Asyndeta ist 1 Kor 13,7. Parallelismen und Antithesen kommen in den Paulusbriefen sehr häufig vor (Parallelismen z. B. in Röm 1,21, 5,12-21; 1 Kor 4,5; 2 Kor 9,6; Gal 6,8; Antithesen in Röm 7,15; 8,10; 10,10; 1 Kor 1,20-25; 7,29-31; 2 Kor 4,8-9; 6,8-9).

Eine treffende Charakterisierung von Paulus' Schreibstil durch Félix-Marie Abel soll hier wiedergegeben werden:

Die Perioden, zu denen der heilige Paulus ansetzt, werden selten glücklich zu Ende geführt. Nicht daß er die Regeln der Grammatik verachtete, aber er vergißt sie einfach, und so läßt sich der Apostel fortreißen vom ungestümen Schwall seines Gedankens in unvermittelte Abschweifungen, Anakoluthe und häufige Ausflüge ins Unerwartete. Anders als der Stil der Pastoralbriefe, dieser nüchterne, lehrhafte, abgewogene und sozusagen gebändigte Stil, ist der Stil der paulinischen Briefe voller Irregularitäten und Härten, über die hinweg sich der Faden der Argumentation fortspinnt unter großem Aufwand an Partikeln und Partizipien, die einen Ausgleich bieten für die Lücken des Diskurses. ${ }^{6}$

Paulus verfasst seine Briefe auf Griechisch - bzw. lässt sie auf Griechisch schreiben -, und es spricht viel dafür, dass Paulus griechischer Muttersprache war, jedenfalls dafür, dass er die Sprache auch mündlich fliessend beherrschte. Letztere Annahme liegt auch innerbiblisch unter Heranziehung von Episoden aus der Apostelgeschichte nahe.

Betreffend Paulus' Gespräch mit Felix und Festus fehlt jeglicher explizite Hinweis darauf, welche Sprache sie verwenden. Der Text scheint stillschweigend davon auszugehen, dass Paulus sowohl mit dem römischen Statthalter Felix als auch mit dessen Nachfolger Festus Griechisch spricht (Apg 24,10-21; Apg 25,8-11) und dass ihm die Konversation in dieser Sprache keine Mühe bereitet.

Weiter bittet Paulus bei seiner Verteidigung im Tempel den Obersten, ein Wort mit ihm reden zu dürfen. Der Oberste zeigt sich erstaunt darüber, dass Paulus Griechisch versteht. Durch Paulus' Griechischkenntnisse realisiert der Oberste, dass Paulus ein anderer ist als der, für den er ihn gehalten hat (Apg 21,37-38). Im Gegensatz dazu bemerkt der Erzähler unmittelbar anschliessend, dass sich Paulus - auf der Freitreppe stehend - in „hebräischer

6 So die Übersetzung von Reiser: ebd., 73. Originaltext: „Les périodes entreprises par saint Paul sont rarement menées à bon terme. Plus oublieux peut-être que dédaigneux des règles grammaticales, l'apôtre se laisse entraîner par la fougue de sa pensée dans de brusques écarts, des parenthèses, des anacoluthes, des incursions fréquentes dans l'inattendu; le style des Pastorales mis à part, ce style sobre, didactique, pondéré et pour ainsi dire dompté, celui des épîtres pauliniennes est plein d'irrégularités et d'aspérités à travers lesquelles le fil de l'argumentation se poursuit à grand renfort de particules et de participes qui compensent les lacunes du discours." Félix-Marie Abel, Grammaire du Grec biblique suivie d'un choix de papyrus, 2. Aufl., Etudes bibliques Lecoffre (Paris: Gabalda, 1927), 359. 


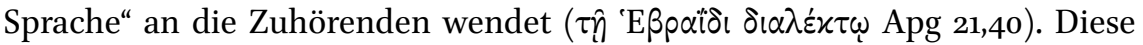
Bemerkung lässt darauf schliessen, dass man eher Griechisch erwarten könnte und dass entsprechend das Hebräische/Aramäische ${ }^{7}$ überraschend kommt. Das unerwartete Hebräische/Aramäische hat jedenfalls den Effekt, dass die

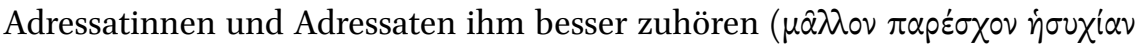
Apg 22,2). Umgekehrt würden die Zuhörenden Paulus sicher auch teilweise oder sogar ganz verstehen, wenn er Griechisch spräche. Wahrscheinlich hat er in der betreffenden Situation einen ganz bestimmten Grund, warum er Hebräisch/Aramäisch und nicht Griechisch spricht. Wie aus Apg 21,21 hervor-

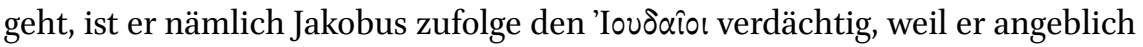

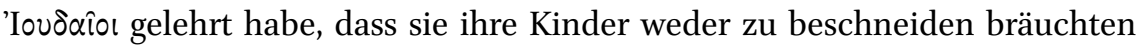
noch sich an die Gebote halten müssten. Gegenüber einer Menschenmenge, die solchen Anschuldigungen Glauben schenken könnte, lässt der Autor der

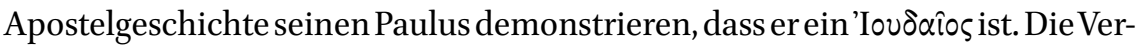
wendung der hebräischen/aramäischen statt der zu erwartenden griechischen Sprache dürfte effektvoll diesem Zweck dienen. Die Betonung der Tatsache, dass Paulus in dieser Situation sich des Hebräischen/Aramäischen bedient, lässt umgekehrt den Schluss zu, dass er normalerweise eine andere Sprache, nämlich Griechisch, spricht. ${ }^{8}$ Aus der Darstellung dieser beiden Erzählungen der Apostelgeschichte geht jedenfalls deutlich ein sprachlich-kultureller Doppelcharakter des Paulus hervor.

Martin Hengel - und mit ihm viele Andere - argumentiert überzeugend für entsprechende Kenntnisse: „Weder in 2. Kor 11,22 noch in Phil 3,5 kann 'Eßpaîos kaum etwas anderes heißen als ein 'Eßpoï $\tau i$ ', d. h. ein die Heilige Sprache bzw. Aramäisch sprechender Palästinajude oder ein Diasporajude, der in seiner Herkunft und Bildung aufs engste mit dem Mutterland verbunden ist. ${ }^{\text {“9 }}$ Andere

7 Ob es sich bei der genannten „hebräischen Sprache“ um Hebräisch oder Aramäisch handelt, was verschiedentlich postuliert wird, kann hier offengelassen werden. Zum aramäischen Hintergrund des Neuen Testaments vgl. Joseph A. Fitzmyer (Hg.), A Wandering Aramean: Collected Aramaic Essays, MSSNTS nr. 25 (Missoula (MT) 1979), 1-27. Zu den im Lande Israel des 1. Jh. gesprochenen Sprachen siehe ebd., 29-56. Zur Bezeichnung des Aramäischen als „Hebräisch“ vgl. Hermann Leberecht Strack und Paul Billerbeck, Das Evangelium nach Markus, Lukas und Johannes und die Apostelgeschichte erläutert nach Talmud und Midrasch, Str-B 2, Ed. 6 (1974), 451-453.

8 Vgl. Sevenster, Do You Know Greek?, 25.

9 Martin Hengel, „Der vorchristliche Paulus“, in: Ulrich Heckel, Martin Hengel und Adolf Schlatter (Hg.), Paulus und das antike Judentum, WUNT 58 (Tübingen, 1991), 177-293, hier: 220. Vgl. auch Timothy H. Lim, Holy Scripture in the Qumran Commentaries and Pauline Letters (Oxford 1997), 63; Jan Dochhorn, „Paulus und die polyglotte Schriftgelehrsamkeit seiner Zeit: Eine Studie zu den exegetischen Hintergründen von Röm 16,20a“, in: $Z N W$ 98, 
wehren sich vehement gegen die Annahme, dass Paulus des Hebräischen mächtig sei.

$\mathrm{Ob}$ er auch Lateinisch beherrscht, wird in den Quellen nirgends angesprochen, und es ist aufgrund der weiten Verbreitung des Griechischen und Paulus' Kompetenz darin zumindest fraglich. In den meisten römischen Kolonien bedarf es des Lateinischen kaum. ${ }^{10}$ Stanley Porter kommt in seiner Untersuchung von Hinweisen innerhalb des Corpus Paulinum zu dem Schluss, dass Paulus möglicherweise Latein gesprochen habe, dies aber nicht unbedingt notwendig gewesen sei. ${ }^{11}$ Robert Jewett zufolge gibt es allerdings keine verlässlichen Hinweise, dass Paulus über genügend Lateinkenntnisse verfügt habe, weshalb er für seine geplante Spanienmission auf Übersetzer angewiesen gewesen sei, da dort nicht Koiné, sondern Lateinisch gesprochen wird. ${ }^{12}$

Aufgrund der überlieferten literarischen Zeugnisse lassen sich unter Einordnung der Briefe in die Bandbreite frühjüdischer Überlieferungen in griechischer Sprache nur sehr vorsichtige Rückschlüsse auf Paulus' Bildungsniveau ziehen..$^{13}$ Im jüdischen Milieu bieten sich Philo und Josephus zum

Nr. 3 (2007), 189-212; Vrasidas Karalēs, „Consequences of Bilingualism in Paul's Letters“, in: Cusack und Hartney, Religion and Retributive Logic, 195. Willem C. Van Unnik kommt in seiner Untersuchung zur Jugendzeit des Paulus zu dem Schluss, dass Paulus nicht nur zweisprachig, sondern dass Aramäisch seine primäre Sprache ist: "It can safely be said, that Aramaic was his earliest and principal tongue." Willem Cornelis van Unnik, Tarsus or Jerusalem, the City of Paul's Youth (London 1962), 301. Hierfür muss die Aussage in Apg 26,4-5 stark gemacht werden, in der Paulus in seiner Rede vor Agrippa betont, er sei von Jugend auf und von Anfang an ( $\dot{\varepsilon} \kappa$

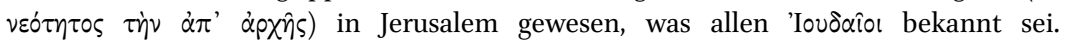

Die Gegenthese, dass Paulus des Hebräischen/Aramäischen nicht mächtig ist, beruht auf der Argumentation, dass man aufgrund des Ausdrucks „Hebräer von Hebräern“ (Phil 3,5) nicht auf Kenntnisse des Hebräischen oder Aramäischen schliessen dürfe; vgl. Markus Tiwald, Hebräer von Hebräern: Paulus auf dem Hintergrund frühjüdischer Argumentation und biblischer Interpretation, HBS $5^{2}$ (Freiburg i. Br. 2008), 177-178.

10 So bspw. in Philippi; vgl. Peter Pilhofer, Philippi: Band I, Die erste christliche Gemeinde Europas, 2 Bde., WUNT 87 (Tübingen 1995), 85-92; oder Korinth; vgl. James R. Wisemann, "Corinth and Rome I: 228 B. C.-A. D. 267“, in: Hildegard Temporini (Hg.), Politische Geschichte: Provinzen und Randvölker: griechischer Balkanraum, Kleinasien, 2 Bde., ANRW, Bd. 7.2 (1979-1980), 438-548 und 507-508.

11 Vgl. Stanley E. Porter, „Did Paul Speak Latin“, in: Stanley E. Porter (Hg.), Paul: Jew, Greek, and Roman, Pauline studies 5 (Leiden 2008), 289-304.

12 Vgl. Robert Jewett, Roy D. Kotansky und Eldon Jay Epp, Romans: A Commentary, Hermeneia (Minneapolis 2007), 79.

13 Vgl. Karl-Wilhelm Niebuhr, „Name, Herkunft, Familie“, in: Horn, Paulus Handbuch, 49-55, hier: 52, mit Verweis auf: John M. G. Barclay, „Paul Among Diaspora Jews: Anomaly or Apostate?", in:JSNT 6o (1995), 89-120. 
Vergleich an, wobei beide nicht aus Kleinasien stammen. Als zeitgenössische Literatur aus Kleinasien wäre die Offenbarung des Johannes und das 4. Buch der Makkabäer heranzuziehen. In theologischen Reflexionen und Argumentationen erreicht Paulus von den genannten Autoren das vergleichsweise höchste Niveau. Was die Sprachkompetenz angeht, verbieten sich wegen der Gattungsunterschiede allerdings ein direkter Vergleich und eine Wertung. Während Philo eine Nähe zu Sprache und Stil von philosophischen Traktaten aufweist, verwendet Josephus in den Antiquitates Judaicae die Koiné hellenistisch-römischer Geschichtsschreibung. Die Offenbarung des Johannes ist in eigenartiger und bisweilen nicht regelkonformer Koiné abgefasst, während das 4. Buch der Makkabäer sowohl inhaltlich als auch sprachlich keine Auffälligkeiten zeigt. ${ }^{14}$ Leider gibt es keine zeitgenössische und von Paulus unabhängige Briefliteratur, mit der die paulinischen Briefe hinsichtlich ihrer Sprache verglichen werden könnten.

Zusammenfassend kann festgehalten werden, dass Paulus auf Griechisch schrieb, vermutlich aber auch Kenntnisse des Hebräischen hatte, vielleicht sogar des Lateinischen. Paulus' Bilingualität, mit der er in seiner Zeit eher ein Regel- als ein Sonderfall ist, erscheint also als sehr wahrscheinlich, auch wenn sie nicht weiter zum Ausdruck kommt. Unsere Quellen sind allerdings ausschliesslich Griechisch. Deshalb wird zu fragen sein, wie die in der Lingua franca ihrer Zeit abgefassten Briefe intralingual eine Bikulturalität ausdrücken.

Es bleibt also eine Tatsache, dass Paulus Griechisch schreibt, wohl auch spricht und denkt. Mehr noch: Er schreibt ein tadelloses, wenn auch eigenwilliges Griechisch. ${ }^{15}$ Er ist nicht bloss ein native speaker, sondern ein gebildeter Sprecher der griechischen Sprache. Ob Paulus ganz allein diese Kompetenz hat oder auf die Hilfe seines Schreibers Tertius (Röm 16,22) angewiesen ist, sei dahingestellt. Es scheint jedenfalls sicher, dass Paulus um ein fehlerfreies Griechisch bemüht ist, wenn er sich mittels Briefen an seine Adressatenschaft wendet. Diese Briefe als Medium paulinischer Korrespondenz werden im nächsten Abschnitt untersucht.

\footnotetext{
14 Vgl. Karl-Wilhelm Niebuhr, „Name, Herkunft, Familie“, in: Horn, Paulus Handbuch, 52-53.

15 Schon Eduard Norden hat sich in seiner bahnbrechenden Studie zur antiken Kunstprosa über den paulinischen Stil gewundert: „Paulus ist ein Schriftsteller, den wenigstens ich nur sehr schwer verstehe; das erklärt sich mir aus zwei Gründen: einmal ist seine Art $\mathrm{zu}$ argumentieren fremdartig, und zweitens ist auch sein Stil, als Ganzes betrachtet, unhellenisch." Eduard Norden, Die antike Kunstprosa vom VI. Jahrhundert v. Chr. bis in die Zeit der Renaissance, 10. Aufl., 2 Bde. (Berlin, New York 2010), 499.
} 


\subsection{Der Brief als Medium paulinischer Korrespondenz}

Die Paulusbriefe sind nur einzelne Elemente im pluriformen Vermittlungsprozess des Völkerapostels, aber die einzigen medialen Quellen, die bis heute überliefert sind. Die individuellen Begegnungen und Faktoren im Vermittlungsprozess sind selbstverständlich nicht mehr nachvollziehbar, und von einer Institution der Paulusbriefe kann zu diesem frühen Zeitpunkt nicht gesprochen werden. Doch im weiteren Verlauf des Vermittlungsprozesses über Paulus' Lebzeit hinaus sollten sie eine überragende institutionalisierte Rolle einnehmen. Die Paulusbriefe sind also nur einzelne Elemente eines umfassenderen Vermittlungswirkens, aber solche, die überliefert sind und aus denen sich auch Informationen zu den Mitwirkenden am Geflecht des Vermittlungsprozesses erschliessen lassen.

Zunächst wird im Folgenden das Briefkorpus als Quelle für die Untersuchung umrissen und chronologisch in das Leben und Wirken des Paulus eingeordnet. Daran schliesst sich eine Diskussion über die Klassifizierung an. Dies dient dem Verständnis und der Charakterisierung dieser Briefe als Medium des Vermittlungsprozesses mit dem Ziel, ihre Funktion näher zu erfassen. Innerhalb dieser Diskussion lassen sich auf sprachlicher Ebene auch bereits Aussagen zum interkulturellen Vermitteln des Paulus machen. Schliesslich kommen praktischen Aspekte hinsichtlich des Mediums Brief zur Sprache, um die Rolle der Briefe im Vermittlungsgeschehen näher zu beschreiben.

\subsubsection{Zum Korpus der Protopaulinen}

Die ursprünglichen Manuskripte der Paulusbriefe sind verloren. Sie dürften in scriptio continua und ohne Akzent abgefasst worden sein, wie es zu ihrer Entstehungszeit üblich war. ${ }^{16}$ Die sieben als echt angesehenen Paulusbriefe sind lediglich als Abschriften überliefert. Bei jeder Abschrift können sich Fehler eingeschlichen haben oder absichtlich Änderungen vorgenommen worden sein. Dennoch sind diese Briefe das Unmittelbarste, was von Paulus überliefert ist.

Diese Briefe erwähnen andere - höchstwahrscheinlich verlorene - Briefe, wie den sogenannten Vorbrief in 1 Kor 5,9, den Tränenbrief 2 Kor 2,1-4, auch 7,8 und 10,10-11 oder die Empfehlungsschreiben, die Paulus in 1 Kor 16,3 den Überbringern der Kollekte nach Jerusalem verspricht. Für den 2 Kor gibt es auch Grund zur Annahme, dass die überlieferte Form nicht ursprünglich ist, sondern dass kürzere Briefe zu Briefkompilationen zusammengefügt worden

16 Entsprechend bedeutet es bereits einen Akt der Interpretation, die scriptio continua durch Worttrennung aufzubrechen und Akzente zu setzen. 
sind. ${ }^{17}$ Verloren sind auch gemeindliche Schreiben an Paulus (vgl. z. B. 1 Kor 7,1). Insbesondere die Korrespondenz mit den Gruppen in Korinth und Philippi dürfte umfangreicher gewesen sein. Die überlieferten Briefe umfassen also lediglich einen Teil des literarischen Schaffens von Paulus und repräsentieren auch nur ein bestimmtes Segment aus seinem Leben und Wirken. Sie stammen wahrscheinlich alle aus der zweiten Hälfte seines missionarischen Wirkens und sind innerhalb von zehn bis ca. zwölf Jahren verfasst worden (zwischen ca. 49 und 6o/62 n. Chr.). Aus der früheren missionarischen Zeit, in der Paulus in Arabia, Syrien und speziell Antiochien sowie Kilikien gewirkt hat, sind keine Briefe überliefert. Möglicherweise fängt Paulus erst in der zweiten Hälfte seines Wirkens an, Briefe zu schreiben. Der Beginn der epistolografischen Tätigkeit des Paulus wird in der Forschung mit den Ergebnissen und Entscheidungen des Apostelkonvents in Jerusalem (48/49 n. Chr., vgl. Gal 2,1-10; Apg 15,1-29) in Verbindung gebracht, konkret mit der Legitimierung der paulinischen Mission unter den Völkern. ${ }^{18}$ Hierfür spricht die Tatsache, dass gerade in den Briefen nach Korinth die Thematik der Kollektenmission eine zentrale Rolle spielt (1 Kor 16,1-4; 2 Kor 8-9), und diese wiederum ist ein direktes Resultat des Apostelkonvents (Gal 2,10).

Zusammenfassend kann festgehalten werden, dass die Briefe, die uns als Abschriften unbekannten Grades überliefert sind, nur ein unvollständiges Bild davon vermitteln, was Paulus bzw. seine Schreiber damals tatsächlich niedergeschrieben haben. Die Basis für die Untersuchung des Paulus in seiner Welt bleibt also fragmentarisch.

\subsubsection{Klassifizierung und Aspekte von Bikulturalität}

Mit dem Schreiben von Briefen hat Paulus Anteil an einer weitverbreiteten kulturellen Praxis. Im Folgenden soll geklärt werden, wie sich die Paulusbriefe hier einordnen lassen bzw. inwiefern sie auch Besonderheiten aufweisen. Vor diesem Hintergrund werden dann die unterschiedlichen paulinischen Formulierungen von Grüssen als Hinweis auf Paulus' Bikulturalität diskutiert.

Bei archäologischen Grabungen im Mittelmeerraum sind Tausende antiker Papyri mit kurzen Privatbriefen gefunden worden. Briefe dienen dem Kontakt zwischen geografisch entfernten Menschen und werden von Cicero (106-43

17 Vgl. z. B. Gerhard Dautzenberg, „Der zweite Korintherbrief als Briefsammlung: Zur Frage der literarischen Einheitlichkeit und des theologischen Gefüges von 2 Kor 1-8“, in: Wolfgang Haase (Hg.), Religion (vorkonstantinisches Christentum: Leben und Umwelt Jesu; Neues Testament; Kanonische Schriften und Apokryphen [Forts.]), ANRW 25.4 (Berlin, New York 1987), 3045-3066.

18 Vgl. Gerd Theißen, Die Entstehung des Neuen Testaments als literaturgeschichtliches Problem, SPHKHAW 40 (Heidelberg 2007), 94-96. 
v. Chr.) beschrieben als „Gespräch von Freunden, die voneinander getrennt sind“ (amicorum conloquia absentium, Cic. Phil. 2.7). Durch einen Brief ist die Distanz zum Adressaten kurzzeitig überwunden: „mit dem Blick auf dich in der Ferne und gleichsam vor dir sitzend“ (te autem contemplans absentem et quasi tecum coram loquerer, Cic. fam. 2.9.2). Paulinische Briefe überwinden geografische Distanzen und tragen dazu bei, dass im Rahmen des Vermittlungsprozesses die Wege des Paulus sich nicht nur persönlich mit jenen der Menschen der Zielkultur kreuzen und dabei mündlicher Austausch stattfindet, sondern sie bedienen darüber hinaus eine schriftliche Ebene, die auch in Paulus' Abwesenheit Kommunikation ermöglicht.

Was die sprachliche oder formale Gestaltung der Briefe anbelangt, unterliegt die Praxis des Briefeschreibens zur Zeit des Paulus keinen verbindlichen epistolografischen Richtlinien. Vielmehr ist sie völlig variabel: „Absender und Adressat genügten, um den Brief zum Brief zu machen. ${ }^{19}$ Gleichwohl scheint es sinnvoll, für die Einschätzung von Funktion und Bedeutung der paulinischen Briefe eine Klassifizierung ihrer Genres vorzunehmen. So haben sich bereits antike Autoren mit der Theorie des Briefschreibens auseinandergesetzt: Die

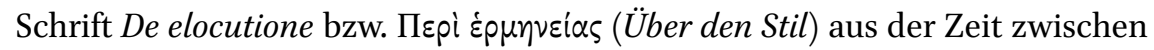
200 v. Chr. und $100 \mathrm{n}$. Chr., unter dem Namen Demetrios von Phaleron verfasst, enthält in einem Exkurs zum Briefstil (223-235) einen Vergleich zwischen einem Brief und den Rollen in einem Dialog. ${ }^{20}$ Darin bezeichnet Demetrios

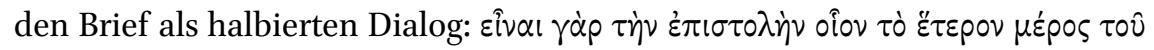
$\delta$ ¿ $\lambda$ ó you (Demetr. eloc. 223).

Auf Demetrios' De elocutione und andere brieftheoretische Erörterungen sich stützend führt Heikki Koskenniemi die ideologischen Grundlagen des griechischen Briefes auf die drei Begriffe Philophronesis, Parusia und Homilia zurück. ${ }^{21}$ Philophronesis ist die von Demetrios entschieden herausgestellte freundschaftliche Gesinnung, die den Briefwechsel trägt. Bei Paulus drückt sich die Philophronesis einerseits in anerkennenden Epitheta in der Anrede wie beispielsweise Phlm 1 aus (vgl. auch die häufige Anrede der Adressaten

19 Eve-Marie Becker, Schreiben und Verstehen: Paulinische Briefhermeneutik im Zweiten Korintherbrief, NET 4 (Tübingen 2002), 50.

20 Vgl. Hans-Josef Klauck (Hg.), Alte Welt und neuer Glaube: Beiträge zur Religionsgeschichte, Forschungsgeschichte und Theologie des Neuen Testaments, NTOA 29 (Freiburg (Schweiz), Göttingen 1994), 149-152. Eine Übersetzung der Verse des Demetrios findet sich ebd.

Vgl. Heikki Koskenniemi, Studien zur Idee und Phraseologie des griechischen Briefes bis 400 n. Chr., AASF B/102.2 (Helsinki 1956). Für den lateinischen Bereich sekundiert ihn Klaus Thraede, Grundzüge griechisch-römischer Brieftopik, Zet. 48 (München 1970); vgl. Hans-Josef Klauck, Die antike Briefliteratur und das Neue Testament: Ein Lehr- und Arbeitsbuch (Paderborn, Zürich 1998), 152-153; Theißen, Die Entstehung des Neuen Testaments als literaturgeschichtliches Problem, 103. Zu den folgenden Ausführungen vgl. auch ebd. 
als $\alpha \gamma \alpha \pi \eta \tau$ tó in den verschiedenen Briefen: 1 Kor 4,14; Phil 2,12; 2 Kor 7,1; 12,19; Röm 12,19;16,8, um nur einige Beispiele zu nennen), andererseits in Wünschen für das Wohlergehen bzw. in Segenswünschen (gewissermassen eine formula valetudinis, Röm 15,33; 16,20a; 2 Kor 13,11; Gal 6,16; Phil 4,9b; 1 Thess 5,28) (2) $^{22}$ und drittens in der Proskynema-Formel, der Versicherung der Fürbitte und des Gedenkens (Röm 1,9-10; 1 Thess 1,2-3; Phil 3; Phlm 4).

An die Philophronesis knüpft die Parusia an, die besagt, dass Briefe den Austausch zwischen Freunden auch über Zeiten und Räume der Trennung hinweg ermöglichen, denn im Brief verwandelt sich die körperliche Abwesenheit in geistige Gegenwart (vgl. Kol 2,5). Der Brief kann mit einem Besuch verglichen werden: Wie bei diesem steht am Anfang des Briefes eine Begrüssung und an dessen Ende eine Verabschiedung. So äussert Paulus in fast allen Briefen den Wunsch auf ein Wiedersehen in der Zukunft (Röm 15,23-29; 1 Kor 16,5-12; 2 Kor 12,14-13,10; Phlm 22). Auffällig ist, dass das Parusiemotiv auch zu finden ist an Orten, an denen Paulus' Anwesenheit aufgrund von Spannungen wohl gar nicht erwünscht ist - ein Phänomen, das bei Freundschaftsbriefen anderer Autoren nicht nachgewiesen ist. ${ }^{23}$ Entsprechend findet sich hier ein Indiz, dass Paulus den Freundschaftsbrief zum sogenannten Gemeindebrief hin weiterentwickelt. ${ }^{24}$

Mit der Parusia wird zugleich zum Dialogcharakter zurückgelenkt, auf den der Begriff der Homilia (von ó $\mu \lambda \varepsilon \varepsilon \hat{\imath}$ - unterreden, sich unterhalten) abzielt. Der Brief bringt die Korrespondenten ins Gespräch miteinander und erstellt eine „Basis für ihr Zusammenleben“25. Paulus verlässt immer wieder den ,Plauderton' zugunsten einer kraftvollen Rhetorik (vgl. 2 Kor 10,10), was wiederum ein Indiz dafür ist, dass er hier das Genre des Freundschaftsbriefes sprengt bzw. auf einen gemeindlichen Kontext hin ausrichtet, indem er öffentlichen Anspruch erhebt. ${ }^{26}$ Ein wichtiger Unterschied zwischen einem Gespräch und einem Brief besteht in der zeitlichen und räumlichen Distanz, die zwischen

22 Zur paulinischen Form der formula valetudinis vgl. Otto Konrad Roller, Das Formular der Paulinischen Briefe: Ein Beitrag zur Lehre vom antiken Briefe, BWANT, Folge 4, Heft 6 (Stuttgart 1933), 66-67; 197-198.

23 Vgl. Theißen, Die Entstehung des Neuen Testaments als literaturgeschichtliches Problem, 104, mit Verweis auf Régis Burnet, Épitres et lettres, $I^{\text {er-II }}{ }^{e}$ siècle: De Paul de Tarse à Polycarpe de Smyrne, LD (Paris 2003).

24 Vgl. Theißen, Die Entstehung des Neuen Testaments als literaturgeschichtliches Problem, 104.

25 Koskenniemi, Studien zur Idee und Phraseologie des griechischen Briefes bis 400 n. Chr., 45.

26 Vgl. Theißen, Die Entstehung des Neuen Testaments als literaturgeschichtliches Problem, 104. 
Äusserung und Gegenäusserung entsteht. ${ }^{27}$ Auffällig an den paulinischen Schreiben ist zumal die aussergewöhnliche Länge. Nicht literarische Briefe umfassen meist nicht mehr als ein einzelnes Papyrusblatt. Vom Umfang her sind die Paulusbriefe daher viel eher mit den philosophischen Lehrbriefen Epikurs, Ciceros oder Senecas zu vergleichen, wobei 1 Kor und Röm auch diese an Länge noch übertreffen.

In seinen Ausführungen zur formgeschichtlichen Einordnung der Paulusbriefe kommt Gerd Theißen zu folgendem Fazit:

Paulus hat den Gemeindebrief geschaffen, indem er den antiken Freundschaftsbrief durch Anlehnung an Herrscherbriefe und den ,literarischen Brief ${ }^{\star}$ umgestaltet hat. Er aktivierte dabei vielleicht auch eine im Judentum schon vorhandene Tradition gemeindeleitender Briefe. Die Anlehnung an Herrscherbriefe erklärt sein Vollmachtsbewusstsein als Briefeschreiber, die Anlehnung an literarische Briefe ihre exzeptionelle Länge, die Anlehnung an gemeindeleitende Briefe die Ausrichtung auf die Adressaten. Paulus gab nach solchen Modellen dem Freundschaftsbrief ein autoritatives Gewicht, einen kollektiven Adressaten und einen gewichtigen Inhalt, der die Länge seiner Briefe erklärt.. ${ }^{28}$

Zugleich kommt es bei der Klassifizierung von Briefen zu so unterschiedlichen Einschätzungen, dass es keine allgemeine Lösungsformel gibt. Die ältere Forschung unterscheidet unter Rückgriff auf Adolf Deissmann zwischen („echtem“) Brief und Epistel: „Der Brief ist ein Stück Leben, die Epistel ist ein Erzeugnis literarischer Kunst.“29 Entsprechend dieser Definition haben die Schreiben des Paulus als Briefe zu gelten, während der Jakobusbrief und der Hebräerbrief Episteln sind. Von dieser strikten Unterscheidung hat sich die nachfolgende Forschung längst distanziert, nicht zuletzt weil gerade die Paulusbriefe Aktuell-Persönliches mit Anteilen für die Öffentlichkeit der

27 Vgl. Müller, W. G. „Art. Brief“, in: Gert Ueding (Hg.), Historisches Wörterbuch der Rhetorik, 12 Bde., Bd. 2, Tübingen, Boston 1994, 6o-76, hier: 61.

28 Theißen, Die Entstehung des Neuen Testaments als literaturgeschichtliches Problem, 109-110. Paulus partizipiert hier an der etablierten jüdischen Tradition, mittels offizieller Briefe mit Gruppen zu kommunizieren. Zu den frühjüdischen gemeindeleitenden Briefen zählen bspw. 2 Makk 1-2; EpJer; ApcBar(syr) 78-86 und auch die Bar-Kochba-Briefe. Irene Taatz hat in einer Untersuchung zu frühjüdischen Briefen aufgezeigt, dass sich im Frühjudentum eine Tradition offizieller gemeindeleitender Briefe entwickelt. Irene Taatz, Frühjüdische Briefe: Die paulinischen Briefe im Rahmen der offiziellen religiösen Briefe des Frühjudentums, NTOA 16 (Freiburg (Schweiz), Göttingen 1991).

29 Vgl. Adolf Deissmann, Licht vom Osten: Das Neue Testament und die neuentdeckten Texte der hellenistisch-römischen Welt, 4. Aufl. (Tübingen 1923), 193-208, Zitat: 195. 
Gruppe und durchaus literarischen Passagen kombinieren und sich schon deshalb einer einfachen Klassifizierung entziehen. ${ }^{30}$

Hans-Josef Klauck unterscheidet zwischen nicht literarischen Briefen (1), diplomatischen Schreiben (2) und literarischen Briefen (3). ${ }^{31}$

Die nicht literarischen Briefe (1) definiert er als „reine Gebrauchsliteratur, ohne Seitenblicke auf die breitere Öffentlichkeit oder die Nachwelt abgefaßt “. ${ }^{32}$ Sie können weiter untergliedert werden in Privatbriefe, amtliche Briefe und Geschäftsbriefe. Zudem gibt es unterschiedliche Typen wie den Familienbrief, den Freundschaftsbrief, den Mahnbrief, den lobenden oder tadelnden Brief und den Trostbrief. Insbesondere im nicht literarischen Bereich strahlt die Briefform in andere Bereiche wie beispielsweise magische Beschwörungen hinein.

Die diplomatischen Schreiben (2) umfassen „königliche oder kaiserliche Briefe von politischem Gewicht". In Stein gemeisselt, wie z. B. im Falle des Briefes von Kaiser Claudius in der Gallio-Inschrift, oder wörtlich zitiert in Geschichtswerken der Antike sind solche zu einem guten Teil für die Nachwelt konserviert und überliefert worden. ${ }^{33}$

Literarische Briefe (3) schliesslich sind mit der Intention verfasst, einen breiteren Adressatenkreis zu erreichen. Sie sind mit wenigen Ausnahmen in Sammlungen und Abschriften überliefert. Das Spektrum ist wiederum sehr gross und umfasst philosophische Lehrschriften, rhetorische Übungen, aber auch Dichtungen.

Es zeigt sich, dass Deissmanns Dichotomie zwischen Brief und Epistel in der kaum aufgebbaren Unterscheidung zwischen literarischen und nicht literarischen Briefen auch in Klaucks Klassifizierung weiterlebt.

In einer umfassenden Studie zu antiken jüdischen Briefen und den Anfängen christlicher Epistolografie hat jüngst Lutz Doering überzeugend aufgezeigt, dass die Paulusbriefe zwar Ähnlichkeiten zu Korrespondenzen philosophischer Schulen und Vereine aufweisen, dass aber das Gros an Korrespondenz mit christusgläubigen Gruppen analog zur Korrespondenz mit

30 Vgl. M. Luther Stirewalt, Paul, the Letter Writer (Grand Rapids (MI):W. B. Eerdmans, 2003), 113-116. Auch die von William G. Doty vorgeschlagene Unterscheidung zwischen privaten und öffentlichen Briefen ist zu stark polarisierend: William G. Doty, „Classification of Epistolary Literature“, in: CBQ 31, Nr. 2 (1969), 183-199; William G. Doty, Letters in Primitive Christianity (Philadelphia 1983).

31 Klauck, Die antike Briefliteratur und das Neue Testament, 71-147. Klauck belegt seine Klassifizierung mit vielen Beispielen.

32 Ebd., 72.

33 Vgl. ebd., 73 . 
jüdischen Gruppen verfasst ist. ${ }^{34}$ Dies ist kaum eine überraschende Erkenntnis, da Paulus und weitere christusgläubige Autoren aus frühester Zeit vorwiegend jüdischer Abstammung sind und daher vermutlich auch bestimmte Traditionen bis hin zu literarischen und epistolografischen Formularen mit jüdischen Gruppen teilen. Hellenistisch-jüdische Briefe nehmen in Doerings Vergleich insofern einen Sonderstatus ein, als christusgläubige Autoren meist auf Griechisch schreiben. Die Paulusbriefe klassifiziert Doering als öffentliche und de facto offizielle Briefe, verfasst unter Einbezug von Mitschreibern und gerichtet an die frühesten christusgläubigen Gruppen. So weisen sie Ähnlichkeiten zu offiziellen Briefen auf, obschon sie nicht an eine Polis oder einen Staat, sondern an eine innere Öffentlichkeit gerichtet sind. Entsprechend tritt auch Paulus in seinen Briefen nicht als Privatmann auf, sondern als Apostel, der mit anderen zusammenarbeitet. Seine Aufgabe, zusammen mit seinen Mitarbeitenden, ist die Verkündigung des Evangeliums unter den Völkern.

Einer Betrachtung wert und hinsichtlich des paulinischen interkulturellen Vermittelns relevant ist das paulinische Präskript bzw. genauer: die darin enthaltene salutatio. Bei dieser hält sich Paulus nämlich statt an einen pagangriechischen Gruss ( $\chi \alpha$ ipelv, sich freuen) an das biblisch geprägte Begriffspaar

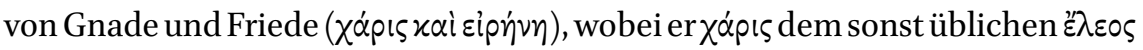
den Vorzug gibt. ${ }^{35}$ In diesem Zusammenhang hat Andrie du Toit interessante Beobachtungen angestellt. ${ }^{36}$ Du Toits Analyse zufolge verwendet Paulus wenn die Mehrheit der Adressaten wahrscheinlich Griechisch sprechende Menschen aus den Völkern sind - regelmässig den in pagan-griechischen

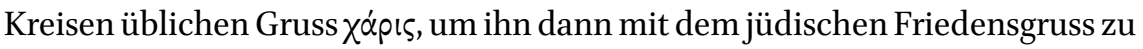
verbinden, wobei er beides in christusgläubiger Perspektive reinterpretiert. In Kontexten hingegen, in denen starke jüdische Assoziationen zu erwarten sind, greife Paulus auf घ̇ $\lambda \varepsilon \circ \varsigma$ zurück. ${ }^{37}$ An anderen Stellen seiner Briefe verwende er $\chi \dot{\alpha}$ pı aus Rücksicht auf seine überwiegend aus den Völkern stammende Adressatenschaft, aber wo jüdische heilsgeschichtlich relevante Assoziationen

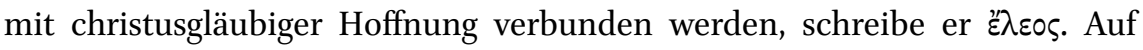

34 Vgl. Lutz Doering, Ancient Jewish Letters and the Beginnings of Christian Epistolography, WUNT 298 (Tübingen 2012). Zur Nähe der Paulusbriefe zu jüdischen gemeindeleitenden Briefen vgl. schon Taatz, Frühjüdische Briefe.

35 Folglich liegen nun zwei Nominalsätze vor: Absender und Adressat; Gnaden- und Friedenswunsch, je nachdem mit verschiedenen Erweiterungen. Die griechische Form des Präskripts, die beides in einem einzigen Satz nennt, findet sich im NT bloss in Jak 1,1;

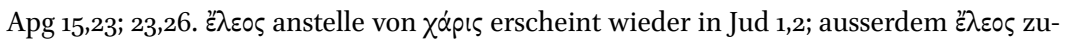

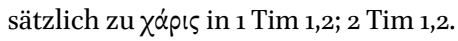

36 Vgl. Andrie du Toit, „Paulus Oecumenicus: Interculturality in the Shaping of Paul's Theology“, in: NTS 55, Nr. 2 (2009), 121-143.

Du Toit nennt Röm 9-11; 15,9 und Gal 6,16, vgl. ebd., 127. 
diese Weise würden Menschen beiderlei Provenienz angesprochen. Paulus vermische diese beiden Traditionen nicht, sondern stelle sie einander gegenüber, indem er jeweils die kulturelle Präferenz sowohl der Griechen als auch

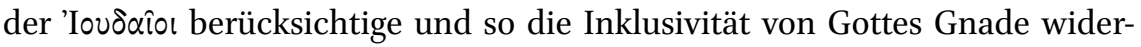
spiegele. Paulus scheint folglich sensibel zu sein für die kulturelle Provenienz und die jeweiligen sprachlichen Konventionen sowohl jüdischstämmiger Adressatinnen und Adressaten als auch von Menschen aus den Völkern. Du Toit bemerkt abschliessend hierzu:

\begin{abstract}
In his communication of grace, he [sc. Paul] applies all the linguistic and sociocultural tools available to him. He takes up the OT-Jewish concept of God as the compassionate and merciful One, merges it with the basic structure and linguistic apparatus of Hellenistic benefaction and sends it through the christological prism. Thus both heritages are transformed. Jesus is now the agent and source of grace. And, most importantly, moving through this christological filter, grace acquires a cruciform shape. Paul is sensitive to differentiate between Jewish and Greek traditions. ${ }^{38}$
\end{abstract}

Du Toits Beispiel ist bestechend. Trotzdem bleibt zu fragen, ob der Wechsel tatsächlich eine bewusste Entscheidung darstellt. Es könnte sich auch um ein unbewusstes Abwechseln zwischen beiden Begriffen handeln. Und falls der Wechsel tatsächlich bewusst ist, bleibt zu fragen, ob dies tatsächlich Teil seiner Missionsstrategie war.

Im Postskript finden sich jeweils Grussauftrag und Grussausrichtung, die eine Verbindung zwischen verschiedenen Personen respektive Gruppen schaffen und ein Gefühl der Verbundenheit hervorrufen. Grüsse des Paulus an andere sowie Grüsse von anderen an die Adressaten dienen überdies der Verbreitung des Briefes. Im abschliessenden Segenswunsch wird die gemeinsame Basis von Briefschreiber und Adressatinnen und Adressaten im Glauben an Jesus Christus ausgedrückt.

\title{
4.2.3 Praktische Aspekte
}

Der Brief als Medium der Kommunikation und des Vermittlungsgeschehens weist einige Spezifika auf: vom Schreibprozess über das Material und die Übermittlung bis hin zu ihrer Rezeption durch die Adressatinnen und Adressaten, bei der inbesondere die Diskrepanz zwischen Mündlichkeit und Schriftlichkeit eine wichtige Rolle spielt. 
Diese praktischen Aspekte werden im Folgenden diskutiert, da sie in mannigfaltiger Weise Hinweise zum praktischen Vollzug des paulinischen Kulturtransferprozesses geben. Es zeigt sich insbesondere, dass das Schreiben und Überliefern von Briefen nicht das Unterfangen eines Einzelnen war, sondern ein in einem Netz von Menschen sich vollziehender Akt.

\subsubsection{Das Schreiben von Briefen}

Für Briefe jeglicher Länge ist es zur Zeit des Paulus gängige Praxis, sich im Bedarfsfall eines eigentlichen Schreibers zu bedienen. Dies ist durchaus auch bei Menschen üblich, die selbst das Schreiben und Lesen beherrschen. ${ }^{39}$ Paulus scheint sowohl einem Schreiber diktiert als auch zumindest Teile seiner Briefe selbst geschrieben zu haben. So betont er in Gal 6,11, wohl um dem Brief noch zusätzliches Gewicht zu verleihen, dass er den Adressatinnen und Adressaten

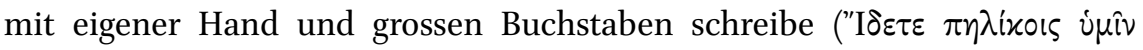

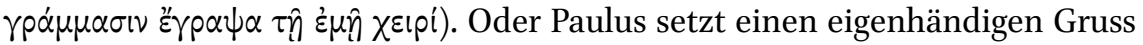
unter einen Brief (1 Kor 16,21) oder erwähnt schlicht, ihn selbst geschrieben zu haben (Phlm 19). In Röm 16,22 geht der Schreiber Tertius - zumal in unüblich starker Selbstprofilierung - über das Diktat von Paulus hinaus, indem er sich selbst zu Wort meldet und alle Adressaten „im Herrn“ ( $\dot{\imath} \vee \chi \cup p i \omega)$ grüsst und sich damit selbst als Christusgläubiger zu erkennen gibt. ${ }^{40}$ Es wird also deutlich, dass Paulus zwar selbst Schreibkompetenz besitzt, sich aber für die Abfassung seiner Briefe eines Schreibers bedient. Auch die autografische Zufügung in Gal 6,11 weist darauf hin, dass Paulus den Brief nicht selbst geschrieben, sondern diktiert hat. Ein Brief ist also in jedem Fall in gewisser Weise schon ein Gemeinschaftswerk.

Der Entwurf eines Briefes kann auch noch überarbeitet werden, bevor ein Schreiber die definitive Fassung aufschreibt und der Brief abgeschickt wird. Neben der Zeit, die das Schreiben eines Briefes in Anspruch nimmt, sind auch die Kosten nicht unerheblich. Zu den Kosten für das Schreibmaterial müssen diejenigen für den Schreiber und gegebenenfalls für die Beförderung dazugerechnet werden. ${ }^{41}$ Paulus ist auf die Unterstützung der Gemeinschaften, in denen er sich jeweils bei der Abfassung eines Briefes aufhält, angewiesen. Zusätzlich zu Material und schreibkundigen Personen dürften sie ihm auch

39 Vgl. Joanna Dewey, „Textuality in an Oral Culture: a Survey of the Pauline Traditions“, in: Joanna Dewey (Hg.), Orality and Textuality in Early Christian Literature, Semeia 65 (Atlanta [GA] 1995), 37-65, hier: 41.

40 Für Weiterführendes zu den Schreibern des Paulus vgl. Ernest Randolph Richards, The Secretary in the Letters of Paul, WUNT II 42 (Tübingen 1991), 189-194.

41 Für Schätzungen vgl. Ernest Randolph Richards, Paul and First-Century Letter Writing: Secretaries, Composition and Collection (Downers Grove 2004), 165-169. 
Boten vermittelt haben. Es zeigt sich, dass ausser Paulus und den eigentlichen Schreibern auch andere Personen am Prozess beteiligt sind. Paulus selbst nennt in den meisten Briefen weitere Verfasser: Timotheus in 1 Thess 1,1; 2 Kor 1,1; Phil 1,1; Phlm 1, Silvanus in 1 Thess 1,1, Sosthenes in 1 Kor 1,1 und „alle Brüder“ $\left(\pi \dot{\alpha} v \tau \varepsilon \varsigma \dot{\alpha} \delta \varepsilon \lambda \varphi o^{\prime}\right)$ in Gal 1,2. Meist werden sie in der Forschung als eine Art „Helfer" angesehen, jedoch nicht als Mitautoren. Mitautoren zu nennen, ist in der Antike eher unüblich. ${ }^{42}$ Umso bedeutsamer ist die Tatsache, dass Paulus nicht als alleiniger Autor auftritt. Sie lässt darauf schliessen, dass Paulus sich als Teil eines Teams versteht. ${ }^{43}$ Besonders deutlich ist dies in 1 Thess 1,1. Dass die Beteiligten allerdings auf gleicher Ebene agieren, ist zweifelhaft. ${ }^{44}$ Die Nennung des Paulus an erster Stelle darf als Hinweis auf eine Vorrangstellung gedeutet werden. Die Verantwortung liegt klarerweise bei ihm. ${ }^{45}$

Zur Nennung von drei Autoren passt auch die konsequente Verwendung der ersten Person Plural im gesamten 1 Thess, unter Ausnahme der Verse 2,18; 3,5 und $5,27 \cdot{ }^{46}$ Aus den Ausnahmen wird auch deutlich, dass die sonstige Verwendung des Plurals bewusst erfolgt und auf den gemeinschaftlichen Charakter des Briefschreibens hinweist.

42 Vgl. Samuel Byrskog, „Co-Senders, Co-Authors and Paul's Use of the First Person Plural“, in: $Z N W$ 87, 3-4 (1996), 230-250, hier: 233-36.

43 Dass Paulus kein Einzelkämpfer ist, sondern mit anderen Menschen zusammenarbeitet, wurde erstmals ausführlich analysiert und dargestellt von Wolf-Henning Ollrog, Paulus und seine Mitarbeiter: Untersuchungen zu Theorie und Praxis der paulinischen Mission (Neukirchener, 1979). Vgl. auch die Aussage: „Die paulinische Mission war von Anfang an ein Gemeinschaftsunternehmen mit einer Art ,Mitarbeiterstab'." Wayne A. Meeks, Urchristentum und Stadtkultur: Die soziale Welt der paulinischen Gemeinden (Gütersloh 1993), 275 .

44 Für eine Gleichrangigkeit argumentiert Byrskog, „Co-Senders, Co-Authors and Paul's Use of the First Person Plural", $236-238$, und für eine gemeinsame Autorenschaft Richards, Paul and First-Century Letter Writing, 34-36; Jerome Murphy-O'Connor, Paul the LetterWriter: His World, his Options, his Skills, GNS (Collegeville [MN] 1995), 16-19.

45 Vgl. Richards: „Paul was clearly in charge. He had disciples, such as Timothy and Titus. He also had peers, such as Barnabas and Luke. Yet these peers were not described as permanent members of the mission team. We see them moving in and out of the Pauline itinerary. They were associates, not understudies. Perhaps it was easier to work as an equal with Paul in small doses." Richards, Paul and First-Century Letter Writing, 33. Vgl. auch die Bezeichnung des Paulus als "Chef vom Dienst' im ,Team' der impliziten Autoren“, bei Christine Gerber, Paulus und seine ,Kinder: Studien zur Beziehungsmetaphorik der paulinischen Briefe, BZNW 136 (Berlin, New York 2005), 80.

46 Hierzu Byrskog: ,the consistent use of the first person plural together with the presentation of the three senders as on the same level lend some probability to the view that the cosenders are also co-authors." Byrskog, "Co-Senders, Co-Authors and Paul's Use of the First Person Plural“", 238. 
Als Konsequenz dieser Beobachtungen stellt sich die Frage, wer jeweils in den Paulusbriefen spricht. In ihrer Untersuchung zur Frage nach der Bedeutung der paulinischen Verwendung der ersten Person Plural hat Christine Gerber die häufig vertretene These, ,wir' sei eine Ersatzform für ,ich` und also ein „schriftstellerischer Plural“, 47 kritisiert und eine ganze Reihe alternativer Möglichkeiten zusammengestellt. Mit „wir“ könne gemeint sein:

1) Alle ChristInnen oder alle Menschen, 2) Paulus und die AdressatInnen,

3) Paulus und ein Teil der AdressatInnen, 4) Paulus und seine Mitabsender bzw. ein Teil der Mitabsender, 5) Paulus und die anderen Apostel oder Missionare oder - in der Auslegung übersehen - 6) Paulus und die anderen ChristInnen jüdischer Herkunft (z. B. Gal 2,15f). ${ }^{48}$

In seiner ebenfalls sehr erhellenden Untersuchung zu dieser Frage nach der Bedeutung von ,wir' kommt Wolff zum plausiblen Schluss, dass:

der Apostel als einzelner Mensch fast nie von sich selbst in der 1.P. Plural schreibt. Tatsächlich widerspräche das insofern dem allgemeinen griechischen (wie römischen) Sprachgefühl, als der Plural zur Selbstvergrößerung (nicht aber als Demutsbezeugung) gebraucht wird. Wenn Paulus einen Plural verwendet, ist es in der Regel ein echter Plural, der sich auf eine Gruppe bezieht. ${ }^{49}$

\subsubsection{Material und Überbringung von Briefen}

Briefe werden meist auf Papyrusblättern verfasst. Diese sind teuer und dürften für die breite Bevölkerung kaum erschwinglich sein. ${ }^{50}$ Alternativ, aber viel seltener, werden Briefe auf Täfelchen aus Holz, Blei oder Wachs eingeritzt, oder man schreibt mit einer Tinte aus einem Gemisch von Russ und Gummi arabicum und einem Schreibrohr aus schräg angespitztem Schilf auf Tonscherben (sogenannte Ostraka), Leinen oder Leder. ${ }^{51}$ Die Papyrusblätter werden gefaltet und mit der Adresse des Empfängers versehen einem Boten übergeben.

Ein Postsystem, der römische cursus publicus, existiert zwar, ist aber ausschliesslich für die Staatspost reserviert. Für private Korrespondenz ist man darauf angewiesen, dass entweder eigene Boten - beispielsweise

47 Vgl. dazu Carl Dick, Der schriftstellerische Plural bei Paulus (Halle a. S. 1899); Markus Müller, „Der sogenannte ,schriftstellerische Plural - neu betrachtet: Zur Frage der Mitarbeiter als Mitverfasser der Paulusbriefe“, in: $B Z$ 42, Nr. 2 (1998), 181-201.

48 Gerber, Paulus und seine,Kinder', 78-80, Zitat: 79 .

49 Wolff, Paulus beispiels-weise, 89-117, Zitat: 116-117.

$50 \quad$ Vgl. Harris, Ancient Literacy, 194.

$5^{1}$ Vgl. Klauck, Die antike Briefliteratur und das Neue Testament, 55-6o. 
Sklaven, Familienangehörige, Freunde - Briefe übermitteln oder dass man sie einem fremden Reisenden wie z. B. einem Händler oder Soldaten anvertrauen kann. Das Reisen ist zur Zeit des Römischen Reiches für viele eine Selbstverständlichkeit - mehr als dies vorher je der Fall war und nachher bis zum 19. Jh. je wieder der Fall sein wird. ${ }^{52}$ Ein dichtes Beziehungsnetz ermöglicht zwischen den von Paulus gegründeten Gruppen diverse Briefsendungen. Dafür spricht allein schon die Tatsache, dass die Paulusbriefe überliefert sind. ${ }^{53}$ Umgekehrt könnten die in 1 Kor 16,17 erwähnten Stephanas, Fortunatus und Achaikus aus Korinth von daselbst Briefe für Paulus mitgebracht haben. Es zeichnet sich ab, dass die Wege der an der Entstehung und Vermittlung von Briefen beteiligten Personen sich kreuzen und Beziehungen sich verflechten.

Über den geschriebenen Brief hinaus kann dem Überbringer bzw. der Überbringerin eine wichtige Funktion zukommen, da sie das Geschriebene zusätzlich noch mündlich zu erläutern vermögen. ${ }^{54}$ Möglicherweise hat die in Röm 16,1 als Überbringerin erwähnte Phoebe just diesen Auftrag. ${ }^{55}$ Ebenso dürfte Timotheus' Aufgabe zu verstehen sein (1 Kor 16,10). Paulus schickt auch seinen engen Mitarbeiter Titus, dem die mündliche Erläuterung des Briefes obliegt, mit einem Brief nach Korinth (vgl. 2 Kor 8,6.16.23; 12,18).

Die Funktion des Boten übersteigt also bei Weitem das blosse Überbringen eines Schreibens. Ihm kommt zugleich eine vermittelnde Funktion zu. Wahrscheinlich gibt es auch Situationen, in denen ein Bote besser mit den Adressaten kommunizieren kann, als wenn Paulus selbst die betreffende Gemeinschaft aufsuchen würde. So dürfte beispielsweise Titus wesentlich zum Gelingen der Kommunikation beitragen, was sich in 2 Kor 7,6-8.13-15 widerspiegelt.

Meist wurde und wird immer noch angenommen, die Briefe würden als Ersatz für einen persönlichen Besuch dienen. ${ }^{56}$ Von Robert Funk stammt die

$5^{2}$ Vgl. Ludwig Friedländer, Darstellungen aus der Sittengeschichte Roms: In der Zeit von August bis zum Ausgang der Antonine, 7., neu bearb. Aufl., 2 Bde. (Leipzig, 19o1), 289-351.

Zur Frage der Beförderungsmöglichkeiten von Briefen siehe F. F. Bruce, „Travel and Communication (NT World)“, in: David N. Freedman und Gary A. Herion (Hg.), The Anchor Bible Dictionary, Bd. 6 (New York 1992), 648-653; Eldon J. Epp, „New Testament Papyrus Manuscripts and Letter Carrying in Greco-Roman Times“, in: Bierger A. Pearson (Hg.), The Future of Early Christianity: Essays in Honor of Helmut Koester (Minneapolis 1991), 35-56; Margaret M. Mitchell, „New Testament Envoys in the Context of GrecoRoman Diplomatic and Epistolary Conventions: The Example of Timothy and Titus", in: JBL 111, Nr. 4 (1992), 641-662.

54 Vgl. Richards, Paul and First-Century Letter Writing, 183.

55 Vgl. Allan Chapple, „Getting Romans to the Right Romans: Phoebe and the Delivery of Paul's Letter", in: TynB 62, Nr. 2 (2011), 195-214.

56 Vgl. Robert W. Funk, „The Apostolic Parousia:Form and Significance“, in:William R. Farmer und Charles F. D. Moule (Hg.), Christian History and Interpretation: Studies Presented to John Knox (Cambridge 1967), 249-269. 
lange Zeit unumstrittene These, dass die persönliche Präsenz des Apostels am wirksamsten, die Anwesenheit eines Boten demgegenüber weniger bedeutend sei und der Brief per se am wenigsten Wirkung habe. Margaret Mitchell stellt Funks These radikal infrage und hält dagegen, dass "the letter (and envoy, in some cases) was not an inadequate substitute for the more desirable Pauline physical presence, but was in fact deemed by him a superior way to deal with a given situation“ ${ }^{\text {“ }}{ }^{5}$ Boten könnten nämlich, so Mitchell, bestimmte Funktionen übernehmen, die Paulus selbst nicht auszuüben vermöchte, selbst wenn er persönlich anwesend wäre. ${ }^{58}$ Insofern entscheiden die Situation und das Anliegen in jedem Fall erneut, welche Form von Kommunikation die adäquateste bzw. wirksamste ist. Zudem vertritt Mitchell die Ansicht, dass gerade die relativ bescheidene Wirkung von Paulus' persönlicher Anwesenheit und sein eigenes Erinnern daran wesentlich dazu beigetragen haben, dass das paulinische Briefkorpus überhaupt überliefert ist. ${ }^{59}$

In seinen Briefen geht Paulus mitunter auf konkrete Fragen ein. Dies wird insbesondere deutlich, wenn er sich beispielsweise in 1 Kor 7,1 darauf bezieht, was die Adressatinnen und Adressaten ihm geschrieben haben: „Пєрi $\delta \dot{\varepsilon} \hat{\omega} \nu \dot{\varepsilon}_{\gamma} p \alpha \dot{\psi} \psi \alpha \tau \varepsilon^{\prime \prime}$. Dass Paulus nicht alles vor Ort geregelt und erklärt hat, ist indes nicht grundsätzlich von Nachteil, wie er selbst betont: dass nämlich die Briefe, wie man sagt, gewichtig und stark seien, hingegen die leibliche Gegen-

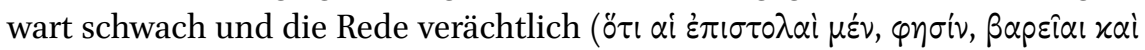

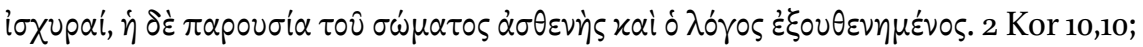
vgl. 10,1). Überdies sei zu bedenken, dass „wie wir im Wort durch Briefe abwesend

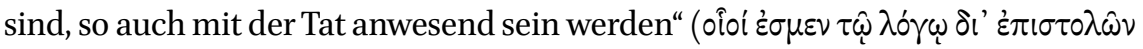

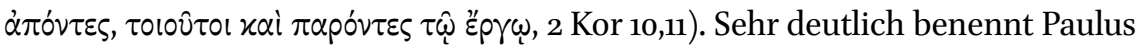

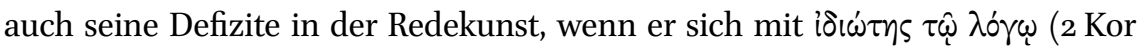
11,6) als darin unkundig bezeichnet. Überdies scheint er sich angesichts gewisser Probleme seines persönlichen Auftretens der Vorteile der schriftlichen Kommunikation bewusst zu sein, wenn er festhält, dass er in Abwesenheit schreibt, um nicht als Anwesender Strenge anwenden zu müssen nach der Vollmacht, die er vom Herrn zur Erbauung und nicht zur Zerstörung erhalten habe

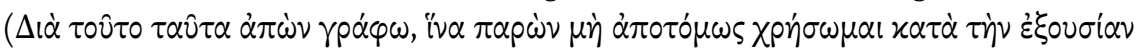

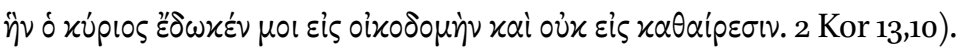

Auf die Zentralität der überbringenden Person weist mit Nachdruck Loubser hin: „The emissaries, and not the letters, were his representatives in the first instance. Most probably they (or one of the addressees) had to read the letters Epistolary Conventions", 642.

58 Vgl. ebd., 643.

59 Vgl. ebd.
} 
with the style and intonation of the Apostle himself, augmenting the message in the process." 60

In ähnlicher Weise argumentiert auch Peter Lampe und fordert, die Paulusbriefe sollten verstanden werden als Reden, die in einem typisch epistolografischen Rahmen verschriftlicht sind. ${ }^{61}$ Auch Verena Jegher spricht hinsichtlich des Galaterbriefes ganz pointiert von einer „Rede im Briefumschlag“. ${ }^{\prime 2}$ Damit rückt die Frage nach der Spannung zwischen Mündlichkeit und Schriftlichkeit im Zusammenhang der Paulusbriefe in den Fokus.

\subsubsection{Paulusbriefe zwischen Mündlichkeit und Schriftlichkeit}

Paulus konzipiert seine Briefe von Beginn an so, dass sie in der Versammlung der jeweiligen Gruppe öffentlich vorgelesen werden sollen. Das wird ersicht-

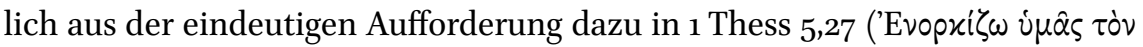

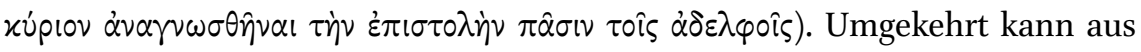
diesem Hinweis auch geschlossen werden, dass es gerade nicht selbstverständlich ist, dass Briefe automatisch einem weiteren Kreis vorgelesen werden, weil es sonst gar nicht erwähnt werden müsste. Aber Paulus setzt sich wiederum auch deutlich von der mündlichen Kommunikation ab, wenn er beispielsweise in Gal 1,20 oder 2 Kor 1,13 die Schriftlichkeit betont.

Anfänglich dürften die Briefe praktisches Mittel zum Zweck der schriftlichen Kommunikation über Distanz gewesen sein. Immer wieder taucht in

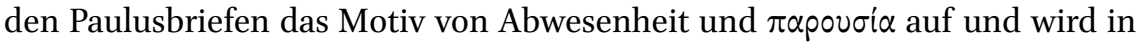
den Reiseberichten ausgeführt. ${ }^{63}$ Die Briefe dienen somit der Überbrückung der geografischen Distanz, bis Paulus selbst anwesend sein kann. Sie erneuern gewissermassen seine physische und damit auch mündliche Präsenz in der Vergangenheit und jene, die für die Zukunft versprochen ist.

Die Länge einzelner Briefe und die in ihnen enthaltenen Abhandlungen komplexer Themen deuten darauf hin, dass Paulus gerade in der Schriftlichkeit und im Senden von Briefen einen Vorteil sieht. Vermutlich ist der schriftliche Verkehr des Paulus aber nicht bloss ein Behelf, um die geografische Distanz zu überbrücken. Seine Briefe sind nicht einfach schriftliche Reden, die er lieber mündlich halten würde. Für Paulus könnte das schriftliche Medium ebenso eine willkommene Alternative zur direkten mündlichen Kommunikation

\footnotetext{
6o Loubser, „Orality and Literacy in the New Pauline Epistles“, 64.

61 Vgl. Peter Lampe, „Rhetorik und Argumentation“, in: Horn, Paulus Handbuch, 149-158, hier: 153 .

62 Verena Jegher-Bucher, Der Galaterbrief auf dem Hintergrund antiker Epistolographie und Rhetorik: Ein anderes Paulusbild, AThANT 78 (Zürich 1991), 5 .

63 Vgl. Werner H. Kelber, The Oral and the Written Gospel: The Hermeneutics of Speaking and Writing in the Synoptic Tradition, Mark, Paul and Q (Philadelphia 1983), 141.
} 
darstellen. Die Schriftlichkeit kompensiert seine Defizite in der mündlichen Darbringung bzw. in der persönlichen Kommunikation. Zu beachten ist, dass Briefe an Gruppen mündlich präsentiert werden. Pieter Botha geht davon aus, dass solche Präsentationen jeweils sorgfältig vorbereitet sind und dass der Brief als Rede dargebracht wird. ${ }^{64}$ Unter den Mitarbeitenden gibt es Personen, die hierfür geeigneter sind als Paulus selbst. Ihnen dienen die Briefe auch dazu, sich vor Ort als Stellvertreter des Paulus einzuführen. Überbringende repräsentieren in erster Linie Paulus und nicht die Briefe. Möglicherweise sollte die mit der Überbringung beauftragte Person (oder gegebenenfalls jemand aus der Adressatenschaft) den jeweiligen Brief so vorlesen, dass vom Stil und der Intonation her Paulus nachgeahmt wird. ${ }^{65}$ Wo Geschriebenes existiert, dient es zunächst als Hilfe für die mündliche Präsentation, und mündliche Elemente haben sich denn auch in seinen Briefen niedergeschlagen. Dennoch haben wir nicht die Möglichkeit, zu eruieren, wie sich der Vortrag von Briefen vor den Adressatinnen und Adressaten genau gestaltet. Wir können die Briefe lesen, als ob sie Reden wären und ihre Wirkung imaginieren, wie dies insbesondere die von der Rhetorik geprägten exegetischen Ansätze tun. ${ }^{66}$ Erst die spätere Verwendung der Paulusbriefe und ihre Überlieferung an andere Gemeinschaften bedarf der Lese- und Schreibfähigkeit.

\subsubsection{Exkurs: Alphabetisierung}

Die Schätzungen zum Alphabetisierungsgrad der Bevölkerung zur Zeit des Hellenismus divergieren enorm. Einerseits wird behauptet, die Fähigkeit zu lesen und zu schreiben sei zwar sicherlich in unterschiedlichem Masse, aber doch weitverbreitet gewesen - dies dank der Elementarschulen, die breiten Bevölkerungskreisen offengestanden hätten. ${ }^{67}$

Demgegenüber sehr kritisch sehen jüngere Untersuchungen die Situation. Ihnen zufolge ist der Alphabetisierungsgrad der antiken Mittelmeerbevölkerung

64 Vgl. Pieter J. J. Botha, „Letter Writing and Oral Communication in Antiquity: Suggested Implications for the Interpretation of Paul's Letter to the Galatians", in: Scr. $(S) 42$ (1992), 17-34, hier: 24 .

65 Vgl. Loubser, „Orality and Literacy in the New Pauline Epistles“, 64.

66 Geprägt hat diesen Ansatz insbesondere Hans Dieter Betz, Der Galaterbrief: Ein Kommentar zum Brief des Apostels Paulus an die Gemeinden in Galatien, mit der Unterstützung von Sibylle Ann, Hermeneia (München 1988); englisches Original: Hans Dieter Betz, Galatians: A Commentary on Paul's Letter to the Churches in Galatia, Hermeneia (Philadelphia 1979).

67 Vgl. Horst Blanck, Das Buch in der Antike, Beck's archäologische Bibliothek (München 1992), 22-39. 
bei weniger als zehn Prozent oder gar nur bei zwei bis vier Prozent anzusiedeln. ${ }^{68}$ In ländlichen Gebieten ist die Alphabetisierungsrate noch tiefer als in städtischen zu erwarten und bei Frauen tiefer als bei Männern. Näher zu definieren ist zudem noch der Grad der Alphabetisierung, denn diese kann von einer minimalen Kompetenz wie dem Lesen und Schreiben des eigenen Namens bis hin zu fliessendem Lesen und Schreiben reichen. Plausibel erscheint die Einschätzung von Aland Millard, dass es in der hellenistisch-römischen Welt gebildete Menschen gibt, die fliessend lesen und schreiben können, weniger gebildete, die lesen, aber kaum schreiben können, und solche, die nur lesen können, teils nur langsam und mit Mühe, und letztlich solche, die gar nicht lesen können. ${ }^{69} \mathrm{Un}$ geachtet der genauen Definition spricht vieles dafür, dass das Gros der Bevölkerung im antiken Mittelmeerraum des 1.Jh. n.Chr. aus Analphabeten besteht. ${ }^{70}$

Die Tatsache, dass nur ein geringer Teil der Bevölkerung das Lesen beherrscht, dürfte einer von mehreren Gründen sein, dass Briefe laut vorgetragen werden.

Trotz der zentralen Funktion der Mündlichkeit im Zusammenhang von Briefen bleibt zu beachten, dass die Paulusbriefe schriftliche Dokumente sind und dass Paulus damit die mündliche Kommunikation verlässt und in der Form seiner Briefe auch literarisiert. Der schriftliche Charakter der Briefe gibt ihnen Beständigkeit, die dem mündlichen Diskurs abgeht. Zugleich ist er ein erster Schritt in Richtung Entwicklung einer lese- und schreibkundigen Tradition, die allmählich zu einem christlichen Kanon von Schriften führt. Die Paulusbriefe dienen also zunächst der mündlichen Kommunikation, stehen aber zugleich am Anfang einer Entwicklung hin zu einem Kommunikationssystem, das auf Schriftlichkeit beruht. ${ }^{71}$ Als Medium in diesem Prozess, der der Vermittlung des Evangeliums unter den Völkern dient, kommt dem Brief nach und nach eine herausragende Rolle $\mathrm{zu}$.

Festzuhalten ist, dass der grundlegende Text hinter einem Brief mündlich ist. Das heisst, eine ursprünglich mündliche Botschaft wird verschriftlicht, um dann wiederum mündlich vor den Adressatinnen und Adressaten am Zielort

68 Vgl. Bruce J. Malina und Richard L. Rohrbaugh, Social Science Commentary on the Synoptic Gospels (Minneapolis 1992), 3; Richard L. Rohrbaugh, „The Social Location of the Marcan Audience“, in: BTB 23, Nr. 3 (1993), 114-127 und 115; Harris, Ancient Literacy, 244. Für die jüdische Bevölkerung Palästinas konstatiert Catherine Hezser gar eine noch tiefere Alphabetisierungsrate als in anderen Gebieten der hellenistischen Welt, weil angeblich der intellektuelle Austausch sich eher mündlich als schriftlich gestaltete; vgl. Catherine Hezser, Jewish Literacy in Roman Palestine, TSAJ 81 (Tübingen 2001).

69 Vgl. Alan Ralph Millard, Reading and Writing in the Time of Jesus, BiSe 69 (Sheffield 200o), 154 .

70 Vgl. Joanna Dewey, „Textuality in an Oral Culture“, in: Dewey, Orality and Textuality in Early Christian Literature, 40.

$71 \quad$ Vgl. ebd., 51. 
vorgetragen zu werden. Das Problem ist, dass die einzigen Dokumente, auf die wir uns stützen können, das Zwischendrin darstellen: das Schriftliche zwischen zwei mündlichen Akten. Diese Briefe sind die primären Quellen, in denen Paulus sich selbst beschreibt - buchstäblich be-schreibt.

\subsubsection{Zusammenfassung und Fazit}

Die Paulusbriefe sind die einzige Quelle aus erster Hand, die das interkulturelle Vermitteln des Paulus im Hinblick auf seine Gruppen Christusgläubiger nachvollziehbar machen. Das sieben Briefe umfassende Korpus ist zugleich konkret und beschränkt. Die Briefe stammen aus der späteren Zeit des paulinischen interkulturellen Wirkens und repräsentieren jeweils nur die paulinische Perspektive einer sicherlich bilateralen, gegebenenfalls auch multilateralen Korrespondenz. Die Perspektiven der Adressatinnen und Adressaten können somit nur textimmanent aus den Paulusbriefen extrapoliert werden. Als einzige direkte Quellen kommt den Briefen in einem sehr viel umfassenderen Vermittlungsgeschehen eine ganz zentrale Bedeutung zu.

Paulus partizipiert mit dem Schreiben von Briefen also an einem wesentlichen Kulturgut des antiken Mittelmeerraums. Es ist das herausragende Medium, mit dessen Hilfe Botschaften über Raum und Zeit hinweg übermittelt werden können. In der Form orientieren sich die Paulusbriefe an Spezifika aus der Ausgangskultur, namentlich den Gepflogenheiten jüdischer gemeindeleitender Briefe mit Aspekten philophronetischer Briefe. Zugleich lassen sie aber insbesondere auf sprachlicher Ebene bereits individuelle interkulturelle Hinwendungen zur paganen Adressatenschaft erkennen. Dies zeigt sich in der Wortwahl beim Gruss. Das Medium verändert sich somit durch seine Ausrichtung auf eine spezifische Adressatenschaft. Diese kulturspezifische Sensibilität lässt die noch zu entfaltende Bikulturalität des Paulus bereits erahnen.

Die Briefe machen einen wichtigen, aber gleichwohl neben den persönlichen Begegnungen nur beschränkten Teil im paulinischen Vermittlungsprozess aus. Überdies hat die Diskussion der praktischen Aspekte aufgezeigt, dass Paulus auf allen Ebenen auf das Mitwirken anderer Personen angewiesen ist: vom Schreiben über die Finanzierung und das physische Überliefern von einem Ort zum anderen bis hin zur mündlichen Kommunikation des schriftlichen Briefes vor Ort. Die Briefe sind somit fassbare Elemente in einem dynamischen System, an dem sowohl beim Prozess des Schreibens als auch bei der Übermittlung und am Empfangsende diverse Menschen beteiligt sind. Der Brief als Medium im Vermittlungsprozess gibt somit Einblick in ein auf mehreren Ebenen eng verflochtenes Beziehungssystem. Zugleich eröffnen die Briefe an verschiedenen Stellen den Blick auf Paulus und 
ermöglichen die Perspektive auf ihn als den Hauptakteur im Vermittlungsprozess - so wie er sich selbst darstellt.

\subsection{Paulinische Selbstbeschreibungen}

Die Paulusbriefe sind situative Schreiben im Hinblick auf bestimmte Adressatenschaften inmitten geschichtlicher und biografischer Zusammenhänge. Die Person des Paulus steht nicht im Zentrum, aber die Briefe enthalten autobiografische Elemente und weitere Informationen zum Verfasser. ${ }^{72}$ Weiterhin ist zu beachten, dass die autobiografischen Elemente nicht um ihrer selbst willen im Text stehen, sondern jeweils einem rhetorischen Zweck dienen. Die Frage „Wer war Paulus?" wäre demnach viel zu weit gefasst. Einerseits geht es nicht darum, ein Bild des Paulus mit Objektivitätsanspruch zu liefern, sondern darum, nachzuzeichnen, wie sich Paulus in seinen Briefen als Apostel für die Völker darstellt und wie er als interkultureller Vermittler angesehen werden kann. Wie sich Paulus selbst tatsächlich gesehen hat, bleibt dabei offen. ${ }^{73}$ Aus der Fülle der Informationen innerhalb der Paulusbriefe werden im Folgenden diejenigen Elemente aufgenommen und in Auseinandersetzung mit der Forschungsliteratur diskutiert, die im Hinblick auf die Beschreibung des Paulus als Apostel für die Völker, also seine Verflechtung mit der Ausgangsund der Zielkultur, relevant sind. Entsprechend der Perspektive, dass es um die Selbstbeschreibung des Paulus geht, stehen die Paulusbriefe im Zentrum. An einigen Stellen drängt es sich allerdings auf, auch Aussenperspektiven mit ins Gespräch zu bringen, sodass auch Zeugnisse der Apostelgeschichte miteinbezogen werden.

72 Zur Definition von Autobiografie und zu weiteren Formen literarischer Selbstdarstellung in der Antike vgl. Wolff, Paulus beispiels-weise, 49-88. Die „rückblickende Perspektive auf das eigene Leben" identifiziert Wolff an folgenden zahlreichen Stellen: Röm 1,5; (7,7-25); 11,1; 15,19-22; 1 Kor 1,14-17; 2,1-5; 3,1-4.5-6.10; 4,9-13.15; 9,19-22; 11,23; 13,11; 15,1-3.8-10.32; 2 Kor 1,8-12.19; 2,5.12-13; 3,4-6; 4,1.6; 7,2; 11,2b.7-9.22.23b-28.32-33; 12,2-4,7-9.12.16-18; Gal 1,9.12-2,14(21); 4,3-4.13-15; 5,21; Phil 1,12.20; 2,16; 3,5-7; 4,15-17; 1 Thess 1,5; 2,1-10.18; ebd., 70.

73 Vgl. dazu die Bemerkung von Stephanie Kurczyk in ihrer Untersuchung zu Ciceros Autobiographie: „Aus autobiographischen Texten kann nicht geschlossen werden, wie sich ein Mensch tatsächlich selbst gesehen hat, sondern wie er sich seinen Rezipienten gegenüber dargestellt hat, wie er gesehen werden wollte." Stephanie Kurczyk, Cicero und die Inszenierung der eigenen Vergangenheit: Autobiographisches Schreiben in der späten Römischen Republik, Europäische Geschichtsdarstellungen (Köln 2006), 31, Hervorhebung im Original. 


\subsubsection{Name und Namenszusätze}

Antiker Konvention entsprechend eröffnet Paulus all seine Briefe mit seinem

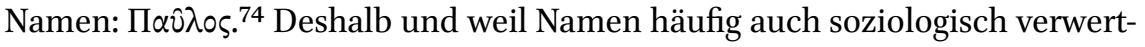
bare Hinweise enthalten und Rückschlüsse erlauben, kommt der Name hier zuerst in den Fokus.

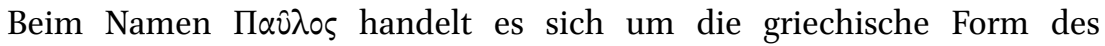
lateinischen „Paul(l)us“ mit der Bedeutung ,klein'. ${ }^{75}$ Schon alleine die Tatsache, dass Paulus einen römischen Namen hat bzw. sich mit diesem vorstellt, ist bemerkenswert. Römische Namen haben in der Regel drei Teile (praenomen, nomen, cognomen), wie beispielsweise Gaius Julius Caesar. Die Nennung der tria nomina ist allerdings in Griechisch sprechenden Kreisen selten, zumal in jüdischen und frühchristlichen. ${ }^{76}$ Im Neuen Testament wird aber kein einziger Römer mit seinen tria nomina erwähnt. Falls Paulus römischer Bürger ist (Apg 22,28), dürfte er auch drei Namen haben. ${ }^{77}$ Diese sind uns jedoch nicht

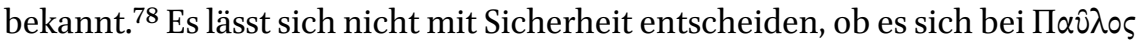
um ein praenomen oder cognomen handelt. ${ }^{79}$ Der Name Паט̂خos ist auch insofern bemerkenswert, als er bei Römern eher selten ist, ${ }^{80}$ bei Nichtrömern

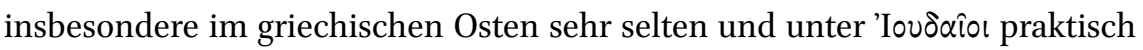
inexistent. 81

Der Apostelgeschichte zufolge hat Paulus noch einen zweiten Namen: $\Sigma \alpha \hat{\nu} \lambda \circ \varsigma$ (Saulus). Apg 7,58-13,7 verwendet ausschliesslich den Namen $\Sigma \alpha \hat{\lambda} \lambda \circ \varsigma$

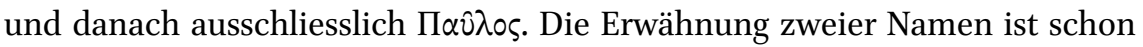
für sich genommen ein Hinweis darauf, dass Paulus als in zwei Welten lebend

74 Der Name wird im NT mit einer Ausnahme (Apg 13,7) ausschliesslich für den Apostel verwendet.

75 Es gibt auch die Varianten Polus und Pollus; vgl. Colin J. Hemer, „The Name of Paul“, in: TynB 36 (1985), 179-183, hier: 183 .

76 Vgl. Martin Hengel, „Der vorchristliche Paulus“, in: Heckel, Hengel und Schlatter, Paulus und das antike Judentum, 197.

77 Der Umkehrschluss ist allerdings nicht möglich: Nicht alle Träger dreier Namen hatten auch das römische Bürgerrecht; vgl. Hemer, „The Name of Paul“, 181.

78 Dass Paulus Cn. Pompeiu Paulus, C. Julius Paulus oder M. Antonius Paulus nach den drei in Tarsus einflussreichen Römern Pompeius, Caesar oder Antonius geheissen haben könnte, wie Hemer postuliert, ist höchst spekulativ; vgl. ebd., 179. Siehe auch G. A. Harrer, „Saul who is also called Paul“, in: HTR 33 (1940), 19-33, hier: 30-31.

79 So Martin Hengel, „Der vorchristliche Paulus“, in: Heckel, Hengel und Schlatter, Paulus und das antike Judentum, 198. Siehe dort Fn. 73 für die entsprechende Diskussion. Hemer spricht sich für cognomen aus; vgl. Hemer, „The Name of Paul“.

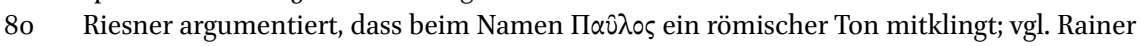
Riesner, Die Frühzeit des Apostels Paulus: Studien zur Chronologie, Missionsstrategie und Theologie, WUNT 71 (Tübingen 1994), 126-127.

81 Vgl. ebd., 127-128, insbesondere: Fn. 57. 


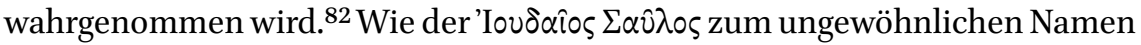

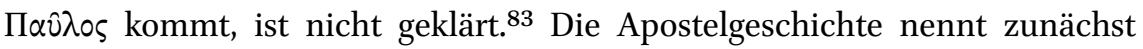
24-mal Saul(os) und später mehr als 100-mal Paulus. ${ }^{84}$ Entgegen der sprichwörtlich gewordenen ,Bekehrung vom Saulus zum Paulus' erscheint aber das römische Cognomen nicht anlässlich Paulus' Berufung zum ersten Mal, sondern im Kontext der paulinischen Erzählung anlässlich seiner Begegnung

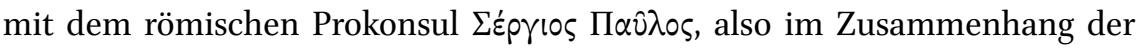

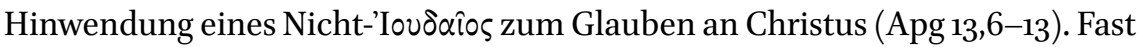
beiläufig erwähnt Lukas dort den „Saulus, der auch Paulus heisst“ (Apg 13,9), um im weiteren Verlauf dann ausschliesslich letzteren Namen zu verwenden. Klaus Wengst hält fest:

An dieser Schaltstelle lässt er auch ganz deutlich erkennen, dass es nicht einen Namenswechsel im Leben dieser Person gab, sondern dass sie einen Doppelnamen hatte, und zwar einen hebräischen und einen griechisch-römischen wie viele in der Diaspora. ${ }^{85}$

Paulus selbst verwendet in seinen Briefen aber ausschliesslich den einzel-

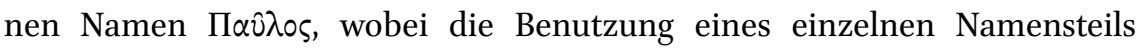
häufig vorkam. ${ }^{86}$ Möglicherweise handelt es sich auch um einen Übernamen (supernomen). ${ }^{87}$ Er dürfte familiären Beziehungen zu einem Patron namens

82 Vgl. Joachim Gnilka, Paulus von Tarsus, Apostel und Zeuge, HThKAT.S 6 (Freiburg i. Br., Basel 1996), 24-25.

83 Vgl. dazu Martin Hengel, „Der vorchristliche Paulus“, in: Heckel, Hengel und Schlatter, Paulus und das antike Judentum, 197-198.

84 In sechs Versen findet sich mit $\Sigma \alpha 0 u \dot{\lambda}$ neunmal die griechische Transkription des hebräischen Namens שָׁאוּ (Apg 9,4.17; 13,21; 22,7.13; 26,14 [es sind nur sechs Stellen, da in drei Instanzen der Name doppelt genannt ist: $\Sigma \alpha 0$ $\lambda$, $\Sigma \alpha 0$ $\lambda]$ ]), in den übrigen 15 Vorkommen findet sich der Name in der gräzisierten Form $\Sigma \alpha \hat{\nu} \lambda$ os (Apg 7,58; 8,1.3; 9,1.8.11.22.24; 11,25.30; 12,25; 13,1.2.7.9).

85 Klaus Wengst, „Freut euch, ihr Völker, mit Gottes Volk!": Israel und die Völker als Thema des Paulus - ein Gang durch den Römerbrief (Stuttgart 2008), 75. Für den Doppelnamen argumentiert auch Riesner, Die Frühzeit des Apostels Paulus, 128.

86 Heike Omerzu, Der Prozess des Paulus: Eine exegetische und rechtshistorische Untersuchung der Apostelgeschichte, BZNW 115 (Berlin, New York 2002), 24-25.

87 Vgl. Harrer, „Saul who is also called Paul“. Sherwin-White vermutet, dass der Grund des ungewöhnlichen Namens im Gleichklang liegt; vgl. Adrian Nicholas Sherwin-White, Roman Society and Roman Law in the New Testament: The Sarum Lectures 1960-1961 (Oxford 1963), 153-154. Auch Colin Hemer weist in Analogie zu Saulus/Paulus auf einen Grabstein mit dem Übernamen "Neon“ hin, der sich auf den Nachnamen „Leo“ reimt; Hemer, „The Name of Paul“, 181. Für eine umfassende Studie zu Übernamen siehe Iiro Kajanto, Supernomina: A Study in Latin Epigraphy, CHL Vol. 40, Nr. 1 (Helsinki 1966). 
Paulus zu verdanken sein. ${ }^{88}$ Statt eines dreiteiligen Namens nennt Paulus nur einen einzigen nicht jüdischen Namen. Möglicherweise setzt er damit gegenüber seinen Adressatinnen und Adressaten aus den Völkern ein Zeichen, dass er mit ihnen auf ein und demselben Boden steht, ${ }^{89}$ oder er tut dies aus Bescheidenheit und Rücksichtnahme auf sie, da wahrscheinlich unter ihnen höchstens eine kleine Minderheit das römische Bürgerrecht besitzt. ${ }^{90}$ Jedenfalls ist es ein Zeichen an die Adressatinnen und Adressaten aus den Völkern, wenn Paulus sie in seinem Bemühen um Vermittlung unter exklusiver Nennung eines römischen und daher pagan konnotierten Namens anspricht.

Zusätzlich zu seinem Namen führt Paulus in den Präskripten von Röm, 1 Kor, 2 Kor und Gal jeweils als Namenszusatz eine Art Titel an. ,Titel ' wird hier nicht im Sinne seiner üblichen Bedeutung verstanden, sondern im Sinne von $\mathrm{Zu}-$ sätzen zum Namen. Die Diskussion dieser Namenszusätze ist relevant, weil sie einiges über die Selbstdarstellung des Paulus im Hinblick auf seine Vermittlertätigkeit, aber auch über seine Beziehung zur Adressatenschaft aussagen.

Nur in vier Briefen findet sich die Selbstbezeichnung als Apostel Jesu Christi

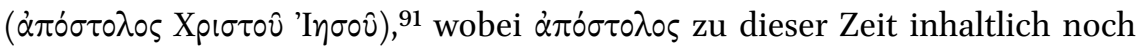

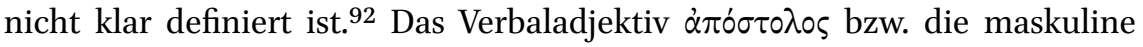
Nominalbildung zum Verb $\alpha \dot{\tau} \sigma \sigma \tau \varepsilon \lambda \lambda \omega$ ist Ausdruck des Gesandtseins und zunächst einfach ein Funktionsbegriff. ${ }^{93} \dot{\alpha} \pi \circ \sigma \tau \dot{\varepsilon} \lambda \lambda \omega$ mit der Grundbedeutung ,fortschicken, fortsenden` wird in der Profangräzität sowohl für Personen als

88 Vgl. Martin Hengel, „Der vorchristliche Paulus“, in: Heckel, Hengel und Schlatter, Paulus und das antike Judentum, 198.

89 Vgl. ebd., 201.

90 Vgl. Riesner, Die Frühzeit des Apostels Paulus, 129.

91 Thomas Schmeller vermutet: „Paulus verweise dann auf seinen Apostolat, wenn dieser in der Adressatengemeinde nicht mehr (1/2 Kor, Gal) oder noch nicht (Röm) anerkannt ist [...]." Thomas Schmeller, Der zweite Brief an die Korinther: (2 Kor 1,1-7,4), EKK 8/1 (Neukirchen-Vluyn: Neukirchener Theologie, 2010), 51. Auch Jörg Frey sieht in der paulinischen Berufung auf den Aposteltitel „ein Ergebnis der Konflikte um die Person des Paulus und sein Amt.“ Jörg Frey, „Apostelbegriff, Apostelamt und Apostolizität“, in: Theodor Schneider und Gunther Wenz für den Ökumenischen Arbeitskreis evangelischer und katholischer Theologen (Hg.), Das kirchliche Amt in apostolischer Nachfolge, DiKi (Freiburg i. Br. 2004), 91-188, hier: 127.

92 Vgl. ebd., 126; Jörg Frey, „Paulus und die Apostel: Zur Entwicklung des paulinischen Apostelbegriffs und zum Verhältnis des Heidenapostels zu seinen ,Kollegen“', in: Becker und Pilhofer, Biographie und Persönlichkeit des Paulus, 192-227, hier: 194-196; Becker, Schreiben und Verstehen, 144.

93 Vgl. die ausführliche Studie von Monika Lohmeyer, Der Apostelbegriff im Neuen Testament: Eine Untersuchung auf dem Hintergrund der synoptischen Aussendungsreden, SBB 29 (Stuttgart 1995), zugleich: Siegen, Univ., Diss., 1994. 
auch Sachen verwendet. ${ }^{94}$ Im Kontext der Entwicklung des frühen Christus-

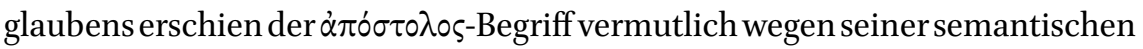
Unscheinbarkeit als brauchbar für die Beschreibung einer neuen Form von Aussendung eines Menschen. Im Gegensatz zum Verb $\alpha \dot{\tau} 0 \sigma \tau \varepsilon \dot{\lambda} \lambda \omega$ wird das dazugehörige Substantiv $\dot{\alpha} \pi \delta ́ \sigma \tau 0 \lambda$ os in der Profangräzität kaum verwendet. Im NT findet es sich hingegen mehr als 80-mal. Allerdings erscheint die Annahme plausibel, dass der Begriff im frühen Christentum nicht klar definiert ist. Für

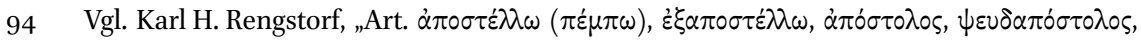

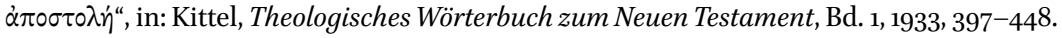
Ausgesandtes kann denn bspw. auch einen Lieferschein oder eine Flottenexpedition bezeichnen, vgl. ebd., Bd. 1, 406-408. Das Kompositum ist gegenüber dem Simplex $\sigma \tau \dot{\varepsilon} \lambda \lambda \omega$ noch schärfer auf Zielbewusstsein und Zielstrebigkeit hin akzentuiert. Im Gegensatz zu $\pi \dot{\varepsilon} \mu \pi \omega$ steht bei $\alpha \dot{\pi} \sigma \sigma \varepsilon \dot{\varepsilon} \lambda \omega$ die Sendung oder der Gesandte unter einem „ganz bestimmten, einmaligen und einzigartigen Gesichtspunkt“. Ebd., Bd. 1, 397. Mit $\alpha \dot{\pi} 0 \sigma \tau \dot{\varepsilon} \lambda \omega \omega$ ist nach Rengstorf auch die Autorisation des Gesendeten verbunden. Gesendete vertreten ihren Sender und seine Autorität. In der Profangräzität, aber auch bei Philo, figuriert $\dot{\alpha} \pi \circ \sigma \tau \dot{\varepsilon} \lambda \omega$ auch als Terminus technicus für eine Bevollmächtigung durch eine Gottheit. Als Beispiele führt Rengstorf Epikt. Diss. 1.24.6 und 3.22.23 an. Es gehört zum Bewusstsein eines wahren Kynikers, dass er von Zeus zu den Menschen gesandt ( $\dot{\alpha} \pi \circ \sigma \tau \dot{\lambda} \lambda \omega)$ ist, vgl. ebd., Bd. 1, 398.

In der LXX kommt $\dot{\alpha} \pi \circ \sigma \tau \dot{\varepsilon} \lambda \omega \omega$ mehr als 70o-mal vor, nicht selten auch in der Variante $\dot{\varepsilon} \xi \alpha \pi \varepsilon \varepsilon \tau \varepsilon 1 \lambda \varepsilon \nu$, und dient in den meisten Fällen einer Übersetzung der Wurzel שלח. Rengstorf hat dies verstanden als Terminus technicus für die Sendung eines Boten mit speziellem Auftrag, vgl. bspw. die Sendung Jesajas, als Gott jemanden braucht, den er aussenden kann als seinen bevollmächtigten Wortführer (Jes 6,8). Charakteristisch ist für $\dot{\alpha} \pi \circ \sigma \tau \varepsilon \lambda \omega$ ebenso wie für שלח die „unbedingte Unterordnung unter den Willen des Sendenden“, ebd., Bd. 1, 401. Während Bevollmächtigungen in aller Regel zeitlich und sachlich beschränkt seien, so Rengstorf, werde שלח in der alttestamentlich-jüdischen Tradition bei der Berufung eines Propheten als lebenslange Sendung verstanden (vgl. nur Jes 6,8); vgl. ebd., Bd. 1, 414. Weiter vertritt Rengstorf die These, dass sich im jüdischen

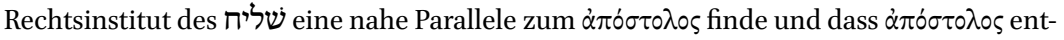
sprechend an altsemitisches Botenrecht anklinge; vgl. ebd., Bd. 1, 415-420, 425-426 und 443. Diese These darf indes als überholt gelten, da die Quellen hierfür wesentlich jünger sind als das Neue Testament; vgl. dazu Lohmeyer, Der Apostelbegriff im Neuen Testament, 78-108; vgl. auch Christine Gerber, Paulus, Apostolat und Autorität, oder Vom Lesen fremder Briefe, ThSt.NF 6 (Zürich 2012), 37-38.

Jürgen Roloff hat postuliert, dass $\dot{\alpha} \pi$ ó $\tau 0 \lambda \circ \varsigma$ mit dem Konzept von Repräsentanz verbunden und damit "ein formaler Autorisationsterminus“ sei; vgl. Jürgen Roloff, „Art. Apostel etc.: I.: Neues Testament“, in: Horst R. Balz et al. (Hg.), Theologische Realenzyklopädie, Bd. 3 (Berlin 1976-2007), 430-445, hier: 433. Dem hält Gerber entgegen, dass die Verwendung im NT weder wirklich eine solche Repräsentanzfunktion noch einen Anschluss an die Rede vom שליח erkennen lasse; vgl. Gerber, Paulus, Apostolat und Autorität, oder Vom Lesen fremder Briefe, 38; mit Verweis auf Jörg Frey, „Apostelbegriff, Apostelamt und Apostolizität", in: Schneider und Wenz, Das kirchliche Amt in apostolischer Nachfolge, 143-144 (allerdings anders ebd., 180). 
Paulus kann zur Zeit seiner Berufung kein ausgereiftes Konzept eines Apostels vorausgesetzt werden. Vielmehr dürfte es erst im Kontext von kritischen Situationen geschärft worden sein. ${ }^{95}$

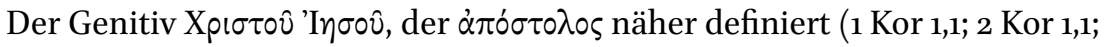
in leichter Variation auch Gal 1,1; Röm 1,1), macht deutlich, dass der Auftrag an den Gesandten nicht von Menschen oder gar von eigener Initiative herrührt, sondern vom Auferstandenen selbst. Und der Auferstandene agiert nach dem Willen Gottes ( $\delta$ เ’̀ $\theta \varepsilon \lambda \eta \dot{\mu} \mu \alpha \tau \circ \theta_{\varepsilon} 0 \hat{v}, 1$ Kor 1,1; 2 Kor 1,1). Der gesamte Brief untersteht somit der von Gott durch Christus vermittelten Beauftragung.

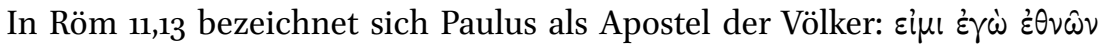
$\alpha \dot{\pi} \delta \dot{\sigma \tau o \lambda o s . ~ F u ̈ r ~ D o u g l a s ~ J . ~ M o o ~ s t e l l t ~ d i e ~ u n g e w o ̈ h n l i c h e ~ F o r m u l i e r u n g ~} \dot{\theta} \theta \nu \omega \hat{\omega} \nu$ $\dot{\alpha} \pi \dot{\sigma} \sigma \tau \lambda$ os eine Art Titel dar. ${ }^{96}$ Dass Paulus hier keinen bestimmten Artikel verwendet, zeigt, dass er nicht beansprucht, der Völkerapostel schlechthin zu sein. Für die Gruppe Christusgläubiger in Korinth stellt er sich als ihr besonderer

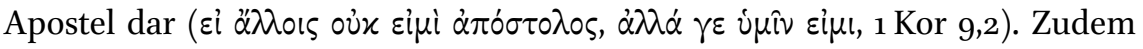
definiert Paulus seinen Auftrag näher: Er ist von Christus nicht ausgesandt zu taufen, sondern das Evangelium zu verkünden ( $\varepsilon \dot{v} \alpha \gamma \varepsilon \lambda \lambda \zeta \xi \varepsilon \sigma \theta \alpha l, 1$ Kor 1,17).

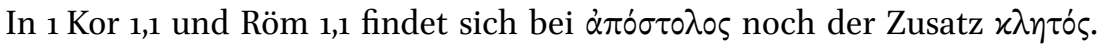
Paulus als $x \lambda \eta$ tós unterscheidet sich von den anderen Menschen ausschliesslich durch seinen Auftrag, denn auch seine Adressatinnen und Adressaten sind $x \lambda \eta \tau o i ́($ Röm 1,6). Durch die Verwendung ein und desselben Begriffs für die Letzteren wie für sich selbst kommt eine essenzielle Gleichheit zum Ausdruck. Paulus bezeichnet seine Adressatinnen und Adressaten sogar als be-

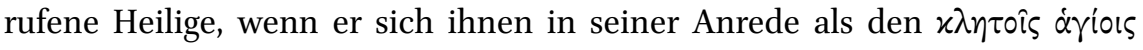
zuwendet (Röm 1,7). Die Gerufenen sind zudem Heilige ( $\dot{\alpha} \gamma$ ío, 1 Kor 1,2) und unterscheiden sich von Menschen ausserhalb der Gemeinschaft dadurch, dass sie den Namen des Herrn Jesu Christi anrufen. Das in der Anrede unscheinbare $\dot{\eta} \mu \hat{\omega} v$ in Bezug auf den Herrn drückt aus, dass Paulus und seine Mitarbeitenden zusammen mit den Adressierten zum gleichen xúplos gehören.$^{97}$ Auffällig ist jedenfalls im Römerbrief der Gebrauch dreier Attribute zu seinem Namen

95 Vgl. Gerber, Paulus, Apostolat und Autorität, oder Vom Lesen fremder Briefe, 38-39.

In seiner Aufarbeitung der Forschungsgeschichte zum Thema postuliert Francis H. Abnew für das entstehende Christentum - bei aller Differenzierung im Detail -

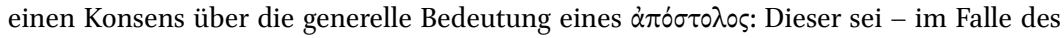
Paulus durch eine Vision des Auferstandenen - offizieller Zeuge von Jesu Auferstehung geworden und vom Auferstandenen dazu beauftragt, das Evangelium zu verkünden, um es weiterzu verbreiten; vgl. Francis H. Agnew, „The Origin of the NT Apostle-Concept: A Review of Research“, in: JBL 105, Nr. 1 (1986), 75-96, hier: 77.

96 Vgl. Douglas J. Moo, The Epistle to the Romans, NICNT (Grand Rapids (MI) 1996), 691 (Fn. 40).

Vgl. Wolff, Paulus beispiels-weise, 217. 


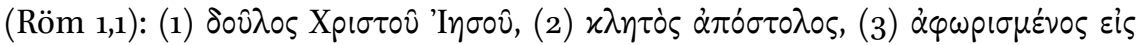
$\varepsilon \dot{a} \gamma \gamma \varepsilon \dot{\lambda}$ เov $\theta \varepsilon \circ \hat{0}$. Diese betonen das Apostolat des Paulus sowie seine göttliche Berufung, das Evangelium zu verkünden.

Im Brief an die Christusgläubigen in Rom geht dem Aposteltitel die Be-

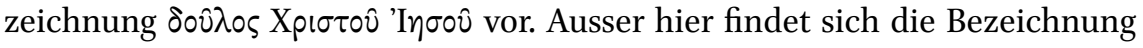
als $\delta 0 \hat{\lambda}$ os auch in Phil 1,1; 2 Kor 4,5 und Gal 1,10. Diese Selbstbezeichnung als Sklave mutet zunächst erstaunlich an. ${ }^{98} \delta 00 \lambda \varepsilon u ́ \omega$ betont (im Unterschied zu den bedeutungsmässig verwandten Begriffen $\theta \varepsilon p \alpha \pi \varepsilon v^{\prime} \omega, \lambda \alpha \tau p \varepsilon \dot{v} \omega, \lambda \varepsilon \varepsilon \tau 0 u p \gamma \varepsilon \dot{\varepsilon} \omega$,

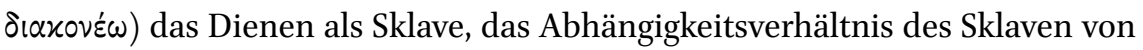
seinem Herrn. ${ }^{99}$ Die Selbstbezeichnung des Paulus als Sklave scheint seinen Anspruch zu unterminieren, zum einen zur Verkündigung des Evangeliums Gottes ausgesondert/auserwählt/ausersehen zu sein (Röm 1,1) und zum anderen von Jesus Christus Gnade und die Aufgabe des Apostolats empfangen zu haben (Röm 1,5). Meist wird in der Sklavenbezeichnung des Paulus ein Anklang an die alttestamentliche Tradition vom Knecht Jahwes identifiziert,

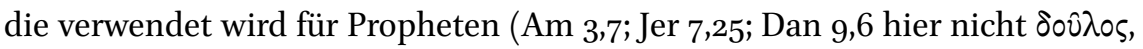
sondern $\pi \propto$ î), jüdische Betende (wie beispielsweise Neh 1,6.11; Ps 19,12.14 etc.) oder auch Israel als Ganzes (Ps 136,22). ${ }^{100}$ Jewett zufolge dürfte allerdings diese

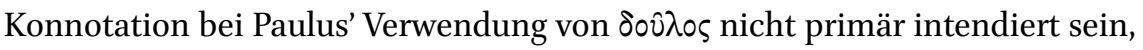
da Paulus in der Wiederaufnahme des Themas in Röm 15,15-20 seinen Dienst eher in priesterlichen als in prophetischen Kategorien beschreibt. Vielmehr müsse die lokale Bedeutung der Terminologie in Betracht gezogen werden, was in der Forschung selten der Fall sei. ${ }^{101} \mathrm{Im}$ römischen Kontext tragen einflussreiche Sklaven und Freigelassene, die zum Herrscherhaus gehören, den

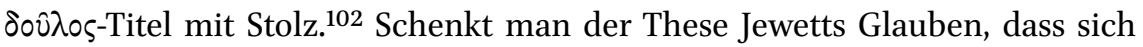
der Brief an die Christusgläubigen in Rom an einflussreiche Sklaven richte, die dem Herrscherhaus dienten, erhält der Sklaventitel einen besonderen Sinn. ${ }^{103}$ In dem Fall spielt Paulus hier auf die sozialen Strukturen des Imperiums an

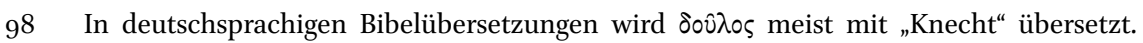
Rengstorf folgend erscheint aber Sklave als adäquatere Übersetzung; vgl. Rengstorf,

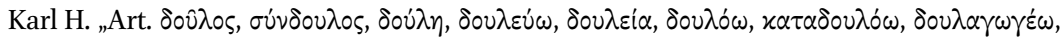
¿ $\varphi \theta \alpha \lambda \mu \circ \delta 00 \lambda i \alpha^{\prime \prime}$, in: Kittel, Theologisches Wörterbuch zum Neuen Testament, Bd. 2, 1935, 264-283, hier: 264 .

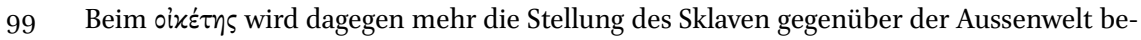
tont; vgl. ebd.

100 Vgl. bspw. Jewett, Kotansky und Epp, Romans, 100.

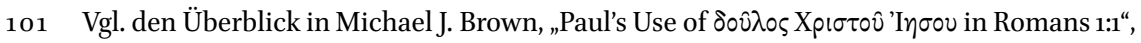
in: JBL 120 (2001), 723-737, hier: 725-28.

102 Vgl. Jewett, Kotansky und Epp, Romans, 100.

103 Deren Grabsteine trugen oft den Titel „Sklave Caesars“; vgl. Robert Jewett, „Romans as an Ambassadorial Letter", in: Interp. 36 (1982), 5-20, hier: 13. 
und stellt sich als hochrangigen Sklaven dar. ${ }^{104}$ Demnach präsentiert er sich als kaiserlichen Repräsentanten Jesu Christi, indem er den Terminus technicus für einen königlichen Beamten oder einen Funktionär der kaiserlichen Administration verwendet. ${ }^{105}$ Aus dieser Perspektive ist der Status, den Paulus in Röm 1,1 und 5 für sich selbst beansprucht, weder aufdringlich noch belanglos. Vielmehr klärt er die autoritative Rolle des Schreibers in einer Art, die für diplomatische Korrespondenz gang und gäbe ist. ${ }^{106}$ Jewetts Interpretation ist plausibel, muss aber die andere überhaupt nicht ausschliessen. Je nach Beschaffenheit der Adressatenschaft kann die eine oder die andere Art von Konnotation stärker wahrgenommen worden sein.

Die Adressatinnen und Adressaten dürften diese Selbstvorstellung jedenfalls verstanden haben als „statement of the sender's credentials ${ }^{“ 107}$. Durch diese erhält der Brief einen offiziellen Charakter, und er verschafft zugleich Paulus das Recht und die Autorität, überzeugend an die Menschen in Rom zu schreiben. ${ }^{108}$ Zugleich dürfte die Selbstbezeichnung als Sklave dazu dienen, soziale Hierarchien zu unterwandern: Hierarchien, die durch die existierenden Gesetze geschaffen sind und unterstützt werden. Unter dem Gesetz sind nämlich Sklaven einerlei. Hier gibt es keine Abstufungen zwischen privilegierteren und niedereren Sklaven, sondern es gehören alle einer einzigen gesetzlichen Kategorie an. ${ }^{109}$ Die Botschaft, die Paulus damit sendet, besagt, dass alle Menschen in ihrem Rechtsstatus vor Gott gleich sind (vgl. Röm 2,9-11). Er setzt damit auch seinen Status gleich mit demjenigen seiner Adressatinnen und Adressaten. ${ }^{110}$

Neben $\delta \circ \hat{\lambda} \lambda$ os verwendet Paulus überdies für sich selbst und auch für

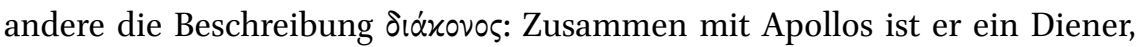
durch den die Adressatenschaft zum Glauben gekommen ist (1 Kor 3,5); zusammen mit Timotheus stellt er sich den Menschen in Philippi vor (Phil 1,1); in einem kollektiven ,wir' bezeichnet sich Paulus als von Gott befähigter

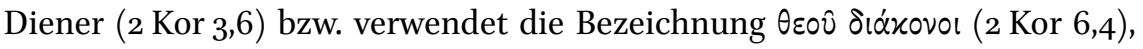

\footnotetext{
104 Vgl. I. A. H. Combes, The Metaphor of Slavery in the Writings of the Early Church: From the New Testament to the Beginning of the Fifth Century, JSNTS 156 (Sheffield 1998), 77.

105 Vgl. Walter Bauer, Griechisch-deutsches Wörterbuch zu den Schriften des Neuen Testaments und der übrigen urchristlichen Literatur (Berlin 1971), 407.

106 Vgl. Jewett, „Romans as an Ambassadorial Letter“, 13.

107 Samuel Byrskog, „Epistolography, Rhetoric and Letter Prescript: Romans 1.1-7 as a Test Case“, in:JSNT 65 (1997), 27-46, hier: 37.

108 Vgl. ebd., 37 und 40.

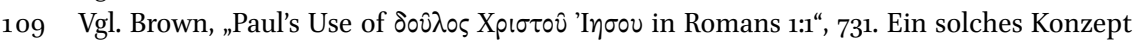
ist beachtlich, wenn man bedenkt, dass die Schaffung von Status fundamental war im römischen Recht.

110 Vgl. ebd., 734.
} 


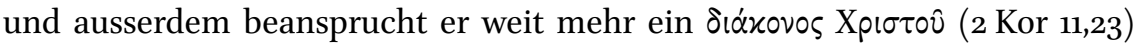
zu sein als die anderen. Zudem subsummiert sich Paulus in 2 Kor 3,6 unter einem nicht näher definierten, wir' und attribuiert diesem Kollektiv, Diener des neuen Bundes zu sein. Insgesamt stehe, so Hermann Beyer, die paulinische

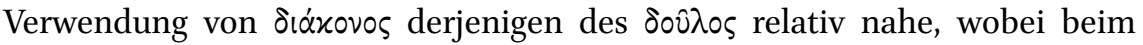

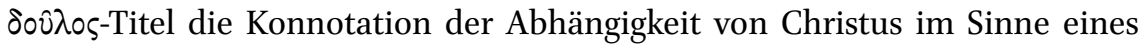
Eigentumsverhältnisses insgesamt noch prononcierter ist. ${ }^{11}$

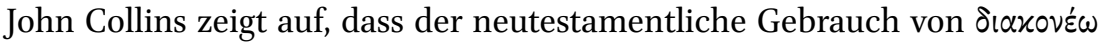
und Derivaten demjenigen in profangriechischen Texten sehr ähnlich ist. Seine Verwendung im Sinne von Liebesdienst oder karitativem Akt, Demut oder Wohltätigkeit kann von den antiken Quellen her nicht bestätigt werden. Collins zufolge gehört $\delta$ เ $\alpha$ ovi $\alpha$ in eines der folgenden Bedeutungsfelder: 1. Bote, Überbringer von Nachrichten; 2. Ausführen einer bestimmten Aufgabe; 3. Dienst für eine Person oder Arbeit in einem Haushalt. Collins sieht die Vermittlung als das zentrale Charakteristikum des Lexems. ${ }^{112}$ Er übersetzt es auch mit "go-between".113

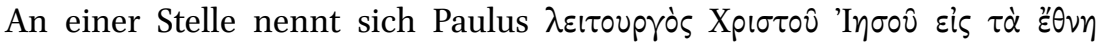
(Röm 15,16). ${ }^{114}$ In der Regel bezeichnet der sowohl in biblischer als auch in

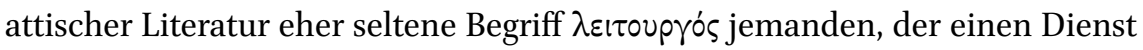

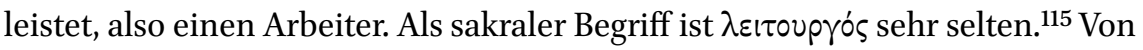
den fünf neutestamentlichen Vorkommen dürften die beiden in Hebr 1,7 und 8,2 priesterlichen Charakter haben. In Röm 13,6 verwendet Paulus den

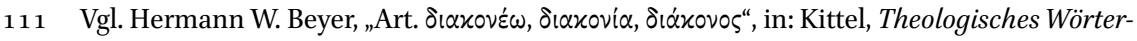
buch zum Neuen Testament, Bd. 2, 1935, 81-93, hier: 89.

112 John N. Collins, Diakonia: Re-interpreting the Ancient Sources (New York 1990); Anni Hentschel, Diakonia im Neuen Testament: Studien zur Semantik unter besonderer Berücksichtigung der Rolle von Frauen, WUNT II 226 (Tübingen 2007). Siehe insbesondere Appendix 1 mit Collins' eigenen Zusammenfassungen der Bedeutungsspektren von

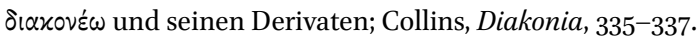

Vgl. zum Thema $\delta 1 \alpha$ xoví im NT die andere grundlegende Studie von Hentschel, Diakonia im Neuen Testament. Über sehr weite Strecken bestätigt Hentschels Unter-

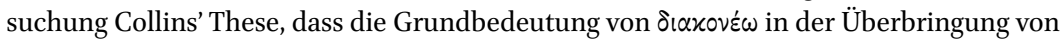
Nachrichten liegt. Allerdings betont Hentschel mehr den Auftragscharakter als wichtigste Eigenschaft, während Collins die Vermittlertätigkeit hervorhebt; vgl. ebd., 85-87.

113 Collins, Diakonia, 335. Vgl. auch John N. Collins, „The Mediatorial Aspect of Paul's Role as Diakonos", in: ABR 40 (1992), 34-44.

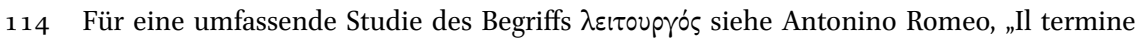
$\Lambda$ EITOYРГIA nella grecità biblica (Settanta e Nuovo Testamento)“, in: Leo C. Mohlberg (Hg.), Miscellanea liturgica in honorem L. Cuniberti Mohlberg, Bd. 2, BEL 23 (Roma 1949), $467-519$.

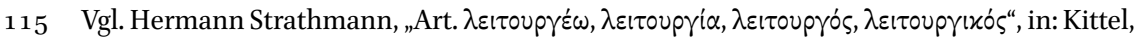
Theologisches Wörterbuch zum Neuen Testament, Bd. 4, 1942, 221-238, hier: 236. 
Begriff hingegen, um einen Staatsbeamten zu bezeichnen. Für sich genommen haftet auch Röm 15,16 keine kultische Bedeutung an. In der Fortsetzung erläutert Paulus seine Aufgabe unter den Völkern jedoch mit der Formulierung i Konnotation kaum abzusprechen sein dürfte. ${ }^{116}$ Die Funktion liegt aber aller Wahrscheinlichkeit nach trotzdem primär darin, die Berechtigung des Paulus als Gesandten zu den Völkern zu betonen: ,its bearing is bureaucratic and diplomatic, not sacerdotal"; dies in Übereinstimmung mit dem Anfang des

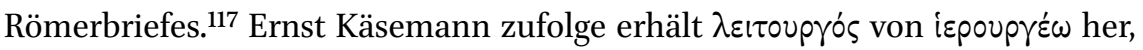
das "priesterlichen Dienst vollziehen“ bedeutet, eindeutig kultischen Sinn. Interpretationen, die die paulinische Mission aufgrund dieser beiden Begriffe in institutionelle Banden zwängen, gehen allerdings deutlich zu weit. ${ }^{118}$ Käsemann dürfte angemessen urteilen, wenn er in Anlehnung an Schlier feststellt:

In Wirklichkeit geht es in unserer Stelle weder um die Gemeinde und die Lebensführung ihrer Glieder noch um die Mission schlechthin, sondern allein um das delegierte, autorisierte und legitimierte Mandat des Heidenapostels. ${ }^{119}$

Dass Paulus in ganz besonderer Weise dafür beauftragt ist, das Evangelium zu verkünden, zeigt sich in Röm 1,1: Paulus ist "ausgesucht für das Evangelium von

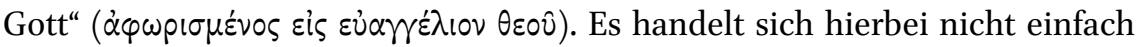
um einen anderen Ausdruck für die Evangeliumsverkündigung, sondern hier betont Paulus seine herausragende Rolle in der Mission unter den Völkern. ${ }^{120}$

116 Vgl. ebd., Bd. 4, 237. Für priesterliche Interpretationen siehe Karl H. Schelkle, „Der Apostel als Priester", in: ThQ 136 (1956), 257-283, insbesondere: 178; Robert M. Cooper, "Leitourgos Christou Iesou: Toward a Theology of Christian Prayers", in: AthR 47 (1965), 263-275; Konrad Weiss, „Paulus - Priester der christlichen Kultgemeinde“, in: ThLZ 79 (1954), 355-364; Cooper 1965.

117 Vgl. Jewett, „Romans as an Ambassadorial Letter“, 16.

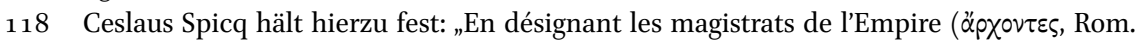

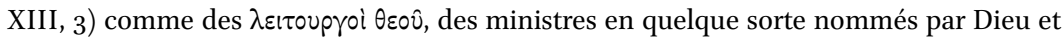
qui s'appliquent à bien remplir leur fonction (V.6) pour faire régner le bon ordre et assurer la prospérité des habitants, saint Paul emploie le mot liturge dans le sens des papyrus: officiers municipaux, fonctionnaires responsables d'une circonscription territoriale." Ceslaus Spicq, Notes de lexicographie néo-testamentaire, 3 Bde., Bd. 1, OBO 22 (Fribourg 1978), 479 .

119 Ernst Käsemann, An die Römer, HNT 8a, Ed. 4 (Tübingen 1980), 378; vgl. Heinrich Schlier, „Die ,Liturgie‘ des apostolischen Evangeliums“, in: Heinrich Schlier, Das Ende der Zeit: Exegetische Aufsätze und Vorträge, 4 Bde., Exegetische Aufsätze und Vorträge 3 (Freiburg i. Br. 1971), 169-183.

120 Vgl. Ekkehard W. Stegemann, ",Set Apart for the Gospel' (Romans 1:1): Paul's SelfIntroduction in the Letter to the Romans", in: Peter Spitaler, Celebrating Paul: Festschrift in 
Zusammenfassend kann festgehalten werden, dass in den Briefanfängen, insbesondere in Röm 1,1, ganz wesentliche Merkmale der Selbstdarstellung von Paulus als interkulturellem Vermittler enthalten sind, die sich durch diverse Stellen in den Briefkorpora ergänzen lassen. Die Elemente zur Beschreibung des kulturvermittelnden Prozesses, die darin angelegt sind, betreffen einerseits den Namen und andererseits die Attribute, die den Namen näher definieren. Paulus stellt sich mit der alleinigen Verwendung eines lateinischen Namens auf eine Ebene mit den Adressatinnen und Adressaten aus den Völkern. Die Attribute der Knechtschaft Christi und das Berufensein sowie das Ausgewähltsein für das Evangelium beschreiben, wie Paulus diese Aufgabe seines Vermittelns verstanden haben will: Er ist von Christus auserwählt und gesandt zum Vermitteln. Zudem benennen sie programmatisch zum Briefbeginn das kulturelle Artefakt, das Paulus zu vermitteln hat.

\subsubsection{Herkunft, Bildung und sozialer Hintergrund}

Nebst den Hypothesen, die aufgrund des Namens und der damit verbundenen Attribute gebildet werden können, lassen sich aus den Paulusbriefen einige Informationen zur Herkunft, Bildung und zum sozialen Hintergrund des Paulus ermitteln. Diese sind deshalb von Bedeutung, weil sie näher beschreiben, wie Paulus sich als Mitglied des hellenistischen Judentums als seiner Ausgangskultur darstellt, wie sie sich entwickelt hat und wie er sie im Verhältnis zu Mitgliedern aus der Zielkultur einordnet.

\subsubsection{Ethnische Herkunft}

Zentral für die Beschreibung der Ausgangskultur des Paulus sind Hinweise seine Herkunft betreffend. Paulus sagt nichts über seinen Geburtsort, schreibt aber mehrfach, in verschiedenen Briefen und in unterschiedlicher Form zu anderen Aspekten seiner Herkunft, insbesondere seiner ethnischen Provenienz. So betont er wiederholt seine Herkunft aus dem Judentum: In Gal 2,15 erwähnt er, dass er als 'Iovס̊îo geboren sei, und in 2 Kor 11,22 reagiert er auf Gegner, die aus ihrer jüdischen Abstammung besondere Ansprüche herleiten. Dabei greift er in polemischer Weise auf, wessen sich seine Widersacher rühmen, und weiss sich ihnen ebenbürtig: In rhetorischen Fragen betont er seine Identität als Hebräer, Israelit und seine Abstammung von Abraham.

Im Brief an die Christusgläubigen in Philippi (Phil 3,5-6) betont Paulus ähn-

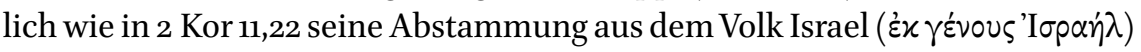

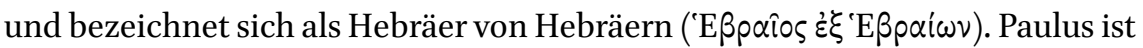

Honor of Jerome Murphy-O'Connor and Joseph A. Fitzmyer, CBQMS 48 (Washington (DC) 2011), 189-209, hier: 197. 
Sohn einer Familie, die auch in der Diaspora den Bräuchen ihres Mutterlandes treu geblieben ist. Die Betonung seines Hebräertums kann auch als Hinweis darauf verstanden werden, dass er des Hebräischen bzw. Aramäischen mächtig ist. ${ }^{121}$ Darüber hinaus führt er an, dass er am achten Tag beschnitten worden

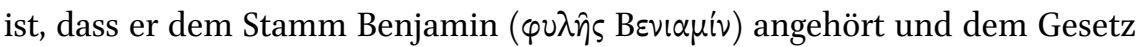

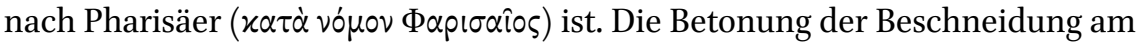

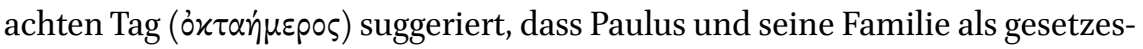

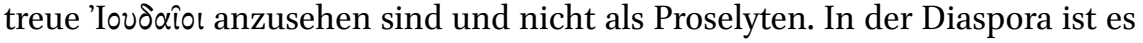
offenbar trotz Gen 17,12 und Lev 12,3 keine Selbstverständlichkeit, die Kinder am achten Tage zu beschneiden. ${ }^{122}$ An diese Herkunftsmerkmale reihen sich drei Informationen über Merkmale, die auf Entscheidung beruhen: dass Paulus Pharisäer und dass er als Verfolger tätig gewesen ist sowie dass er die Gesetze strikt befolgt hat. Die Tatsache, dass Paulus sich als Pharisäer bezeichnet, bedeutet, dass er - im Unterschied zu den Sadduzäern - mit grosser Wahrscheinlichkeit (schon als Pharisäer) an die Auferstehung glaubt. Als Hebräer ist Paulus nicht nur Mitglied dieser bestimmten ethnischen Gruppe, sondern ordnet sich als Abkömmling des Stammes Benjamin zugleich in der Untergruppe dieses spezifischen Vorfahrens ein. Die Herkunft aus einem bestimmten Stamm hervorzuheben ist nennenswert, da nicht viele Familien ihre Herkunft auf einen einzigen Stamm bestimmen können. ${ }^{123}$

Auch im Brief an die Christusgläubigen in Rom finden sich Hinweise auf Paulus' Abstammung. Als Antwort auf die rhetorische Frage, ob Gott sein Volk verstossen habe, schreibt Paulus in Röm 11,1 - wohl nicht ohne Stolz auf die bis in die biblische Frühzeit zurückreichende Abstammung seiner Familie -,

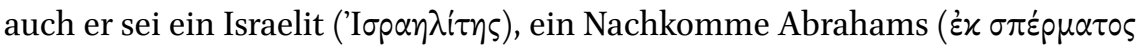

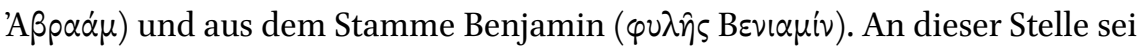

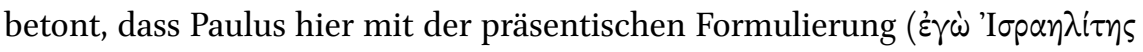

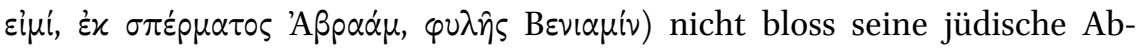
stammung unterstreicht, sondern damit vielmehr die bleibende Bedeutung dieser Herkunft für seine gegenwärtige Identität hervorhebt, die ihn auch für sein Wirken als Völkerapostel prägt. Sein Vermitteln unter den Völkern stellt Paulus also so dar, dass es sich innerhalb seines angestammten Orientierungssystems bewegt.

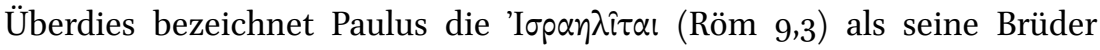

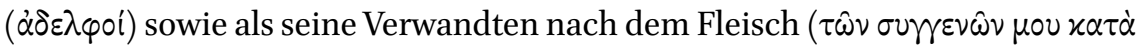

\footnotetext{
121 Vgl. dazu die Ausführungen unter 4.1. „Welche Sprachen spricht Paulus?“.

122 Vgl. Martin Hengel, „Der vorchristliche Paulus“, in: Heckel, Hengel und Schlatter, Paulus und das antike Judentum, 221.

123 Vgl. ebd., 211.
} 
$\sigma \alpha ́ p \varkappa \alpha)$. Darauf folgt eine ausführliche Beschreibung der Privilegien, die Israel gemäss biblischer Tradition geniesst (Röm 9,4-5): Sohnschaft bzw. Gotteskind-

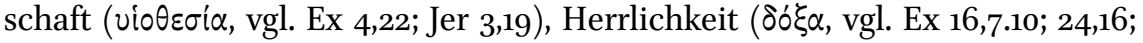

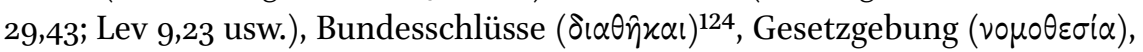
Gottesdienst bzw. Tempelkult ( $\lambda \alpha \tau \rho \varepsilon i \alpha)$ und Verheissungen ( $\left.\dot{\pi} \pi \alpha \gamma \varepsilon \lambda \lambda^{\prime} \alpha \iota\right)$, die fleischliche Abstammung Christi von den Vätern. ${ }^{125}$ Gnadengaben und Berufung Israels sind unwiderruflich (Röm 11,29).

Paulus scheint keinerlei Zweifel offenzulassen, dass er sich selbst in Kontinuität und Solidarität mit Israel versteht und als innerhalb dieses Orientierungssystems betrachtet werden will. ${ }^{126}$ Phil 3,3-6 und 2 Kor 11,22 zeigen noch einmal deutlich Paulus' Kontinuität mit Israel auf. Selbst in Passagen wie Gal 1,13-14 und Phil 3,7-9 bleibt sie vorausgesetzt. ${ }^{127}$ Auch wenn

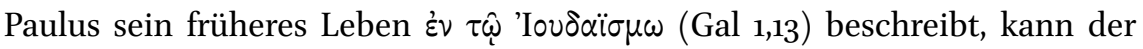

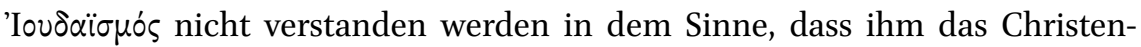
tum als eine definierte Entität gegenübersteht, wie verschiedene Bibelüber-

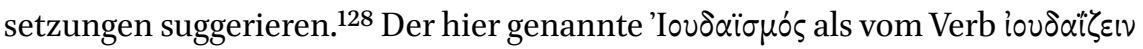
deriviertes Substantiv dürfte zu verstehen sein im Sinne einer innerjüdischen

124 Der Plural weist darauf hin, dass mehrere Bundesschlüsse gemeint sein könnten: zumindest der Bund mit den Vätern und der Bundesschluss am Sinai.

125 Vgl. dazu Röm 4; 9,6-13.

126 Vgl. die umfassende Studie von Karl-Wilhelm Niebuhr, Heidenapostel aus Israel: Die jüdische Identität des Paulus nach ihrer Darstellung in seinen Briefen, WUNT 62 (Tübingen 1992) sowie den jüngeren Aufsatz: Karl-Wilhelm Niebuhr, „Paulus und das Judentum seiner Zeit: Der Heidenapostel aus Israel in ,neuer Sicht'“, in: IKaZ 38 (2009), 108-118. Vgl. ausserdem Martin Hengel, „Der vorchristliche Paulus“, in: Heckel, Hengel und Schlatter, Paulus und das antike Judentum; Jörg Frey, „Paul's Jewish Identity“, in: Jörg Frey, Daniel R. Schwarz und Stephanie Gripentrog (Hg.), Jewish Identity in the Greco-Roman World: Jüdische Identität in der griechisch-römischen Welt (Leiden 2007), 285-321, hier: 289-292; Cavan W. Concannon, „When you were gentiles": Specters of Ethnicity in Roman Corinth and Paul's Corinthian Correspondence, Synkrisis: comparative approaches to early Christianity in Greco-Roman culture (New Haven 2014), 29-31; James C. Miller, „Paul and His Ethnicity: Reframing the Categories“, in: Burke und Rosner, Paul as Missionary.

Dagegen schliesst Strecker aufgrund von Gal 1,13 ff. und Phil 3,7, dass Paulus „nach eigenem Verständnis sich fundamental vom Judentum geschieden wußte“; Georg Strecker, Theologie des Neuen Testaments, bearb., erg. und hg. von Friedrich Wilhelm Horn, De Gruyter Lehrbuch (Berlin 1996), 24. Vgl. auch die Behauptung, dass „der Christ Paulus seine jüdische Lebensperiode fast ganz abgestoßen hat"; Jürgen Becker, Paulus: Der Apostel der Völker, 3. Aufl. (Tübingen 1998), 34.

127 Vgl. dazu auch Jörg Frey, „Paul's Jewish Identity“, in: Frey, Schwarz und Gripentrog, Jewish Identity in the Greco-Roman World, 290-291.

128 Vgl. bspw.: „wie ich früher als Jude gelebt habe“ (Herder), „von meinem ehemaligen Wandel im Judentum“ (Schlachter 2000), „von meinem Leben früher im Judentum“ (Lutherbibel 1984), „wie ich einst als Jude gelebt habe“ (Neue Zürcher Bibel). 


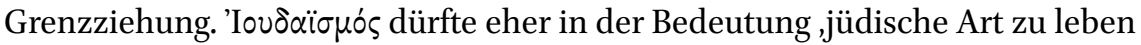
und zu glauben ${ }^{129}$ denn als ,Judenheit' im Sinne von ,Gesamtheit der Jüdinnen und Juden ${ }^{130}$ aufzufassen sein. Das heisst, dass Paulus hier nicht davon spricht, seine Identität als 'Iovס̊îos überhaupt aufgegeben und die Judenheit verlassen zu haben, sondern lediglich, dass er sich nicht mehr zu jener - vermutlich militanteren - Gruppierung zählt, der er vor seiner Berufung angehört hat. ${ }^{131}$

Paulus hat das Judentum niemals verlassen, um ,Christ' zu werden. ${ }^{132}$ Für die Zeit des Paulus von Christentum zu sprechen, wäre ohnehin verfehlt, da es deutlich anachronistisch wäre. ${ }^{133}$ Nach seiner Selbstdarstellung verbleibt Paulus sein Leben lang in seinem angestammten Orientierungssystem. ${ }^{134}$

129 Vgl. dazu nur Otto Betz: „Im Unterschied vom formal ähnlichen $\dot{\varepsilon} \lambda \eta v i \zeta \omega$,die griech.

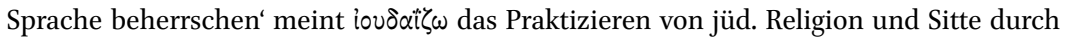
sympathisierende oder konvertierte Heiden; das auf die Sprache bezogene Seitenstück

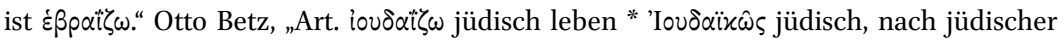

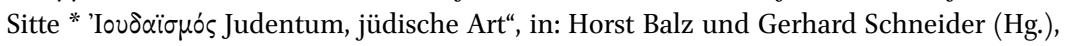
Exegetisches Wörterbuch zum Neuen Testament, 3 Bde., Bd. 2, 2. Aufl. (Stuttgart 1992), 470472, hier: 471.

130 Vgl. https://www.duden.de/node/685286/revisions/1152570/view (Zuletzt geprüft am 01.03.2019).

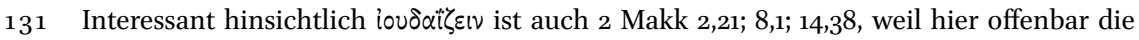
Abgrenzung zum Hellenisieren gemeint ist. Obschon Erich Gruen und Bezalel BarKochva betont haben, dass "Judaism" in 2 Makk zwar mehrfach genannt werde, aber nie als Gegensatz zu „Hellenism“, muss mit Daniel R. Schwartz festgehalten werden, dass es sich bei diesen Neologismen sehr eindeutig aufdrängt, sie in gegenseitiger Opposition zu verstehen. Vgl. Daniel R. Schwartz, 2 Maccabees, CEJL (Berlin 2008), 173; Erich Gruen, Heritage and Hellenism: The Reinvention of Jewish Tradition, Hellenistic Culture and Society 30 (Berkeley (CA) 1998), 3-4; Bezalel Bar-Kochva, „Judaism and Hellenism Between Scholarship and Journalism“, in: Tarbiz 63 (1993/94), 451-480, hier: 464-465.

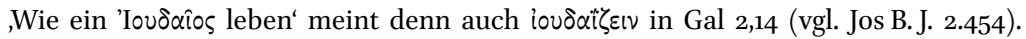

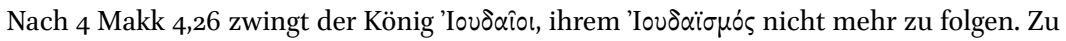

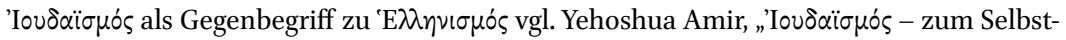
verständnis des hellenistischen Judentums“, in: Studien zum Antiken Judentum, 101-113, BEAT 2 (Frankfurt a. M. 1985), 106-107.

132 Vgl. den pointierten Titel von Pamela Michelle Eisenbaum, Paul was not a Christian: The Original Message of a Misunderstood Apostle, First HarperCollins paperback edition (New York 2010 [2009]).

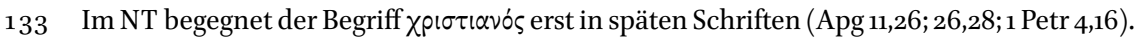
Zur Verwendung des Begriffs siehe David G. Horrell, „The Label Xpı $\tau \tau \iota \alpha v o ́ s: 1$ Peter 4:16 and the Formation of Christian Identity“, in: JBL 126, Nr. 2 (2007), 361-381. Die frühesten Be-

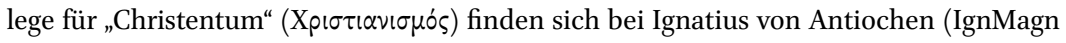
8,1; 10,3; IgnRom 3,3; IngPhld 6,1).

134 Sinngemäss sagt dies auch Eisenbaum: „In terms of religious identity, Paul was representative of the Jews who produced the writings that now make up the New Testament. They were, to be sure, Jews who believed in Jesus, but they did not proclaim their religious identity as Christian. They thought of Jesus as the realization of classical Jewish hopes, and 
Verwurzelt darin vermittelt er an seine Adressatinnen und Adressaten aus den Völkern das für ihn zentral gewordene kulturelle Artefakt, nämlich den Glauben an Jesus als den Messias. ${ }^{135}$ Dadurch bekommen auch die Menschen aus den Völkern Zugang zum Heil Israels.

Bei der Interpretation all dieser Stellen ist zu beachten, was Niebuhr auf den Punkt gebracht hat:

\begin{abstract}
Alle eben wiedergegebenen Aussagen des Paulus [Röm 11,1; Phil 3,5-6; 2 Kor 11,22-23] stammen aus der Zeit, in der seine Mission für Christus schon ihren Höhepunkt erreicht hatte. Mit ihnen will Paulus keineswegs etwas über seine biographische Herkunft sagen, gar über seine, jüdische Vergangenheit', die er seit seiner Berufung zum Christusverkündiger hinter sich gelassen und inzwischen bewältigt hätte. Vielmehr geht es ihm im Zusammenhang der genannten Stellen immer um seine gegenwärtige Identität als Apostel für Jesus Christus. Die Zugehörigkeit zu Israel, dem Volk Israel, dem Gottesvolk, ist für Paulus ein gegenwärtig gültiges und wesentliches Merkmal seiner Identität als Missionar und Theologe, auch wenn oder vielleicht sogar gerade weil der Inhalt seiner Verkündigung und seiner Theologie ganz und gar durch Jesus Christus bestimmt ist. ${ }^{136}$
\end{abstract}

Die Solidarität mit den jüdischen Brüdern hat Paulus nie aufgegeben. Die Tatsache, dass er der Gesandte für die Völker wird, beauftragt, das Evangelium

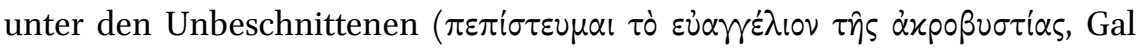
2,7) zu verkündigen, zeigt allein schon seine jüdische Perspektive. Die Wiederholung der dichotomen Unterscheidung zwischen Beschnittenen und Un-

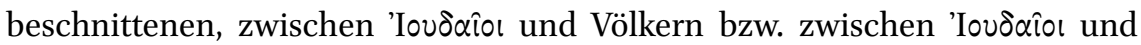
Griechen unterstreicht diese jüdische Sichtweise. Auch die Erwähnung, dass Paulus sich der Synagogalstrafe von 39 Geisselhieben stellt (2 Kor 11,24), spricht

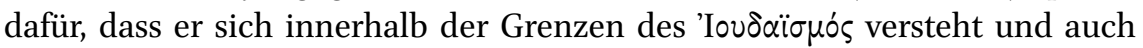

they thought of themselves as the true Israel or the faithful remnant of Israel, although those hopes were understood somewhat differently among different groups of Jews. This description of the religious identity of New Testament texts in historical context makes them analogous to other Jewish sectarian writings of the period, like the Dead Sea Scrolls. We have scores of Jewish texts from antiquity, many of which reflect a sectarian perspective, that is, a distinctive perspective on what it means to be Jewish. Sometimes this perspective overlaps with other Jews' points of view; sometimes it is idiosyncratic." Eisenbaum, Paul was not a Christian, 6-7, Hervorhebungen EK.

135 Matthew Novenson hat überzeugend aufgezeigt, dass „Christos“ bei Paulus als messianischer Ehrentitel und nicht bloss als ein zweiter Name für Jesus verwendet wird; vgl. Matthew V. Novenson, Christ Among the Messiahs: Christ Language in Paul and Messiah Language in Ancient Judaism (Oxford 2012).

136 Niebuhr, „Paulus und das Judentum seiner Zeit“, 108-109, Hervorhebung EK. Vgl. dazu auch Kimberly Ambrose, Jew among Jews: Rehabilitating Paul (Eugene (OR) 2015). 
von anderen so angesehen wird, denn ansonsten wäre die Geisselstrafe auf ihn nicht anwendbar. ${ }^{137}$

\subsubsection{Geografische Herkunft, Staatsbürgerschaft und Ausbildung} Neben der ethnischen Herkunft spielt auch die geografische eine Rolle hin-

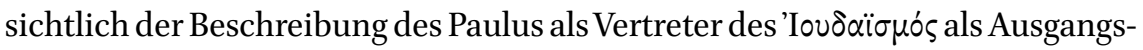
kultur. Überlegungen zur Staatsbügerschaft ordnen ihn ein in die politische Welt, was wiederum Aufschluss gibt über seinen Stand bzw. seine Rechte innerhalb der römischen Welt. Die Ausführungen zur Ausbildung hängen mit geografischen Einordnungen zusammen und helfen, die Bildung des Paulus und damit seine intellektuellen Einflussmöglichkeiten auf seine Adressatenschaft zu beleuchten.

Wie bereits festgehalten, benennt Paulus keine geografische Herkunft. Wichtiger als seine Herkunft aus dem hellenistisches Diasporajudentum scheint für ihn seine Identität als Pharisäer ${ }^{138}$ zu sein und Jerusalem ${ }^{139}$ zentraler als jeder andere Ort, denn:

Nur von Lukas erfahren wir seine Herkunft aus der kilikischen Hauptstadt Tarsus, sowie daß er das dortige und das römische Bürgerrecht besaß. Der Briefautor Paulus würdigt diesen Teil seiner Vergangenheit keines Wortes mehr, sie scheint für ihn sehr viel ferner zu sein als die palästinisch-pharisäische. ${ }^{140}$

An keiner Stelle äussert sich Paulus zu einer römischen oder tarsischen Staatsbürgerschaft. Angaben hierzu finden sich lediglich in der Apostelgeschichte: Direkt angesprochen wird die römische Staatsbürgerschaft in Apg 16,37-38; 22,25-28; 23,27 und indirekt vermutlich in Apg 25,10-11; 28,19. Die tarsische wird lediglich in Apg 21,39 erwähnt und in der Forschung weitgehend bezweifelt. ${ }^{141}$ Deutlich plausibler, aber auch nicht unumstritten, ist die römische Staatsbürgerschaft. Bestritten wird sie vor allem aufgrund fehlender Selbstzeugnisse über eine Staatsbürgerschaft und wegen wiederholter Erwähnungen körperlicher Züchtigungen (vgl. insbesondere 2 Kor 11,24-25 mit der Nennung

137 Vgl. A. E. Harvey, „Forty strokes save one: Social aspects of judaizing and apostasy“, in: A. E. Harvey (Hg.), Alternative Approaches to New Testament Study (London 1985), 79-96.

138 Vgl. Phil 3,5; Apg 23,6; 26,5. Ein wesentliches Indiz für die Herkunft aus der Diaspora ist natürlich seine Verwendung der Koiné. Vgl. die detaillierteren Ausführungen unter 3. „Die Welt des Paulus".

139 Vgl. Röm 15,19.25.26.31; 1 Kor 16,3; Gal 1,17.18; 2,1; 4,25.26.

140 Martin Hengel, „Der vorchristliche Paulus“, in: Heckel, Hengel und Schlatter, Paulus und das antike Judentum, 180, Hervorhebungen im Original.

141 Vgl. Wolfgang Stegemann, „War der Apostel Paulus ein römischer Bürger?“, in: $Z N W 7_{78}$, Nr. 3 (1987), 200 und 221; Riesner, Die Frühzeit des Apostels Paulus, 130-131. 
dersynagogalenPrügelstrafeundderdreimaligenstaatlichen Auspeitschung). ${ }^{142}$ Wolfgang Stegemann zufolge sprechen gegen eine römische Staatsbürgerschaft insbesondere die jüdische Herkunft des Paulus, aber auch feststellbare sozialgeschichtliche Faktoren. ${ }^{143}$ Für eine römische Staatsbürgerschaft spricht trotz der wiederholten körperlichen Züchtigungen durch die Römer die Überführung des Paulus nach Rom, die sich ohne römische Staatsbürgerschaft nur schwer erklären lässt. Unterstützt wird die Annahme des römischen Bürgerrechts auch durch den zwar nur einteiligen, aber gleichwohl römischen Namen, durch Paulus' "Grundhaltung zum römischen Staat sowie die von ihm gewählten Missionsrouten“. ${ }^{144}$

Die Apostelgeschichte nennt die kleinasiatische Stadt Tarsus als Herkunftsort (Apg 9,11; 21,39; 22,3), und es gibt im Gegensatz zur Bürgerschaft kaum Gründe, die Angabe von Tarsus als Geburtsort zu bezweifeln. ${ }^{145}$ Die kleinasiatische Diaspora hat florierendes jüdisches Leben aufzuweisen und gilt als eine Hochburg der Bildung. ${ }^{146}$ Verbindungen kleinasiatischer 'Iovס\&î nach Jerusalem sind ein wichtiges Identitätsmerkmal. Sie äussern sich beispielsweise in der ausdrücklichen Erlaubnis seitens der römischen Behörden, Gelder zugunsten des Tempelkults nach Jerusalem zu überweisen. ${ }^{147}$ Eher als von einer weitgehenden Assimilation dürfte das jüdische Milieu von einem

142 Zur Beurteilung von Misshandlungen und römischem Bürgerrecht vgl. Riesner, Die Frühzeit des Apostels Paulus, 132-133.

143 Vgl. Stegemann, „War der Apostel Paulus ein römischer Bürger?“. Ähnlich auch Klaus Wengst, Pax romana: Anspruch und Wirklichkeit. Erfahrungen und Wahrnehmungen des Friedens bei Jesus und im Urchristentum (München 1986), 94-95. Für Kritik an der römischen Staatsbürgerschaft mit Hinweis auf Porphyrios als antiken Kritiker siehe auch Karl L. Noethlichs, „Der Jude Paulus - Ein Tarser oder Römer?“, in: Raban v. Haehling (Hg.), Rom und das himmlische Jerusalem: Die frühen Christen zwischen Anpassung und Ablehnung (Darmstadt 2000), 53-84.

144 Vgl. Omerzu, Der Prozess des Paulus, 17-52, Zitat: 28.

145 Vgl. Tor Vegge, Paulus und das antike Schulwesen: Schule und Bildung des Paulus, BZNW 134 (Berlin 2006), 457. Hengel bezweifelt, dass Paulus tatsächlich aus Tarsus stammt, lässt aber die Möglichkeit gelten: „Es ist eigenartig, daß trotz der heute verbreiteten Tendenz, bei Lukas nahezu alles in Frage zu stellen, diese Nachricht von der Herkunft aus Tarsus, soweit ich sehe, kaum bezweifelt wurde, obwohl der Apostel mit keinem Wort über seine Heimatstadt spricht und man aufgrund der Briefe eher einen Ursprungsort im jüdischen Mutterland oder in dessen Nähe annehmen müßte.“ Martin Hengel, „Der vorchristliche Paulus“, in: Heckel, Hengel und Schlatter, Paulus und das antike Judentum, 182.

146 Strab. geogr. 14.5.13. Zu Tarsus vgl. bspw. ebd., 180-193; Jerome Murphy-O'Connor, Paul: A Critical Life (Oxford 1996), 33-35; Alphons Steinmann, Zum Werdegang des Paulus: Die Jugendzeit in Tarsus (Freiburg i. Br. 1928), 10-15.

147 Vgl. Niebuhr, „Paulus und das Judentum seiner Zeit“, 115. 
distinkten Bewusstsein für die jüdische Identität geprägt sein. ${ }^{148}$ Davon rührt sicherlich auch die Versiertheit des Paulus in den jüdischen Traditionen, konkret der Septuaginta, her.

Höchst umstritten ist die Frage, wo Paulus seine ihn prägende jüdische und griechische Bildung erhalten hat: in Tarsus oder in Jerusalem oder an beiden Orten. In der Zeit vor der Tempelzerstörung darf Jerusalem als äusserst

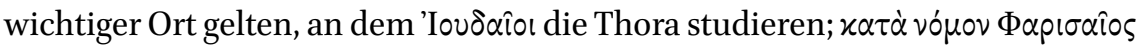
(Phil 3,5) dürfte daher als weiterer Hinweis auf Jerusalem gewertet werden.

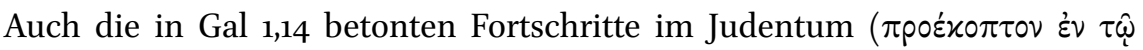

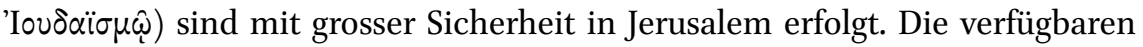
Quellen über das Pharisäertum weisen es als Bewegung im Lande Israel mit Jerusalem als Zentrum aus. ${ }^{149}$ Pharisäische Thorastudien sind für die Zeit des Paulus an keinem anderen Ort vorstellbar. Ohne an dieser Stelle auf die Diskussion über die Gestalt des Pharisäertums vor $70 \mathrm{n}$. Chr. einzugehen, sei festgehalten, dass es sich um eine relativ einflussreiche, jedenfalls sicherlich mehr als marginale Bewegung des Judentums handelt, die die Einhaltung der Gesetze zum Kern ihrer Lehre hat, was auch Paulus selbst bestätigt (Gal 1,13). ${ }^{150}$ Die beiden autobiografischen Berichte (Gal 1,14 und Phil 3,5) müssen schlechterdings auf ein pharisäisches Gesetzesstudium in Jerusalem hinweisen, denn eine vergleichbare Ausbildung in Tarsus oder überhaupt in der Diaspora ist höchst unwahrscheinlich. 151

148 Vgl. Böhlig, Die Geisteskultur von Tarsos im augusteischen Zeitalter. Vgl. dazu auch Barclays hilfreiche Unterscheidung zwischen „assimilation“, „acculturation“ und „accomodation“, Barclay, Jews in the Mediterranean Diaspora, 92-98.

149 Vgl. A. Oepke, „Probleme der vorchristlichen Zeit des Paulus“, in: Karl H. Rengstorf (Hg.), Das Paulusbild in der neueren deutschen Forschung, 3. Aufl., WdF, Bd. 24, Ed. 3 (Darmstadt 1982), 410-446; Martin Hengel, „Der vorchristliche Paulus“, in: Heckel, Hengel und Schlatter, Paulus und das antike Judentum, 225-232.

150 Zum Pharisäertum vgl. die umfassende forschungsgeschichtliche Studie von Roland Deines, Die Pharisäer: Ihr Verständnis im Spiegel der christlichen und jüdischen Forschung seit Wellhausen und Graetz, WUNT 101 (Tübingen 1997), aber auch Peter Schäfer, „Der vorrabbinische Pharisäismus“, in: Heckel, Hengel und Schlatter, Paulus und das antike Judentum, 125-175; Albert I. Baumgarten, The Flourishing of Jewish Sects in the Maccabean Era: An Interpretation, JSJ.S 55 (Leiden 1997); Günter Stemberger, Pharisäer, Sadduzäer, Essener: Fragen - Fakten - Hintergründe (Stuttgart 2013); Jacob Neusner, „Die Verwendung des späteren rabbinischen Materials für die Erforschung des Pharisäismus im 1. Jahrhundert n. Chr.", in: ZThK 76 (1979), 292-309; Anthony J. Saldarini, Pharisees, Scribes and Sadducees in Palestinian Society: A Sociological Approach (Grand Rapids (MI) 2001); Jacob Neusner, In Quest of the Historical Pharisees (Waco (TX) 2007); Stemberger, Pharisäer, Sadduzäer, Essener.

151 Vgl. Martin Hengel, „Der vorchristliche Paulus“, in: Heckel, Hengel und Schlatter, Paulus und das antike Judentum, 240. 
In einer detaillierten philologischen Untersuchung der Zeugnisse aus der Apostelgeschichte kommtWillem Cornelis van Unnik ebenfalls zu dem Schluss, nur Jerusalem könne der Ort von Paulus' Kindheit und Jugend gewesen sein. Er stützt sich dabei auf Apg 22,3 und argumentiert, dass Lukas hier mit den drei aufeinanderfolgenden Partizipien $\gamma \varepsilon \gamma \varepsilon v \nu \eta \mu \varepsilon \dot{v} 0 \varsigma$ (geboren), $\alpha \nu \alpha \tau \varepsilon \theta \rho \alpha \mu \mu \varepsilon \dot{\varepsilon} 0 \varsigma$

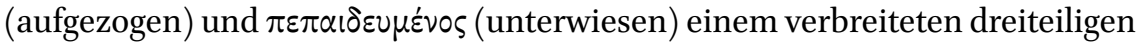
biografischen Schema folge. Paulus müsse kurz nach seiner Geburt mit seinen Eltern nach Jerusalem gegangen und dort aufgewachsen sein. ${ }^{152}$

Jerusalem und Tarsus müssen aber nicht zwingend als sich ausschliessende Alternativen gesehen werden. Plausibel erscheint die These, dass Paulus zumindest einen Teil seiner Bildung noch in Tarsus erhalten habe, um später in Jerusalem weiterzulernen. ${ }^{153}$

Andreas B. du Toit hingegen deutet in einer linguistischen, rhetorischen und narratologischen Untersuchung die biografischen Hinweise dahingehend, dass Paulus eher erst in seinen Jugendjahren nach Jerusalem gegangen sei,

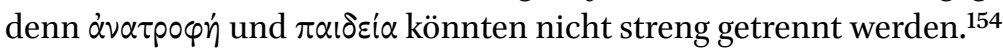

Klaus Haacker legt eine andere ,Lösung vor, derzufolge Paulus in einem hellenistisch-jüdischen Haus in Jerusalem aufgewachsen sein könnte. In diesem

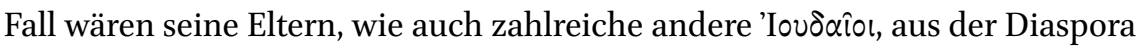
nach Jerusalem zurückgekehrt. Gelegentlich werden Zweifel geäussert, ob Paulus überhaupt je in Jerusalem gelebt habe. ${ }^{155}$

Die in den Briefen ersichtliche Beherrschung der griechischen Sprache und Paulus' Interaktion mit den hellenistischen Synagogen Jerusalems (vgl. Apg 9,29) weisen ihn sozusagen als ,jüdischen Graeco-Palästiner" aus. ${ }^{156}$ Haacker

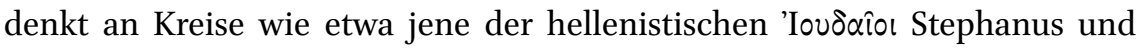
Barnabas. Dagegen, und ebenso gegen die lukanische Aussage, dass „alle Juden“ Paulus' Lebenswandel von Jugend auf kennen, widerspricht dessen Aussage Gal 1,22-23, dass er den judenchristlichen Gruppen in Judäa unbekannt war. Haacker relativiert dieses Argument mit dem Hinweis, dass

152 Vgl. van Unnik, Tarsus or Jerusalem, the City of Paul's Youth.

153 So Martin Hengel, „Der vorchristliche Paulus“, in: Heckel, Hengel und Schlatter, Paulus und das antike Judentum, 186 und 217; und später auch Andreas B. du Toit, „A Tale of Two Cities: ,Tarsus or Jerusalem' Revisited“, in: NTS 46, Nr. 3 (2000), 375-402; Jörg Frey, „Paul's Jewish Identity“, in: Frey, Schwarz und Gripentrog, Jewish Identity in the Greco-Roman World, 296.

154 Vgl. du Toit, „A Tale of Two Cities“, 378-383. Darauf hingewiesen hat auch Klaus Haacker, Paulus: Der Werdegang eines Apostels, SBS 171 (Stuttgart 1997), 52.

155 Vgl. Paula Fredriksen, Paul: The Pagans' Apostle (New Haven 2017), 61-62.

156 Haacker, Paulus, 53 . 
zwischen Judäa und Jerusalem in jüdischen und christlichen Quellen häufig unterschieden wird (vgl. u. a. Mt 3,5; 4,25; Apg 1,8) und daß von Christen in Judäa erstmals in Apg 8,1 die Rede ist: die in Jerusalem verfolgten (hellenistischen Juden-)Christen fliehen u. a. nach Judäa (vgl. dann wieder Apg 9,31-43). Eigentliche Gemeinden sind in Judäa, wenn man Jerusalem ausnimmt, vielleicht erst danach entstanden und mit Paulus tatsächlich nicht persönlich in Berührung gekommen. ${ }^{157}$

Insofern bleibt unsicher, wo Paulus seine Erziehung erhalten hat. Die vermutlich unhistorische Aussage in Apg 22,3, dass Paulus „zu Füssen Gamaliels“ unterwiesen worden sei, wäre dahingehend zu deuten, dass Paulus entweder unter den Augen des/in Gegenwart von Gamaliel I. aufgewachsen oder nach pharisäischen Bildungsidealen für judäische Männer erzogen worden ist. ${ }^{158}$ Dass Paulus aber tatsächlich in Jerusalem studiert und bei Gamaliel I. selbst gelernt hat, erscheint sehr unwahrscheinlich: Ein derart prestigeträchtiges Faktum hätte er in Phil 3,5-6 höchstwahrscheinlich, und möglicherweise auch in Gal 1,13-14, erwähnt. ${ }^{159}$

In seiner umfassenden Untersuchung zu Paulus und dem antiken Schulwesen kommt schliesslich Tor Vegge zu dem Schluss, dass Paulus eine literarische Ausbildung „in ihrer allgemeinen griechisch-hellenistischen Form“160 erhalten haben dürfte. Entsprechend wird er die Progymnasmata bei einem Redelehrer durchlaufen haben und dadurch mit philosophischer Lehre und philosophischem Ethos vertraut sein. Seinen jüdischen Wurzeln sei er erst später nachgegangen und habe sich dazu der Schulrichtung der Pharisäer angeschlossen. ${ }^{161}$ Vegge hält bei alledem fest:

Wichtiger als der Frage, wo Paulus seine Jugendzeit verbrachte und ausgebildet wurde, nachzugehen, ist es, eine Vorstellung von der Progression in seiner Ausbildung und Bildung zu entwickeln. Es kann vorausgesetzt werden, daß Paulus eine literarische Ausbildung in ihrer allgemeinen griechisch-hellenistischen Form erhielt und daß er danach bei einem Redelehrer die Progymnasmata durchlief, wodurch er sich die Grundlage seiner literarischen Virtuosität verschaffte. Seine Schriften legen außerdem nahe, daß Paulus auch mit philosophischer Lehre und philosophischem Ethos vertraut war[,] und belegen in ihrer nach dem Muster philosophischer Texte zugeschnittenen Form seine literarische und rhetorische Kompetenz. Es ist davon auszugehen, daß Paulus

\footnotetext{
157 Ebd., 59.

$15^{8}$ Vgl. Wolfgang Stegemann, „Hat der Apostel Paulus eine rabbinische Ausbildung in Jerusalem erhalten?", in: KuI, Nr. 2 (2014).

159 Vgl. Bauer, Paulus und die kaiserzeitliche Epistolographie, 417. Siehe auch Stegemann, „Hat der Apostel Paulus eine rabbinische Ausbildung in Jerusalem erhalten?“.

160 Vegge, Paulus und das antike Schulwesen, 494.

161 Vgl. ebd.
} 
vor dem Erwerb seiner spezifisch jüdischen Bildung eine literarische und philosophische Bildung genossen hatte. Diese dient als Basis für seine Beschäftigung mit dem Pharisäismus, bei der er nach eigener Aussage größere Fortschritte machte als viele Gleichaltrige ( $\mathrm{Gal} \mathrm{1,14)} \cdot{ }^{162}$

Plausibel scheint jedenfalls die Annahme, dass Paulus einen höheren Schulunterricht durchlaufen hat:

Einzelne stilistische Ungeschicklichkeiten im Vergleich mit den literarischen Briefen besagen nicht zwangsläufig, dass er keine höhere Ausbildung genossen hat (etwa bei einem Grammatiker). Nur weil die literarische Qualität seiner Briefe gegenüber den literarischen Spitzenleistungen abfällt, kann man sie noch nicht auf das Niveau von Papyrusbriefen der mehr oder weniger Ungebildeten stellen. ${ }^{163}$

Überdies wird in der Forschung auf Einflüsse der Rhetorik bei Paulus hingewiesen. ${ }^{164}$ Diese manifestieren sich in Techniken der Stofffindung, der Argumentation und der wirkungsvollen Darstellung. Paulus dürfte mit antiker Brieftheorie bestens vertraut sein, und er versteht es, auf gängige Konventionen des gepflegten Briefstils zurückzugreifen. Das Argumentationsniveau und die briefliche Selbstdarstellung des Paulus lassen sich ohne jegliche rhetorische Ausbildung des Autors kaum erklären. ${ }^{165}$ Dies alles erlaubt ihm, seine Botschaft auf dem Niveau eines Gebildeten auszudrücken und an seine Adressatinnen und Adressaten zu richten.

\subsubsection{Wirtschaftliche Aspekte}

Falls Paulus eine kostenpflichtige griechisch-jüdische Bildung genossen hat, darf das als Hinweis auf eine sozial mittlere oder höhere Herkunft gewertet werden. Seine eigene Darstellung seines sozialen Standes divergiert allerdings deutlich von derjenigen der Apostelgeschichte:Während die Apostelgeschichte Paulus als Mitglied der lokalen Elite darstellt, lassen die Selbstzeugnisse eher auf ein Mitglied der relativ Armen (über dem Existenzminimum Lebenden)

\footnotetext{
162 Ebd., 462.

163 Bauer, Paulus und die kaiserzeitliche Epistolographie, 101.

164 Vgl. Norden, Die antike Kunstprosa vom VI.Jahrhundertv. Chr. bis in die Zeit der Renaissance, 502-520; Horacio E. Lona, Kleine Hinführung zu Paulus (Freiburg i. Br., Basel, Wien 2006); Vegge, Paulus und das antike Schulwesen, 343-424; Carl J. Classen, „Paulus und die antike Rhetorik“, in: ZNW 82, 1-2 (1991), 1-33; Carl Joachim Classen, Rhetorical Criticism of the New Testament, WUNT 128 (Tübingen 2000), 1-28.

165 Vgl. das Kapitel „Paulus und die kaiserzeitliche Epistolographie“ in Bauer, Paulus und die kaiserzeitliche Epistolographie, 388-418.
} 
der antiken Unterschicht schliessen. ${ }^{166}$ Die Überlegungen zu wirtschaftlichen Aspekten sind deshalb relevant, weil sie die diesbezüglichen Einflussmöglichkeiten des Paulus auf respektive seine Abhängigkeiten von Christusgläubigen erhellen, aber auch etwas über seine Interaktionen mit Menschen aus der Zielkultur sowie über seine Evangelisationsbemühungen im Rahmen seiner Werktätigkeit aussagen.

Seinen eigenen Zeugnissen zufolge arbeitet Paulus handwerklich für seine Subsistenz (vgl. 1 Kor 4,12), ist aber zugleich auf finanzielle Unterstützung angewiesen (2 Kor 11,8-9; Phil 4,10). Dass es sich um schwere Arbeit handelt,

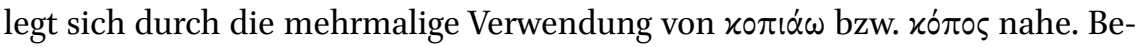
stätigt wird dies durch Paulus' Aussage, er habe in der Nacht und bei Tag ge-

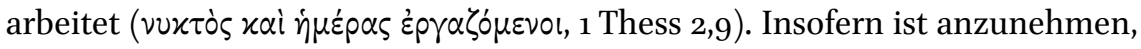
dass die der Subsistenz dienende handwerkliche Tätigkeit des Paulus für sein Leben grundlegend und zentral ist. ${ }^{167}$ Zugleich ist das handwerkliche Arbeiten durchaus charakteristisch für die Evangelisationstätigkeit, weil das eine mit dem anderen verbunden ist (1 Thess 2,9). ${ }^{168}$ An einigen Orten hat Paulus nach eigenen Angaben Versammlungen bzw. Gemeinschaften ,ausgeraubt' ( $\alpha \lambda \lambda \alpha \varsigma$

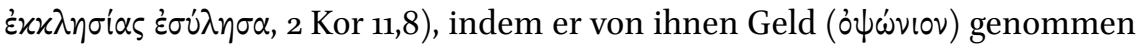
hat, um den Menschen in Korinth zu dienen. Brüder aus Mazedonien haben ihn unterstützt (2 Kor 11,9). Zugleich legt Paulus aber grossen Wert darauf, dass er in Korinth niemandem zur Last gefallen ist, obschon er Mangel gelitten hat.

166 Zu Paulus' sozialem Stand und den divergierenden Darstellungen in der Apostelgeschichte und den Paulusbriefen vgl. Ekkehard W. Stegemann und Wolfgang Stegemann, Urchristliche Sozialgeschichte: Die Anfänge im Judentum und die Christusgemeinden in der mediterranen Welt (Stuttgart 1997), 256-260. Vgl. auch Steven J. Friesen: „[T] observation is that the author of Acts portrays Paul not simply as the poor man but as a man of the highest social skills who commands respect from some of the wealthiest and most powerful Roman imperialists.“ Steven J. Friesen, „Injustice or God's Will: Explanations of Poverty in Proto-Christian Communities“, in: Susan R. Holman (Hg.), Wealth and Poverty in Early Church and Society (Grand Rapids (MI) 2008), 17-36, hier: 30-31.

167 Zu Paulus als Zeltmacher siehe ausführlich Ronald F. Hock, „Paul's Tentmaking and the Problem of His Social Class“, in: JBL 97, Nr. 4 (1978), 555-564; Todd D. Still, „Did Paul Loathe Manual Labor? Revisiting the Work of Ronald F. Hock on the Apostle's Tentmaking and Social Class", in:JBL 125, Nr. 4 (2006), 781-795. Zu den Gründen für diese Tätigkeit vgl. auch den Abschnitt „A Closer Look: Why Paul Made Tents“ in Ben Witherington, Conflict and Community in Corinth: A Socio-Rhetorical Commentary on 1 and 2 Corinthians (Grand Rapids (MI), Carlisle 1995), 208-209.

168 Für die These, dass die Werkstatt selbst Paulus jeweils als Ort für die Verkündigung dient; vgl. Ronald F. Hock, The Social Context of Paul's Ministry: Tentmaking and Apostleship (Philadelphia 1980), 37-42. 
Die aus Mazedonien kommenden Brüder helfen ihm aus. Paulus will auch in Zukunft den Menschen in Korinth nicht zur Last fallen. Über den Mangel, den er erleidet, will Paulus allerdings nicht jammern, wie er wenigstens gegenüber den Christusgläubigen in Philippi festhält. Er kennt sowohl Überfluss als auch Not, Hunger und Sättigung (Phil 4,11-12).

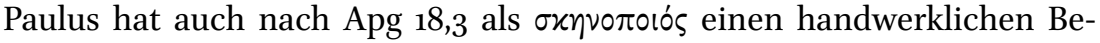
ruf, mit dem er seinen Unterhalt mehr oder weniger finanzieren kann. Der Beruf des Zeltmachers, allenfalls verstanden in einem weiten Sinn als Lederwerker oder auch als Verarbeiter anderer Materialen wie beispielsweise groben Stoffes, ${ }^{169}$ ermöglicht es ihm, an verschiedenen Orten zu arbeiten. ${ }^{170}$ Es scheint für Handwerker durchaus üblich zu sein, mit ihrem Werkzeug umherzureisen und am Ort, an dem sie gerade verweilen, ihr Handwerk auszuüben. ${ }^{171}$

\subsubsection{Zusammenfassung}

Die Tatsache, dass Paulus griechischer Muttersprache sein dürfte und mit der Septuaginta souverän umzugehen weiss, deutet darauf hin, dass er in der Diaspora aufgewachsen ist, daselbst am hellenistischen Bildungssystem partizipiert und im Umfeld der Synagoge seine religiöse jüdische Formung und Ausbildung geniesst und dann zur weiteren Ausbildung nach Jerusalem gekommen ist. ${ }^{172}$ Der gebürtige Diasporajude griechischer Muttersprache dürfte sich im ebenfalls hellenisierten Jerusalem intensiv in die jüdischen Überlieferungen vertieft haben. ${ }^{173}$ Alles, was über diese Annahmen hinausgeht, bleibt sehr spekulativ, denn das Wissen über jüdische Bildungseinrichtungen in der Diaspora ist bis heute sehr mangelhaft. ${ }^{174} \mathrm{Um}$ seine Subsistenz zu gewährleisten und den jeweiligen Gruppen nicht zur Last zu fallen, betätigt

169 Vgl. Martin Hengel, „Der vorchristliche Paulus“, in: Heckel, Hengel und Schlatter, Paulus und das antike Judentum, 211.

170 Vgl. Hock, „Paul's Tentmaking and the Problem of His Social Class“. Zur Diskussion um die

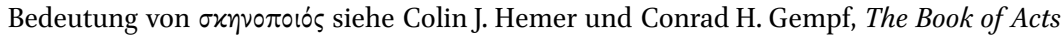
in the Setting of Hellenistic History, WUNT 49 (Tübingen 1989), 119 (Fn. 46) und 233; Peter Lampe, „Paulus - Zeltmacher“, in: BZ 31, Nr. 2 (1987), 256-261.

171 Vgl. Hock, The Social Context of Paul's Ministry, 26-31; Martin Hengel, „Der vorchristliche Paulus", in: Heckel, Hengel und Schlatter, Paulus und das antike Judentum, 211.

172 Dunn argumentiert, dass Jerusalem angesichts seines griechisch sprechenden Milieus auch als primärer Bildungsort infrage kommt; James D. G. Dunn, Beginning from Jerusalem, Christianity in the making (Grand Rapids (MI) 2009), 330-335.

173 Vgl. bspw. Martin Hengel, „Der vorchristliche Paulus“, in: Heckel, Hengel und Schlatter, Paulus und das antike Judentum, 212-214; Gnilka, Paulus von Tarsus, Apostel und Zeuge, 21-27.

174 Vgl. Vegge, Paulus und das antike Schulwesen, 281-284. 
Paulus sich auch auf Reisen als Handwerker. Diese Tätigkeit ist ein wesentlicher Aspekt seiner Freiheit und seines Verständnisses als Apostel, auf die er insbesondere in 1 Kor 9 eingeht. ${ }^{175}$

Die Angaben zu Herkunft, Bildung und zum sozialen Hintergrund unterstreichen die angestammten Wurzeln im und die bestehenden Verflechtungen mit dem Judentum als Ausgangskultur für Paulus' Aufgabe als Vermittler und erhellen seine Einflussmöglichkeiten auf die Adressatinnen und Adressaten in mannigfaltiger Weise.

\subsubsection{Berufung und Beauftragung}

Dass es zur Beauftragung des Paulus als interkulturellen Vermittler unter den Völkern kommt, hängt mit der Lebenswende zusammen, die von einer visuellen Erscheinung des Auferstandenen herrührt und die Paulus mit Mustern seines angestammten Orientierungssystems deutet.

Paulus erwähnt in mehreren Briefen und in unterschiedlichen Zusammenhängen seine Lebenswende, die eine tief greifende und existenzielle Neuorientierung zur Folge hat. Es sind alles relativ kurze Texte, die in ihrem jeweiligen Zusammenhang einer bestimmten Argumentation dienen. Insgesamt sind die retrospektiven Erwähnungen sehr knapp gehalten: Gal 1,11-19; 1 Kor 9,1; 15,8; Phil 3,5-9, eventuell spielt auch 2 Kor 4,6 darauf an (vgl. dazu Apg 9,1-30; 22,3-21; 26,9-20, wo das Erlebnis im Gegensatz zu den paulinischen Zeugnissen als Audition dargestellt ist). Gemeinsam ist den Texten, dass sie das Ereignis, aufgrund dessen Paulus vom Gegner des Christusglaubens zum Vermittler desselben wird, als Erkenntnisakt beschreiben und nicht als Willensentscheidung. Es gilt, aufbauend auf eine Klärung der Begrifflichkeit aufzuzeigen, dass und inwiefern sich Paulus sowohl vor als auch nach diesem Ereignis als Iovoðios darstellt, als solcher zwar eine spezielle Aufgabe bekommt, sie aber auch mit ihrer Ausrichtung auf die Menschen aus den Völkern als Zielkultur vollumfänglich innerhalb seines angestammten Orientierungssystems deutet. Ein Perspektivenwechsel beleuchtet die mögliche Aussensicht auf Paulus als Apostaten.

175 Vgl. dazu weiter unten die Ausführungen unter 4.3.4. „Apostolat und apostolische Lebensweise". 


\subsubsection{Zur Begrifflichkeit}

In der Forschung wird die Lebenswende des Paulus häufig als Bekehrung oder Berufung bezeichnet. ${ }^{176}$ Meist meint der Bekehrungsbegriff einerseits den willentlichen Übertritt von einer Religion oder Konfession zu einer anderen, andererseits wird er verbunden mit Busse, Reue und Sündenbewusstsein. Im Hinblick auf Paulus bedeutet das in der Regel die Vorstellung, dass er vom Judentum zum Christentum übergetreten ist. Kritik an der Anwendung des Bekehrungsbegriffs auf Paulus, und zwar in allen genannten Aspekten, übt schon Krister Stendahl in seinem berühmt gewordenen und die „New Perspective on Paul“ ankündigenden Aufsatz. ${ }^{177}$ Er verabschiedet die traditionelle Sichtweise, dass sich Paulus vor Damaskus vom Judentum zum Christentum bekehrt: „Hier ist nichts von jenem Religionswechsel zu merken, den wir gemeinhin mit dem Wort Bekehrung assoziieren. Im Dienst für ein und denselben Gott empfängt Paulus einen neuen, besonderen Ruf.،178 Bei Paulus unreflektiert von einer Konversion oder Bekehrung - zumal vom Judentum zum Christentum - zu sprechen, ist zudem in hohem Masse anachronistisch. Dazu müsste es das Christentum als organisierte Glaubensgemeinschaft bereits gegeben haben, was aber für die Zeit des Paulus schlechterdings nicht postuliert werden kann. ${ }^{179}$

In jüngerer Zeit hat Alan F. Segal den Bekehrungsbegriff wieder prominent platziert: „Paul the Convert. The Apostolate and Apostasy of Saul the Pharisee“. ${ }^{180}$ Nach eingehender Reflexion über die Problematik des Begriffs kommt er zu dem Schluss, dass der Bekehrungsbegriff gleichwohl sinnvoll anzuwenden ist, da bei Paulus die dafür entscheidende und vom Subjekt vollzogene Zäsur zwischen dem Früher und dem Jetzt gegeben sei. ${ }^{181}$

176 Den Begriff ,Lebenswende verwendet auch Ulrich B. Müller, „Die Lebenswende des Apostels Paulus und seine bleibende Orientierung am Kyrios Jesus“, in: $B Z$ 56, Nr. 2 (2012), $161-187$.

177 Krister Stendahl, Der Jude Paulus und wir Heiden: Anfragen an das abendländische Christentum, KT 36 (München 1978 [1976]). Der Begriff der neuen Paulusperspektive wurde geprägt von James D. G. Dunn, „The New Perspective on Paul“, in: BJRL 65 (1983), 95-122.

178 Stendahl, Der Jude Paulus und wir Heiden, 18.

179 Für eine kritische Diskussion traditioneller Darstellungen, wovon und wozu Paulus sich bekehrt haben soll; vgl. James D. G. Dunn, „Paul's Conversion: A Light to Twentieth Century Disputes“, in: James D. G. Dunn (Hg.), The New Perspective on Paul: Collected essays, WUNT 185 (Tübingen 2005), 341-359, hier: 341-350.

180 Alan F. Segal, Paul the Convert: The Apostolate and Apostasy of Saul the Pharisee (New Haven 1990).

181 Vgl. ebd., 16-30 und 285-300. 
Für den Berufungsbegriff - call auf Englisch - hat sich eine ganze Reihe von Forschenden stark gemacht bzw. hat ihn ohne besondere Begründung bevorzugt. ${ }^{182}$ Auch von einer, Wende ${ }^{‘}$ wird bisweilen gesprochen. ${ }^{183}$ James D. G. Dunn plädiert dafür, dass das Ereignis bei Paulus sowohl eine Bekehrung als auch eine Berufung bzw. Beauftragung sei. ${ }^{184}$ Will man sich allerdings auf einen einzigen Begriff festlegen, erscheint von den paulinischen Zeugnissen her der Berufungsbegriff am adäquatesten.

\subsubsection{Vor der Berufung}

Über seinen Wandel vor der Berufung zeichnet Paulus ein krasses Bild: Er hat

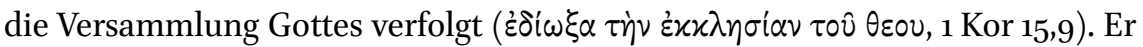
führt diese Verfolgertätigkeit als Ausdruck seines früheren Verständnisses als

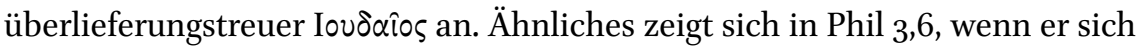

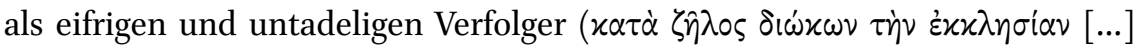

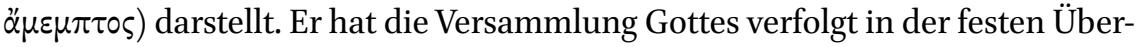
zeugung, somit gemäss dem Gesetz und dem Willen Gottes zu handeln. Auch in Gal 1,13-14 berichtet er, wie er einst ( $\pi \circ \tau \varepsilon)$ die Versammlung Gottes über die

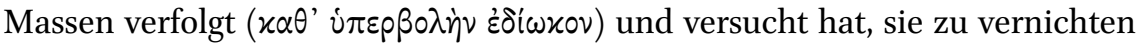

182 Vgl. Christian Dietzfelbinger, „Die Berufung des Paulus als Ursprung seiner Theologie“ (Habil.-Schr. theol., München, 1985); John J. Pilch, „Paul's Call to be a Holy Man (Apostle): In His Own Words and in Other Words", in: HTS 61, 1-2 (2005), 371-383. Dunn verwendet beide Begriffe: Im Kommentar zum Gal setzt er über die Kommentierung der Verse 1,15-17 die Überschrift „Paul's Calling“, gibt allerdings seinem Aufsatz zum Thema den Titel „Paul's Conversion“; vgl. James D. G. Dunn, The Epistle to the Galatians, 1st publ. 1993, repr., BNTC (Peabody (MA) 1993), 62; James D. G. Dunn, „Paul's Conversion“, in: The New Perspective on Paul.

183 Vgl. Wengst, „Freut euch, ihr Völker, mit Gottes Volk!“, 93-97.

184 „We need not engage in further dispute on the point; indeed the dispute (conversion or commissioning) is somewhat artificial. There clearly was a conversion, a turning from and a turning to; and there evidently was that kind of wrenching, transforming experience which continues to makes [sic!] Paul's experience a model of conversion experience. But if we take Paul's own testimony (and that of Acts) seriously we have also to speak of a calling or commissioning. The point is surely that in Paul's mind they both amounted to the same thing - a conversion from persecutor to apostle, a conversion from one rather introverted ,sect' within first century Judaism to another more missionary minded ,sect', a conversion in other words, at whose heart was the newly implanted conviction that the time of Abraham's blessing to the nations, of the Servant's light to the nations, had now come and that he was to be a key figure in bringing about that blessing and in spreading that light.“ James D. G. Dunn, „Paul's Conversion“, in: The New Perspective on Paul, 358. 


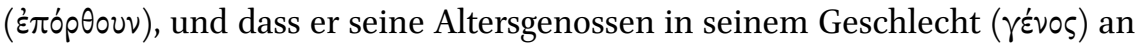

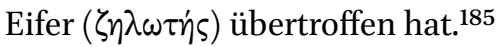

$\mathrm{Zu}$ fragen ist dabei nach der genaueren Bedeutung von $\delta \iota^{\omega} \kappa \omega$ und $\pi \circ p \theta \varepsilon \dot{\varepsilon} \omega$. Der ursprüngliche Wortsinn von $\delta i \omega x \omega$ ist „treiben, antreiben, in Bewegung setzen“. Er entfaltet sich dann hin zu „verfolgen, vertreiben, [...] nach etwas voll Eifer trachten“. ${ }^{186}$ Das Imperfekt ह̇ंíwxov (Gal 1,13) dürfte als Durativ verstanden werden, was bedeutet, dass Paulus die Versammlung Gottes längere Zeit bzw. beharrlich verfolgt hat. $\pi$ op $\theta \tilde{\varepsilon} \omega$ hat eine deutlich gewaltsame Bedeutung: „vernichten, zerstören“. 187 Dieses Verb, das von Homer bis hin in die Koiné verwendet wird, aber bezeichnenderweise in der Septuaginta fehlt, dient hier dazu, Paulus' Verhalten gegenüber den Christusgläubigen auszudrücken. Möglicherweise handelt es sich um ein Imperfekt de conatu in dem Sinne, dass Paulus bloss versuchte, die Versammlung Gottes zu zerstören. Erklärungen, dass Paulus nicht die Personen an sich, sondern lediglich den Glauben der Christusgläubigen angegriffen habe, vermögen nicht zu überzeugen. ${ }^{188}$ In $\mathrm{Zu}-$

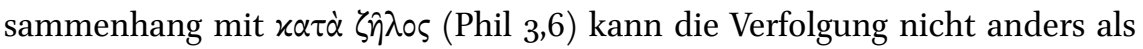
gewalttätig verstanden werden: „Es geht um brutale Gewaltanwendung.“189

Wenn Paulus von Verfolgung spricht (Gal 1,13-14; Phil 3,6; vgl. 1 Kor 15,9; vgl. Apg 8,3; 9,1-2), dürfte die Durchsetzung der Synagogaljustiz gemeint sein, die vermutlich in erster Linie auf Griechischsprachige ausgerichtet ist. In den Augen der Pharisäer ist deren meist liberalere Position in der Einhaltung der

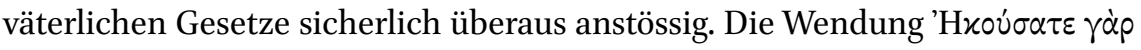

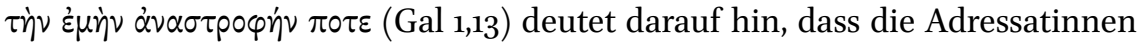
und Adressaten von Paulus' Verfolgertätigkeit bereits Kenntnis haben. Indem

185 Mit Haacker sei betont, dass der Eifer nicht „in einem rein psychologischen Sinn“ zu verstehen ist, sondern dass es sich hier um „eine klare theologische Kategori“ " handelt; vgl. Klaus Haacker, „Die Berufung des Verfolgers und die Rechtfertigung des Gottlosen: Erwägungen zum Zusammenhang zwischen Biographie und Theologie des Apostels Paulus“, in: ThBeitr 6 (1975), 1-19, Zitat: 8; Hervorhebung im Original. Wengst zufolge hat Paulus „besonders diejenigen Gebote und Verbote der Tora und ihrer Auslegung im Blick, die jüdische Lebensweise von nichtjüdischer Lebensweise abgrenzen; und richtet sich gewaltsam gegen diejenigen, die diese Grenzmarkierungen gegenüber der nichtjüdischen Welt überschreiten oder gar beseitigen“. Wengst, „Freut euch, ihr Völker, mit Gottes Volk!", 84.

186 Otto Knoch, „Art. $\delta 1 \omega \dot{x} \varkappa \omega^{\prime}$, in: Horst Balz und Gerhard Schneider (Hg.), Exegetisches Wörterbuch zum Neuen Testament, 3 Bde., Bd. 1, 2. Aufl. (Stuttgart 1992), 817-819.

187 Spicqübersetzt ins Französische „saccager, ravager, ruiner une ville, dévaster un territoire“, Spicq, Notes de lexicographie néo-testamentaire, Bd. 2, 723.

188 Vgl. Ph. Menoud, „Le sens du verbe $\pi \circ p \theta \varepsilon i v$ (Gal 1,13.23; Apg 9,21)“, in: Walther Eltester und Franz Heinrich Kettler (Hg.), Apophoreta: Festschrift für Ernst Haenchen zu seinem siebzigsten Geburtstag am 1o. Dez. 1964, BZNW, Beih. 30 (Berlin 1964), 178-186.

189 Martin Hengel, „Der vorchristliche Paulus“, in: Heckel, Hengel und Schlatter, Paulus und das antike Judentum, 275 . 
Paulus seine Tätigkeit in der Vergangenheit beschreibt $(\pi \circ \tau \varepsilon)$, betont er, dass der unterdessen eingetretene Wandel in keiner Art und Weise als seine Leistung angesehen werden kann und dass er auch von ihm selbst her nicht hätte geschehen können. Der Wandel stellt somit ein positives Zeugnismoment dar für den Anspruch, dass sein Evangelium nicht menschlichen, sondern göttlichen Ursprungs ist. Umso mehr ist seine neue Aufgabe als Vermittler als legitimiert anzusehen.

4.3.3.3 Die paulinischen Berichte zu seiner Berufung in Anlehnung an die Propheten

Der ausführlichste paulinische Bericht über das Berufungserlebnis findet sich in Gal 1,11-17. In Gal spricht Paulus von einer ,Offenbarung' ( $\delta \iota^{\prime} \dot{\alpha} \pi 0 x \alpha \lambda \dot{\psi} \psi \varepsilon \omega \varsigma$ 'Inбov̂ Xp lung Jesu selbst einstuft, wenn er sagt, dass es Gott wohlgefallen habe, in ihm seinen Sohn zu offenbaren (Gal 1,15-16). Das Handeln Gottes und Jesu ist offenkundig weitgehend austauschbar. Die Berufung erfolgt ad personam und dürfte

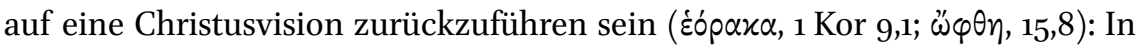
1 Kor 15,8 führt Paulus den Menschen in Korinth vor Augen, dass er selbst wie die übrigen Apostel - den Kyrios gesehen hat und genau deshalb ebenfalls als Apostel qualifiziert ist. Das Motiv vom alles überstrahlenden Licht in 2 Kor 4,4-6, bezogen auf die Verkündigung des Apostels, dürfte auf die ursprüngliche Vision des Paulus verweisen. ${ }^{190}$ Die Radikalität der Transformation, die Paulus durch diese Vision erlebt hat, kann kaum überschätzt werden. Paulus spricht davon sogar in Kategorien von Sterben und Leben (Gal 2,19-20) und

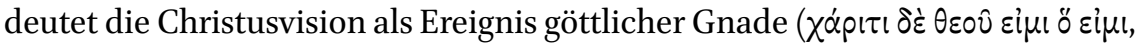

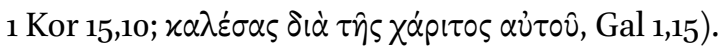

Paulus sieht sich durch seine Vision nicht nur eingereiht unter die Apostel, sondern stellt sich auch in prophetische Tradition und gliedert sich damit unter die grossen Autoritäten seiner Ausgangskultur ein, an denen sich deren Mitglieder über die entsprechenden Schriften orientieren. Der Erwählungsbericht in Gal 1,15-16 klingt inhaltlich und sprachlich bis in den Wortlaut hinein stark an Berichte der Propheten Jesaja (Jes 49,1.6) und Jeremia (Jer 1,5) an. ${ }^{191}$ Im Buch Jesaja steht: „Der Herr rief [schon] vom Leibe meiner Mutter her

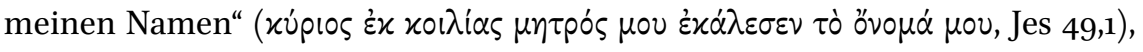

190 Im Gegensatz zu den paulinischen Zeugnissen stellt die Apostelgeschichte das Ereignis eher als Audition denn als Vision dar (Apg 9,3-8; 22,6-11; 26,9-18).

191 Hierzu siehe ausführlich Karl Olav Sandnes, Paul - One of the Prophets? A Contribution to the Apostle's Self-Understanding, WUNT II 43 (Tübingen 1991), 48-69. Zur paulinischen Anlehnung an die alttestamentlichen Propheten vgl. auch Traugott Holtz, „Zum Selbstverständnis des Apostels Paulus“, in: ThLZ 91, Nr. 5 (1966), 321-330. Eine Übersicht alternativer „Deutungsmodelle des Damaskusgeschehens“ aus tiefenpsyschologischer, 
und es beschreibt den Ruf Gottes zum Wirken unter den Völkern mit den Worten: „Siehe, ich habe dich [auch] eingesetzt zum Bund eines Stamms, zum

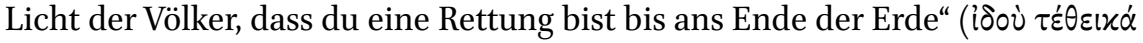

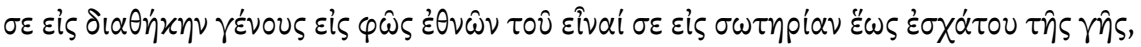
Jes 49,6). Auch Paulus ist von Gott bereits im Mutterleib für den Dienst unter

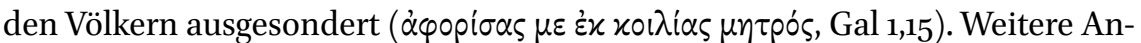
spielungen auf den deuterojesajanischen Gottesknecht sind sehr deutlich: Röm 15,20-21 dürfte sich auf Jes 52,15 beziehen; 2 Kor 6,2 auf Jes 49,8. Wie der Prophet Jesaja ist auch Paulus zum Wirken unter den Völkern bestimmt. So wie Jesaja ist auch der Prophet Jeremia vor seiner Geburt - ja sogar vor seiner Empfängnis - zum Propheten für die Völker auserkoren: „Bevor ich dich in der Leibeshöhle geformt habe, habe ich dich gekannt, und bevor du aus dem Mutterschoss herausgekommen bist, habe ich dich geheiligt [und] dich zum

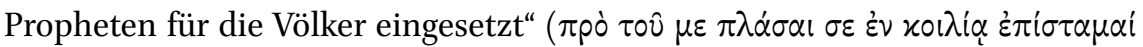

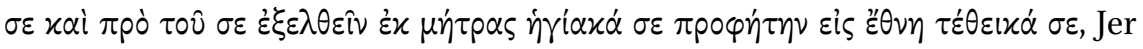
1,5). Mit der deutlichen Anlehnung an diese prophetischen Berufungen reiht Paulus sich erkennbar unter die Propheten ein, die vorgeburtlich erwählt waren und den Auftrag hatten, unter die Völker zu gehen.

Paulus sieht die Versöhnung der Völker mit dem Gott Israels als essenzielles Geschehen für die Errettung Israels an (Röm 11,13.25-32). Sein Auftrag unter den Völkern ist ein wesentlicher Schritt auf Israels Weg zu diesem Ziel. Insofern versteht Paulus seinen Auftrag voll und ganz innerhalb der Geschichte Israels mit seinem Gott und keinesfalls als Bruch mit Israel. Somit verortet er seine Berufung vollumfänglich innerhalb seines angestammten Orientierungssystems. Dies gilt auch für seinen Auftrag, unter den Völkern zu wirken.

\subsubsection{Verbleib im Judentum und apostolischer Auftrag zum Wirken unter den Völkern}

Paulus stellt seine Berufung als vorgeburtliches Faktum dar, sodass trotz der grossen Wende in seinem Leben nicht von einer gebrochenen Biografie gesprochen werden kann. Wenn von einem Bruch die Rede sein kann, dann nur hinsichtlich seiner Verfolgertätigkeit, denn diese entspricht nicht der vorgeburtlichen Berufung. ${ }^{192}$ Die Verfolgertätigkeit ist es auch, die Paulus beinahe unwürdig macht, den Aposteltitel zu tragen (oủx Eił ì ixavós, 1 Kor 15,9). Gleichwohl sind die dem Paulus widerfahrene Offenbarung und der damit verbundene Auftrag der Mission unter den Völkern von der Vision des auferstandenen

soziologischer und kulturanthropologischer Perspektive findet sich bei Bernd Kollmann, „Die Berufung und Bekehrung zum Heidenmissionar“, in: Horn, Paulus Handbuch, 88-91.

Vgl. Wolff, Paulus beispiels-weise, 24. 
Kyrios her klar und bedürfen keiner menschlichen Legitimierung oder Erklärung. Deshalb geht Paulus auch nicht erst zu den Aposteln in Jerusalem. Darin drückt sich auch seine Unabhängigkeit von diesen aus. Paulus subordiniert sich nicht ihrer Autorität, denn er will die göttliche Offenbarung von alleine verstanden haben und braucht weder die Zustimmung noch eine Erklärung der Jerusalemer Apostel. Wenn diese in der Repräsentanz der Botschaft Christi einen überragenden Anspruch haben, dann allein deshalb, weil sie früher als er diesen Auftrag erhalten haben. ${ }^{193}$ Qualitativ unterscheiden sich die Aufträge nicht. Genau wie Petrus das Evangelium unter den Beschnittenen zu verkündigen hat, so Paulus unter den Unbeschnittenen (Gal 2,7). Er ist unabhängig und frei (1 Kor 9,1). Wenn er schon für ,die anderen', d. h. für die

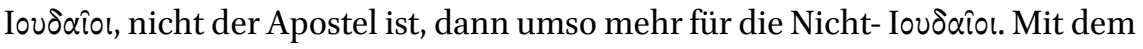

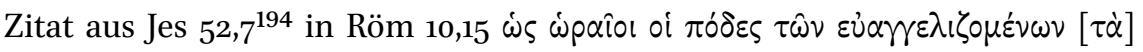
$\dot{\alpha} \gamma \alpha \theta \dot{\alpha}$ reiht Paulus sich explizit unter den prophetischen Botschaftern ein und versteht sein Wirken unter den Völkern als Teil des göttlichen Heilsplans. Seine Verkündigung fusst auf der Überzeugung, dass durch die Mission unter den Völkern das Volk Israel zum Heil gelangt (Röm 11,13-14). Von diversen Texten her ist zu begründen ( $\mathrm{Gal}$ 1,11-17; Gal 2,1-10; Röm 1,1-6; 13; 15,15-21), dass die Mission unter den Völkern nicht bloss die Folge, sondern vielmehr der zentrale Zweck der Christusoffenbarung ist. Zum Inhalt seines Auftrags schreibt Paulus, dass Christus ihn nicht ausgesandt habe, zu taufen, sondern das Evangelium zu verkündigen (1 Kor 1,17). Paulus überliefert, was er empfangen hat: dass Christus für die Sünden der Menschen gestorben ist gemäss den Schriften, dass er begraben und am dritten Tag auferweckt worden ist (1 Kor 15,3-4).

Grundsätzlich und immer wieder beruft sich Paulus auf die Schriften Israels und verortet damit sich selbst und den Inhalt seiner Verkündigung in dieser Tradition. ${ }^{195}$ Somit ist auch das kulturelle Artefakt, das Paulus an die Völker vermitteln soll, seiner Darstellung nach in der Ausgangskultur verankert. Das Evangelium von der Auferstehung Christi eröffnet die Möglichkeit, dass auch Menschen aus der anvisierten Zielkultur, nämlich die breite Masse aller Menschen aus den Völkern, innerhalb des jüdischen Orientierungssystems ihren Platz finden und am Ende der Tage Anteil haben am Heil Israels, wie

\footnotetext{
193 Das $\pi$ pó in Gal 1,17 dürfte temporal zu verstehen sein.

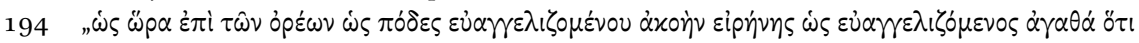

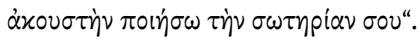

195 Vgl. Paula Fredriksen: „Paul lived his life entirely within his native Judaism. Later traditions, basing themselves on his letters, will displace him from this context. Through the retrospect of history, Paul will be transformed into a ,convert,' an ex- or even an antiJew; indeed, into the founder of gentile Christianity." - so eine grundlegende These ihres jüngsten Buches, Fredriksen, Paul, xii.
} 
es von den Propheten verheissen ist. Die Verkündigung dieses Evangeliums gilt zuerst den Iovoðîo, aber auch den Heiden (Röm 1,16; Röm 15,14-21). Dies ist schon vom Bunde Abrahams her gegeben (Gen 12,3; 18,18). Hierauf bezieht sich Paulus in Gal 3,8, wo er festhält, dass die Schrift vorausgesehen hat, dass die Völker von Gott gerecht gemacht würden. Mit Paulus' Berufung fällt auch sein apostolischer Auftrag zusammen (Gal 1,15-16). Der gnädige Ruf Gottes hat ihn zum Apostel gemacht (Gal 1,15). Die Gnade, die Paulus für seinen Auftrag erhalten hat, betont er mehrfach: Gal 2,9; 1 Kor 3,10; Röm 12,3. Diese Gnade ist von Gott her gegeben, und Paulus hat sie durch Christus empfangen (Röm 1,5). Jesus selbst ist die Gnade Gottes (Röm 5,15).

Grundlegend für einen Apostel Jesu Christi sind nach Paulus' Verständnis einerseits die Erscheinung des Auferstandenen (1 Kor 9,1; 15,5-8) und andererseits die Beauftragung, das Evangelium zu verkündigen. Folgerichtig kann es auch nicht beliebig viele Apostel geben, sondern deren Zahl ist beschränkt. Paulus ist derjenige, der den Auferstandenen als Letzter in einer langen Reihe von Autoritäten gesehen hat, und er ist seiner Selbstbeurteilung nach gewissermassen eine Fehlgeburt ( $\varepsilon^{\prime} \chi \tau \rho \omega \mu \alpha, 1$ Kor 15,8). ${ }^{196}$ Diese hebt seine Nichtigkeit hervor. Paulus ist der Geringste ( $\dot{\varepsilon} \lambda \alpha \dot{\chi} \chi \sigma \tau 0 \varsigma, 1$ Kor 15,9) unter den Aposteln und nicht würdig, Apostel genannt zu werden, weil er die Versammlung Gottes

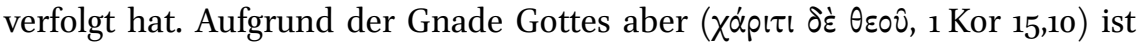
er, was er ist. Die Erscheinung Jesu begründet die Berufung des Paulus zum Apostel ohne Zweifel. Die Realität der Erscheinung des Auferstandenen wird hier herausgestrichen, und zugleich verteidigt Paulus die Legitimität seines apostolischen Wirkens neben den zuvor in 1 Kor 15,5-7 genannten Autoritäten. Der apostolische Auftrag kann weder von Menschen verliehen noch durch

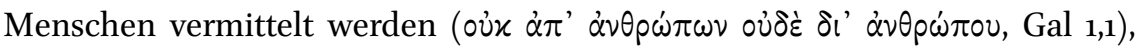
sondern allein durch Jesus Christus und Gott den Vater (Gal 1,1). Insofern beansprucht Paulus, das Evangelium nicht aus der Tradition übernommen oder gelernt, sondern durch eine Offenbarung Jesu Christi empfangen zu haben $(\delta i$ '

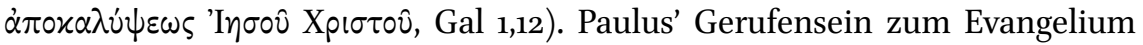
erfährt noch eine Erläuterung. Er hat vermittelt durch Jesus Christus Gnade

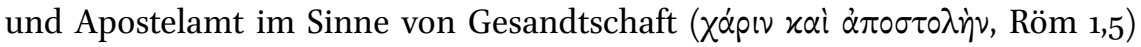
empfangen. ${ }^{197}$ Auch hat er nach eigenen Angaben von allen Aposteln am

196 Vgl. Johannes Munck, „Paulus tanquam abortivus: 1 Cor. 15:8“, in: Angus J. B. Higgins und Thomas W. Manson (Hg.), New Testament Essays: Studies in Memory of Thomas Walter Manson/1893-1958, sponsored by pupils, colleagues and friends (Manchester 1959), 180-193; Peter v. d. Osten-Sacken, „Die Apologie des paulinischen Apostolats in 1 Kor 15:1-11“, in: ZNW 64, 3-4 (1973), 245-262, hier: 250-257.

197 Dass er hier im Plural spricht, ist vermutlich weder als ein pluralis maiestatis zu verstehen, noch sind mehrere Apostel gemeint, sondern die Verwendung an dieser Stelle wird von den meisten Kommentatoren als schriftstellerischer Plural angesehen, bei dem 


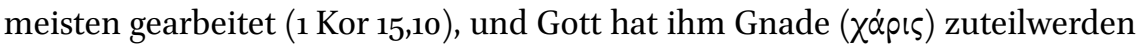
lassen für seine Aufgabe (Röm 15,15).

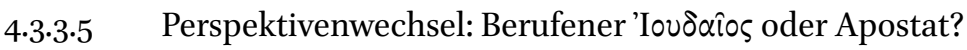

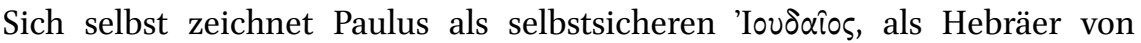
Hebräern (Phil 3,5). Nicht auszuschliessen ist, dass er in den Augen anderer 'Iovঠðîo - christusgläubig oder nicht - als Apostat erscheint, da er spezifische Identitätsmerkmale des Orientierungssystems vom Volk Israel (Thora und Beschneidung) so stark differenziert und in seinen interkulturellen Kontext umdeutet, um sie in seine Soteriologie einzupassen. ${ }^{198}$ Barclay jedenfalls argumentiert, dass Paulus mehrfach mit Apostasievorwürfen belegt wurde. ${ }^{199}$ Sicherlich richtig ist an seiner Argumentation, dass Apostasie immer eine Frage der Perspektive ist. ${ }^{200}$ Apostasie kann nicht von einem Akt per se behauptet

das Ich des Schreibenden in den Hintergrund tritt. Vgl. dazu grundlegend: Dick, Der schriftstellerische Plural bei Paulus; aus der Fülle der Kommentare vgl. bspw. Heinrich Schlier, Der Römerbrief: Kommentar, 3. Aufl., HThKNT 6 (Freiburg 1987), 27-28; Otto Kuss, Der Römerbrief, 3 Bde. (Regensburg 1957-1978), 9; Charles E. B. Cranfield, A Critical and Exegetical Commentary on the Epistle to the Romans: Romans 1-8, Reprinted 2010 with corrections, ICC (London, New York 2010), 65.

Eine weitere Möglichkeit wäre, dass der Plural die $x \lambda \eta \tau$ тó in Rom in sein Gesandtsein $(\dot{\alpha} \pi \circ \sigma \tau 0 \lambda \hat{\eta})$ mit einbezieht im Sinne eines von ihm so genannten „Pluralis sociativus“. Dieser Plural ist, so Friedrich Slotty, allen indogermanischen Sprachen gemeinsam, und es drückt sich darin ein Gemeinschaftsgedanke aus, der das redende oder schreibende Individuum mit seinem Gegenüber bzw. seinen Adressatinnen und Adressaten zusammenschliesst; vgl. Friedrich Slotty, „Der soziative und affektische Plural der ersten Person im Lateinischen“, in: IGF 44 (1927), 264-305; Friedrich Slotty, „Der sogen. Pluralis modestiae“, in: IGF 44 (1927), 155-190; Friedrich Slotty, „Der soziative und affektische Gebrauch des Plurals der ersten Person und das Subjektspronomen im Lateinischen“, in: Glotta 16 (1927/28), 253-274.

Wolff hingegen spricht bei diesem, unlogischen Plural' von einem „Pluralis affectus“: „Paulus zeigt gleich im Präskript gegenüber der römischen Gemeinde seine herausgehobene Position an. Dass er hier auf den Affekt Stolz verfällt, nimmt nicht wunder, da es sich ja beim Röm um ein Vorstellungsschreiben an die ihm noch unbekannte Gemeinde handelt. Paulus versucht mit dem Röm, einen guten und starken Eindruck auf sie zu machen, und dazu passt es sehr gut, dass er voller Selbstbewusstsein und eben voller Stolz verkündet, von Gott das Amt eines Apostels empfangen zu haben." Wolff, Paulus beispiels-weise, 112.

198 Die Aussage in Röm 10,4 ist dabei nicht als Ende, sondern als Wende des Gesetzes zu verstehen. Vgl. mit Verweisen Jewett, Kotansky und Epp, Romans, 619. Christus hat den Fluch des Gesetzes, der auf demjenigen liegt, der die Thora nicht hält bzw. sie übertritt, auf sich genommen.

199 Vgl. John M. G. Barclay, "Who Was Considered an Apostate in the Jewish Diaspora?“, in: John M. G. Barclay (Hg.), Pauline Churches and Diaspora Jews, 141-155, WUNT 275 (Tübingen 2011), 135 .

200 Wie bereits der Titel impliziert, ebd. 
werden, sondern sie betrifft solche Akte nur dann, wenn diese eine negative soziale Antwort oder Reaktion bekommen. Apostasie ist demnach ein soziales Produkt, und ihr haftet eine grosse Relativität an. Sie sagt mindestens so viel über diejenigen aus, die andere als deviant ansehen, wie über den als deviant angesehenen Akt selbst. Bezüglich möglicher Apostasievorwürfe wird es, so Barclay weiter, auch eine nicht zu unterschätzende Rolle gespielt haben, dass Paulus' soziale Stellung in den Diasporagruppen eher schwach gewesen sein dürfte, denn er war weitgehend ein Aussenseiter. Sein sozialer Status darf als verhältnismässig niedrig eingeschätzt werden, denn er verfügt weder über eine wirtschaftliche noch politische Grundlage von Macht, auf die er seine Verteidigung stützen kann. So dürften Machtkämpfe innerhalb von Synagogen fast zwangsläufig zu seinen Ungunsten ausgefallen sein. ${ }^{201}$

Die von Barclay angeführten Belege für seine These der Apostasievorwürfe an Paulus vermögen indes nicht zu überzeugen. Dass Paulus Widerstand erfährt - bis hin zu Nachstellungen und Gefährdungen (bspw. 2 Kor 11,24-26; Gal 2,11-17; 5,11; 1 Thess 2,15-16) -, zeigt eher das Gegenteil: dass Paulus von anderen 'Iovठ aîo immer noch als „einer der ihren“ angesehen wird.

\subsubsection{Zusammenfassung}

Paulus sieht sich in prophetischer Tradition von Mutterleib an berufen. Daraus ergibt sich eine konsistente Biografie als 'Iovoðios, und von einem ,Religionswechsel' kann keine Rede sein. Vielmehr deutet er sein Berufungserlebnis und den daraus resultierenden Auftrag in den Kategorien seines angestammten Orientierungssystems und verortet sich nach seiner Selbstdarstellung weiterhin in der Judenheit. Das Berufungserlebnis bewirkt lediglich innerhalb seines Orientierungssystems eine Neuorientierung hinsichtlich Christi. Durch die Vision des auferstandenen Christus hat sich Paulus' Perspektive auf ihn verändert, ja radikal gewendet. Paulus wird vom Verfolger von Christusgläubigen zum Verkündiger des Auferstandenen. ${ }^{202}$ Durch seine Christusvision ist er bevollmächtigt zur Evangeliumsverkündigung unter den Völkern. Diese Vollmacht zur Evangeliumsverkündigung ist für ihn konstitutiv. In seinem Fall soll die Evangeliumsverkündigung unter den Völkern geschehen: Die Völker sind seine Zielkultur.

201 Vgl. John M. G. Barclay, „Deviance and Apostasy: Some Applications of Deviance Theory to First-Century Judaism and Christianity“, in: John M. G. Barclay (Hg.), Pauline Churches and Diaspora Jews, WUNT 275 (Tübingen 2011), 123-139, hier: 136.

202 In diesem Punkt stimmen die paulinischen Eigenaussagen auch gänzlich mit den in der Apostelgeschichte referierten Berichten über das Berufungserlebnis überein: Paulus ist beauftragt, Apostel für die Völker zu werden. 


\subsubsection{Apostolat und apostolische Lebensweise}

Der Auftrag, den Paulus in seiner Berufung und Beauftragung bekommen hat, erfährt unter dem Begriff des Apostolats eine nähere Beschreibung. Aus Passagen zum Apostolat lassen sich auch Rückschlüsse auf die Interaktionen mit Menschen aus der Zielkultur und damit auf die Wirksamkeit des Vermittelns ziehen. Dabei wird auch ersichtlich, dass sich Erwartungen und Sichtweisen der Adressatinnen und Adressaten mit denen des Paulus kreuzen und sich zum Teil auch widersprechen. So gibt Paulus in 1 Kor 9,1 im Zusammenhang seiner rhetorischen Frage, ob er denn kein Apostel sei (oỉx

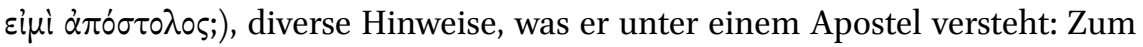
Apostolat zählt als wichtiges Merkmal seine Freiheit, die er in einer weiteren rhetorischen Frage ebenso wie sein Apostelsein als gegeben voraussetzt: O $u x$

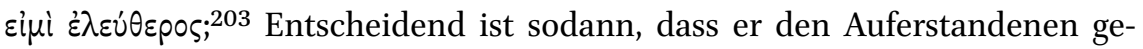
sehen hat, was er wiederum durch eine rhetorische Frage konstatiert (ovixi

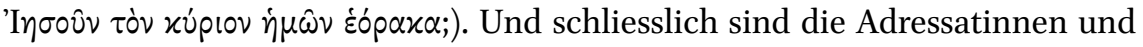
Adressaten selbst ein Beweis dafür, dass Paulus für den Herrn tätig ist (oủ

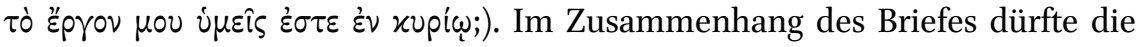
Pragmatik nicht einer Verteidigung des paulinischen Rechts auf Unterhalt, sondern den „Starken“ als Beispiel für den Rechtsverzicht dienen. ${ }^{204}$ Es geht hier also nicht um eine Verteidigung von Paulus' Apostelsein, sondern Paulus präsentiert sich als Vorbild. ${ }^{205}$ Dass die Autorität des Gesandtseins des Paulus bzw. seine Vollmacht, zu vermitteln, theoretisch bestritten werden könnte,

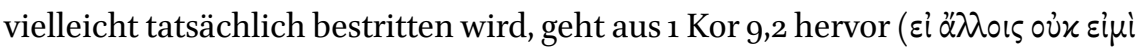

203 Aufgrund eines scheinbaren Themenwechsels haben Literarkritiker bei 1 Kor 9,1 einen Bruch konstatiert. So rechnet bspw. Johannes Weiss damit, dass die Stellung von 1 Kor 9 späterer Redaktionsarbeit zuzuschreiben ist: Johannes Weiss, Der erste Korintherbrief, 9. Aufl., KEK, Abt. 5, Ed. 9 (Göttingen 1910), XLII.

Allerdings fügen sich die Ausführungen zur apostolischen Freiheit ab 9,1 (insbesondere: 9,12.15) sehr gut an 1 Kor 8,9.13 an. Paulus exemplifiziert in 1 Kor 8,13 an seiner eigenen Praxis in Sachen Fleischkonsum seine Freiheit, die darin liegt, dass er die Freiheit zum Verzicht hat und dass er diese aus Rücksicht auf andere auslebt. Den Verzicht auf die apostolische Freiheit diskutiert er im Anschluss daran (1 Kor 9) ausführlich. Entsprechend sieht Mitchell in 1 Kor 9 eine beispielhafte Ausführung des in 1 Kor 8,13 aufgestellten Paradigmas. Vgl. Margaret M. Mitchell, Paul and the Rhetoric of Reconciliation: An Exegetical Investigation of the Language and Composition of 1 Corinthians, HUT 28 (Tübingen, Louisville (KY) 1991), 250.

204 Vgl. Wolfgang Schrage, Der erste Brief an die Korinther: 1 Kor 6,12-11,16, 4 Tlbde., EKK 7.2 (Solothurn 1995), 278-285; Mitchell, Paul and the Rhetoric of Reconciliation, 243 ff.; Gerber, Paulus und seine, Kinder', 157-160.

205 Intendiert ist demnach nicht eine Apologie des Apostolats, wie sie oft postuliert wird, wie bspw. von Christian Wolff, Jeremia im Frühjudentum und Urchristentum, TU (Berlin 1976), 187-188. Für zahlreiche weitere Verweise und Diskussionen vgl. Gerber, Paulus und seine ,Kinder', 157 (Fn. 16). 
à $\dot{\sigma} \sigma \tau 0 \lambda \circ \varsigma)$, allerdings bloss von Aussenseitern, nicht aber von den Adressaten des Briefes selbst, denn diese sind das Siegel ( $\sigma \varphi p \alpha \gamma i \varsigma)$ von Paulus' Gesandtsein bzw. Vollmacht.

Weiter beharrt Paulus auf seinem Recht, Essen und Trinken zu erhalten, sich eine "Schwester“ zur Ehefrau zu nehmen und auf Arbeit zu verzichten (1 Kor 9,4-6). Diese Privilegien, die ihm und seinen Mitarbeitenden zustehen, führt er mit Metaphern aus der Welt des Kriegs, der Agrikultur und der Viehwirtschaft und unter Rekurs auf das Gesetz aus (1 Kor 9,7-10). Die Welt der Arbeit stellt einen kohärenten Bildspendebereich für die zahlreichen Metaphern bereit, die Paulus zur Beschreibung seines Rechtsverzichts dienen. Für das Geistliche, das Paulus seinen Adressaten bietet, darf er in Analogie $\mathrm{zu}$ anderen, die etwas leisten, durchaus Materielles erwarten (1 Kor 9,11). Trotz seines Rechts ( $\dot{\xi} \xi \circ v \sigma i \alpha)$ ist er bemüht, seinen Verzicht darauf zu betonen (1 Kor 9,12-18) - dies im Unterschied zu anderen, die von ihrem Recht Gebrauch machen. Lieber will Paulus sterben, als seinen Privilegienverzicht

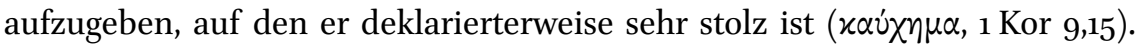
Seinen Dienst am Evangelium und den damit verbundenen Verzicht auf seine Rechte versteht Paulus als Sklavendienst (1 Kor 9,19-23). Diesem unterwirft er sich in aller Freiheit um des eschatologischen Zieles willen (1 Kor 9,24-27).

Dem Vers 1 Kor 9,19 kommt eine zentrale Bedeutung innerhalb des gesamten

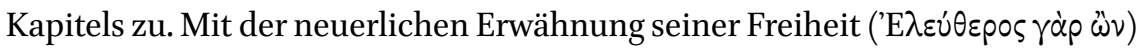
greift Paulus das zu Beginn des Kapitels genannte Thema und zentrale Attribut seines Apostolats wieder auf. Wenn er die Freiheit als Wesensmerkmal seines Apostolats im Folgenden entfaltet, erscheint sein freiwilliger Verzicht als Konsequenz seines zielorientierten Einsatzes für das Evangelium. Die Zielorientiertheit zeigt sich allein schon in der siebenmaligen Verwendung von iv $\alpha$ und wird schliesslich im Bild des zielorientierten Läufers und Faustkämpfers entfaltet (1 Kor 9,24-27). ${ }^{206}$

In seiner Freiheit und Versklavung steht Paulus als Nachfolger Christi in der Christusmimesis: In 1 Kor 4,11-12 beschreibt Paulus ein Wir, das Hunger und Durst leidet, nackt ist, keine Wohnung hat und Faustschläge erhält, und er hält fest, dass er und die Seinen sich abmühen und mit den Händen arbeiten. Bei Schmähungen segnen sie und Verfolgungen erdulden sie. Wenige Verse später fordert Paulus die Adressatinnen und Adressaten direkt auf, seinem Beispiel

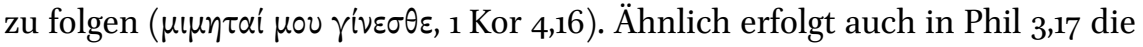

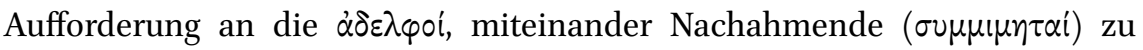
werden. Die Adressatinnen und Adressaten in Thessalonich werden gelobt,

206 Hierauf wird an entsprechender Stelle im Rahmen der Exegese von 1 Kor 9,19-23 noch ausführlich eingegangen. 
weil sie Nachahmer ( $\left.\mu \mu \eta \eta \tau \alpha^{i}\right)$ von Paulus und seinen Leuten geworden sind und das Wort in Bedrängnis „mit Freude des Heiligen Geistes“ aufgenommen haben (1 Thess 1,6). Gott macht sich zudem "mittels des Duftes seiner Erkennt-

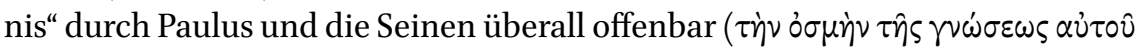

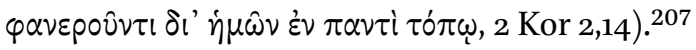

Dass Paulus sein Wirken nicht auf sich selbst bezogen versteht, sondern alleine im Dienste des Evangeliums, drückt er aus mit der Aussage, dass er und seine Mitwirkenden nicht "sich selbst“ predigen, sondern dass sie Jesus Christus, den Herrn, verkündigen, sich selbst dagegen verstehen als „Sklaven

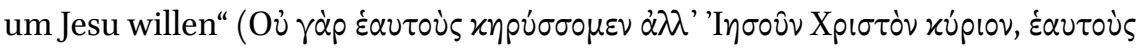

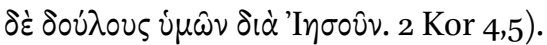

Weil Gott sich mit sich selbst versöhnt und den Dienst der Versöhnung

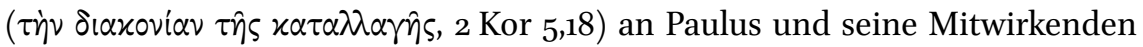

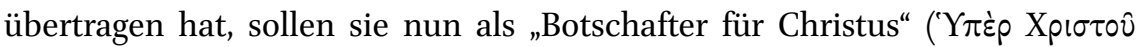

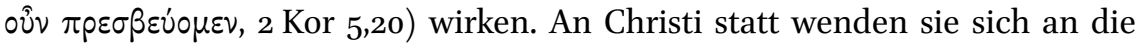
Adressatinnen und Adressaten mit der Aufforderung, sich mit Gott zu versöhnen ( $\varkappa \alpha \tau \alpha \lambda \lambda \dot{\alpha} \gamma \eta \tau \varepsilon \tau \hat{\varphi} \theta \varepsilon \hat{\omega}, 2$ Kor 5,20$)$.

Der Auftrag der Vermittlung ist also auch auf der christologischen Ebene klar: Paulus und seine Mitarbeitenden wenden sich in aller Freiheit als Gesandte Christi ihren Adressatinnen und Adressaten zu, bitten an Christi statt, um auch sie zur Christusmimesis zu überzeugen. Für Paulus selbst gilt es festzuhalten, dass die Christozentrik seines apostolischen Auftrags zwar eine beachtliche Anpassung seines früheren Eifers in der Umsetzung von Gottes Willen bedeutet, aber die missionarische Hinwendung zu den Völkern als Zielkultur erst eröffnet.

\subsubsection{Missionsverständnis}

4.3.5.1 Mission als multidimensionales und reziprokes Geschehen

Wie bereits ausgeführt, ist Paulus ausgesandt, um die Botschaft vom Aufer-

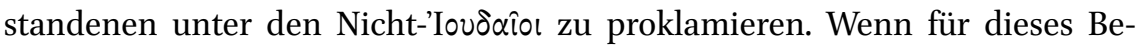
streben der Begriff der Mission verwendet wird, geschieht dies im Sinne der von Volker Rabens aufgestellten Definition von Mission als:

das multidimensionale Engagement eines Einzelnen oder einer Glaubensgemeinschaft [...], das das Ziel verfolgt, andere Menschen für die eigenen Glaubensinhalte und die damit verbundene Lebenspraxis zu gewinnen. ,Multidimensional' bedeutet im Fall von Paulus, dass dieses Engagement nicht auf die verbale Verkündigung beschränkt ist, sondern ein ganzheitliches und reziprokes Teilen von Leben umfasst, zu dem u. a. das gemeinsame Arbeiten und Essen,

207 Zur Duftmetapher vgl. ebd., 172-175. 
theologische Reflektion [sic!] und Diskussion, ethische Unterweisung und die Erfahrung von Geistesgaben und Wundern gehören. ${ }^{208}$

Die Mission ist demnach ein anderer Ausdruck für das Kulturtransfergeschehen, dessen zentraler Akteur Paulus als Vermittler ist. In der angeführten Definition von Mission wird deutlich, dass der Kulturtransfer ausdrücklich kein eindimensionales Geschehen ist. Vielmehr ist die Interaktion aller Beteiligten von grosser Bedeutung. Es ist davon auszugehen, dass nicht nur die Adressatinnen und Adressaten der missionarischen Bestrebungen durch die Hinwendung zum und Aufnahme des kulturellen Artefakts eine Veränderung erfahren. Das Geschehen hat reziprok auch eine Wirkung auf diejenigen, die vermittelnd tätig sind, also auf Paulus und seine Mitarbeitenden.

\subsubsection{Klärungen in der Ausrichtung des Missionsauftrags}

Für die Mission des Paulus unter den Völkern stellt das Treffen in Jerusalem, von dem Paulus im Galaterbrief berichtet, ein äusserst bedeutendes Ereignis dar (Gal 2,1-10), das für die Ausrichtung seiner Vermittlertätigkeit eine klärende Funktion hat. Nicht ohne Polemik berichtet Paulus in narrativer Weise von seiner Begegnung mit den ,Säulen', d.h. den Jerusalemer Autoritäten, den Diskussionen und Auseinandersetzungen mit ihnen und der schliesslich erreichten Einigung. Im Verhältnis zu ihnen stellt Paulus sich als gleichberechtigt dar. Sein Besuch bei Kephas in Jerusalem drei Jahre nach seiner Berufung dient nicht der Legitimation seines Apostolats durch eine menschliche Oberhoheit, sondern ist der Besuch eines Ebenbürtigen. Die Einigung, dass fortan die Jerusalemer unter den Beschnittenen wirken und Paulus unter den Völkern, bestätigt dies (Gal 2,7-9). Die Jerusalemer Autoritäten teilen von Anfang an mit Paulus die Hochschätzung des kulturellen Artefakts, aber die Ausrichtung, wohin es vermittelt werden soll, steht zur Debatte. Resultat ist, dass die Jerusalemer Autoritäten bei der Vermittlung innerhalb von Adressatenkreisen bleiben, die schon vorher zum 'Iovoaï $\sigma$ ós gehört haben, während Paulus sich explizit auf Menschen ausrichtet, die nicht zu ihrem gemeinsamen Orientierungssystem zählen.

Entscheidend für seine Missionsstrategie ist sein Grundsatz, dass das

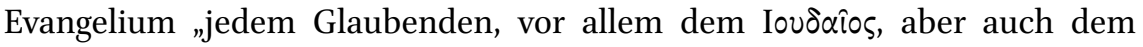

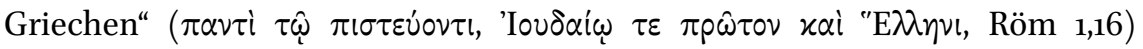
gehört. ${ }^{209}$ Deutlich ist hier, dass nach Paulus' Verständnis die Welt eingeteilt ist

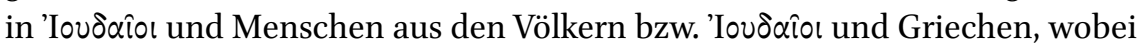

208 Volker Rabens, in: Reinhard von Bendemann (Hg.), Das frühe Christentum und die Stadt, BWANT, Folge 10, H. 18 = H. 198 (Stuttgart 2012), 219.

$209 \pi \rho \hat{\omega} \tau$ เov wird hier qualitativ verstanden, nicht temporal. 


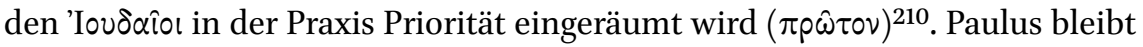
seiner Darstellung nach dem ihm angestammten Volk und damit seiner Ausgangskultur verbunden, auch wenn er in deren Orientierungssystem wesentliche Änderungen postuliert. Ausdrücklich ist sein Wirken auf die Völker ausgerichtet, wie er es an mehreren Orten festhält. Darüber hinaus aber hofft er, auch einige, die aus seinem eigenen Fleisch sind, zu erretten ( $Y \mu i \nu ~ \delta \dot{\varepsilon} \lambda \varepsilon_{\varepsilon} \gamma \omega$

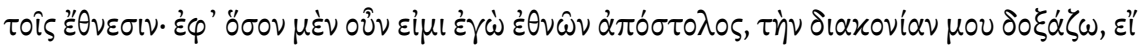

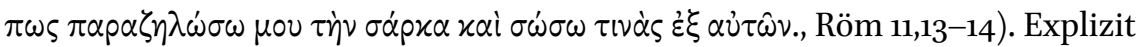

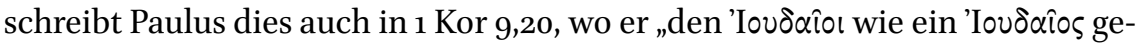

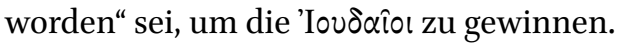

\subsubsection{Mission als gemeinschaftliches Unterfangen}

Bedeutend für das Vermittlungsgeschehen ist, dass Paulus in seinem missionarischen Bestreben zwar eine herausragende Stellung hat, aber keineswegs ein Einzelkämpfer ist. Vielmehr ist er in ein Netz von Menschen eingebunden, die mit ihm an der Christusbotschaft weben und diese in die pagane Welt hineinvernetzen. Verschiedentlich nennt Paulus Kollektive, in vielen Fällen erwähnt er aber auch namentlich Mitarbeitende, häufig mit einer näheren Bezeichnung ihrer Stellung bzw. des Verhältnisses zu ihm. ${ }^{211}$ Paulus benennt zahlreiche Männer und Frauen, Freie und Unfreie, die er zu seinem Mitarbeitendenkreis zählt: vor Ort, aber auch unterwegs mit ihm oder in seinem Auftrag.

Die Mitarbeitenden im Detail:

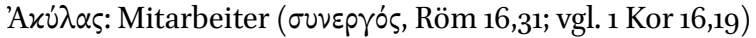

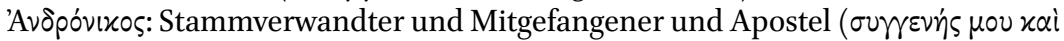

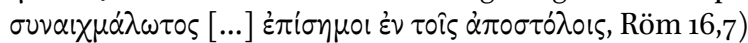

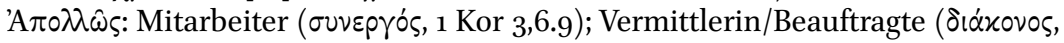
1 Kor 3,5); Bruder ( $\dot{\alpha} \delta \varepsilon \lambda \varphi \dot{o} \zeta, 1$ Kor 16,12)

'A $\pi \varphi$ ía: Schwester (Phlm 2)

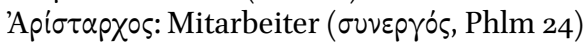

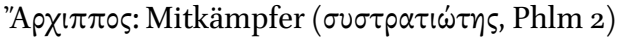

'A хä̈xós: Begleiter des Paulus (1 Kor 16,17)

B $\alpha p v \alpha \beta \alpha \hat{\varsigma}$ : Begleiter des Paulus ( $\sigma \nu \mu \pi \alpha \rho \alpha \lambda \alpha \beta \hat{\omega} \nu$, Gal 2,1)

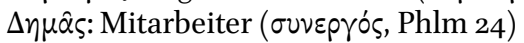

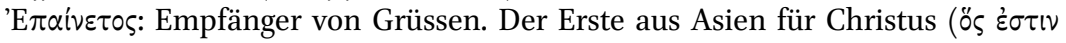

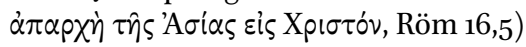

210 Vgl. Röm 2,9-11; 3,9.29-30; 10,12-13.

211 Ollrog deutet den Begriff ouvepyós als „terminus technicus für die mit ihm in der Missionsarbeit stehenden Personen“. Als Bezeichungen für Mitarbeitende können gelten:

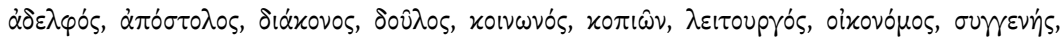

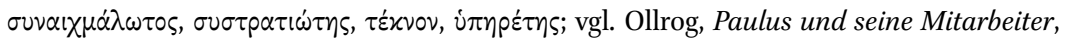
63-84, Zitat: 72. 


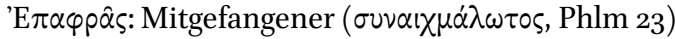

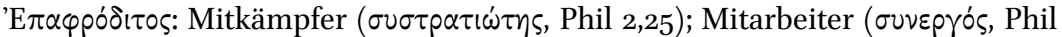
2,25); Abgesandter ( $\alpha \pi \delta ́ \sigma \tau 0 \lambda \circ \varsigma$, Phil 2,25); Bruder ( $\dot{\delta} \varepsilon \lambda \varphi_{\varphi} \varsigma^{212}$, Phil 2,25); Diener ( $\lambda \varepsilon$ เा०uprós, Phil 2,25)

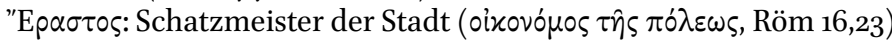

Ev่odía: hat mit Paulus mitgekämpft (

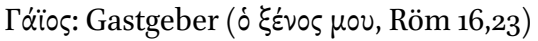

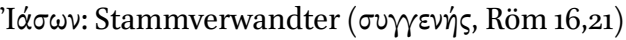

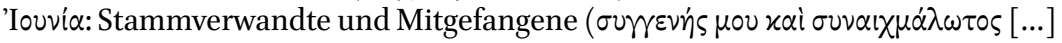

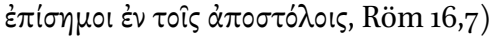

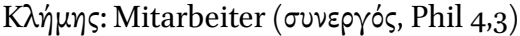

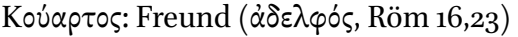

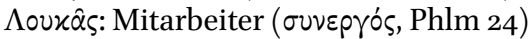

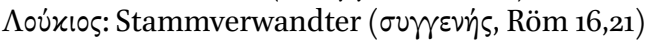

Mapía: Empfängerin von Grüssen des Paulus, die sich um die Adressaten von

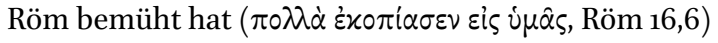

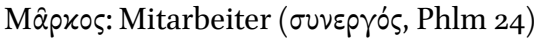

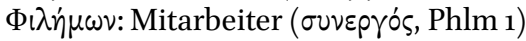

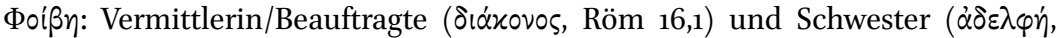

Röm 16,1)

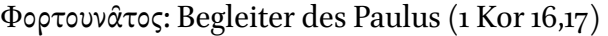

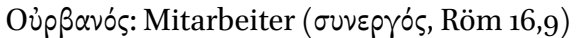

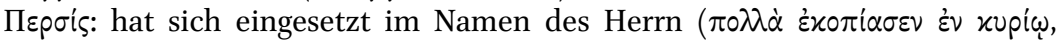

Röm 16,12)

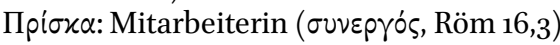

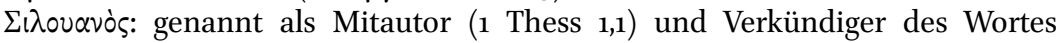

$(2$ Kor 1,19$)$

$\Sigma \tau \dot{\alpha} \chi \cup \varsigma:$ ( $\tau \dot{v} v \dot{\alpha} \gamma \alpha \pi \eta \tau o ́ v ~ \mu o v$, Röm 16,9)

$\Sigma \tau \varepsilon \varphi \alpha \nu \alpha \hat{s}$ : Begleiter des Paulus (1 Kor 16,17)

$\Sigma \omega \sigma \theta \varepsilon \dot{v} \eta \varsigma:$ genannt als Mitautor und Bruder ( $\dot{\delta} \delta \varepsilon \lambda \varphi o ́ \varsigma, 1$ Kor 1,1)

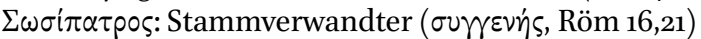

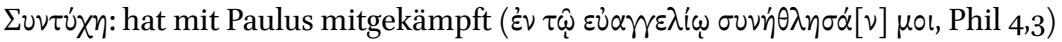

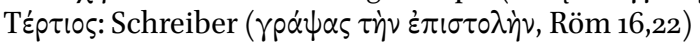

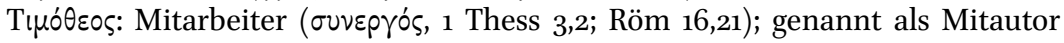

(2 Kor 1,1; 1 Thess 1,1; Phil 1,1; Phlm 1); Abgesandter des Paulus (है $\pi \varepsilon \mu \psi \alpha$ i $\mu \hat{\imath} \nu$

Tiнó $\theta \varepsilon \circ \nu, 1$ Kor 4,17; vgl. 1 Kor 16,10; Phil 2,19; 1 Thess 3,2.6); geliebtes Kind ( $\mu \circ v$ $\tau \varepsilon \dot{\varepsilon} x$ vov $\alpha \gamma \alpha \pi \eta \tau \dot{v} v, 1$ Kor 4,17); zusammen mit Paulus und Silvanus Verkündiger

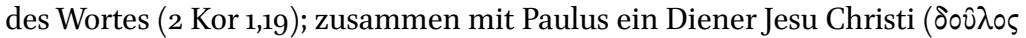

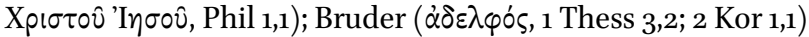

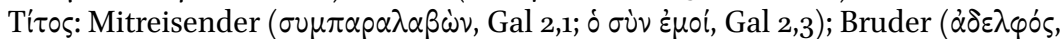

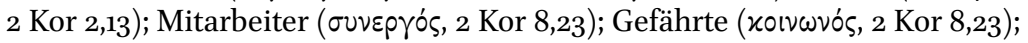
Gesandter ( $\alpha$ đó $\sigma \tau 0 \lambda \circ \varsigma, 2$ Kor 8,23; vgl. 2 Kor 2,13; 7,6.13.14; 8,6.16; 12,18)

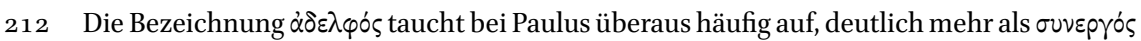

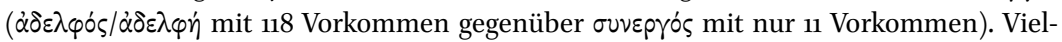
fach erscheint $\dot{\alpha} \delta \varepsilon \lambda \varphi \circ i$ als direkte Anrede an die Angeschriebenen. Diese Kategorie ist in der Liste nicht berücksichtigt. Daneben erhalten einzelne Namen die Bezeichnung $\alpha \dot{\alpha} \varepsilon \lambda \varphi o^{\prime} \varsigma$ oder $\alpha \dot{\delta} \varepsilon \lambda \varphi \eta \dot{\eta}$ als Epitheton zugeschrieben. Diese sind in der Liste berücksichtigt. 


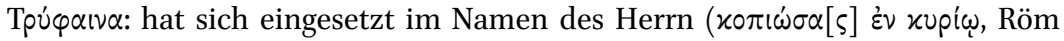
$16,12)$

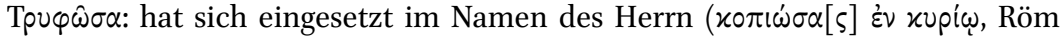
$16,12)$

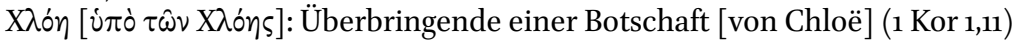

Hinzu kommen noch diverse namentlich genannte, aber in ihrer Tätigkeit nicht näher beschriebene Empfänger von Grüssen: 'A $\mu \pi \lambda \iota \hat{\alpha} \tau \circ \varsigma$ (Röm 16,7),

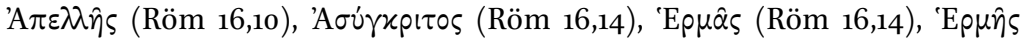

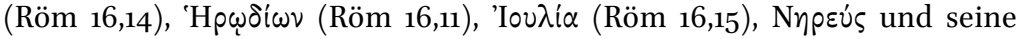

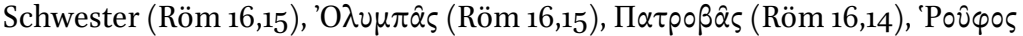

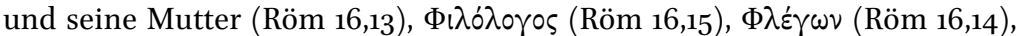

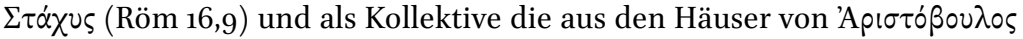

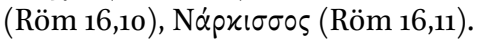

Zu den namentlich genannten kommen weitere nicht namentlich genannte Mitarbeitende bzw. Begleitende hinzu:

Paulus nennt einerseits einen Plural von бuveproí (Phil 4,3) und andererseits

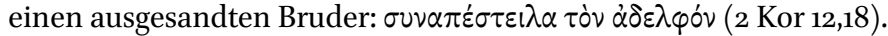

Summarisch nennt er auch ein Kollektiv von $\dot{\alpha} \delta \varepsilon \lambda \varphi 0^{\prime}$ als Mitautoren (Gal 1,2) bzw. Mitgrüssende (1 Kor 16,20; Phil 4,21)

Weiter nennt er einzelne Brüder oder ein Kollektiv von Brüdern als Gesandte (2 Kor 8,$18 ; 9,3.5 ; 12,18)$ oder als mit ihm Wartende (1 Kor 16,11).

Und schliesslich erwähnt er die aus Mazedonien angereisten Brüder, von denen er Unterstützung erhält (2 Kor 11,9), sowie die Menschen in Philippi (Phil 4,15-16).

Allein schon vom Umfang dieser Liste her tritt deutlich vor Augen, dass Paulus nicht alleine agiert, sondern sich in und mit einem Netz von zahlreichen Mitarbeitenden und Begleitenden bewegt. Ihrer aller Aktivitäten kreuzen sich bzw. sind ineinander verwoben. Bei den meisten Briefen ist Paulus nicht alleiniger Autor; Menschen überbringen die Briefe an die Empfängergruppen; es reisen Menschen mit, wenn Paulus unterwegs ist; vor Ort hat er Kontakte, die für das Gelingen seines Vermittelns unter den Völkern eine entscheidende Rolle spielen.

\subsubsection{Zum Missionskonzept in der Welt der Völker}

Der Frage, wie Paulus sich innerhalb der grossen Welt der Völker ,seine‘ Zielgruppen aussucht, und auch, was er tut, wenn er an einem anvisierten Ort ankommt, ist jüngst Volker Rabens nachgegangen. ${ }^{213}$ Die Studie von Rodney Stark aufnehmend nennt Rabens drei sich auf statistische Untersuchungen

213 Vgl. Volker Rabens, „Paul's Mission Strategy in the Urban Landscape of the First-Century Roman Empire“, in: Steve Walton, Paul R. Trebilco und David W. J. Gill (Hg.), The Urban World and the First Christians (Grand Rapids (MI) 2017), 99-122. Beim genannten Aufsatz handelt es sich um eine übersetzte und erweiterte Version von Volker Rabens, „,Von 
stützende Hypothesen zur paulinischen Auswahl seiner Destinationen: (1) Paulus konzentriert sich unter den möglichen Städten im Römischen Reich auf die stärker hellenisierten; er visiert (2) mit Vorliebe Hafenstädte an, in denen (3) substanzielle jüdische Gruppen leben. ${ }^{214}$ Trotz berechtigter Kritik an der von Stark verwendeten Methodik ist davon auszugehen, dass Paulus weitgehend den grossen Handelsrouten folgt und sich eher auf die grösseren Städte konzentriert. ${ }^{215}$ Hinweise in den Paulusbriefen lassen erkennen, dass Paulus hinsichtlich seiner Routen weiter reichende Pläne hat (z. B. 1 Thess 2,18; 1 Kor 4,19; 11,34; 16,5-6; Röm 15,19-25). ${ }^{216}$ Diese muss er allerdings mehrfach den jeweils sich ergebenden Umständen anpassen (1 Thess 2,18; 2 Kor 2,12-13; Röm 1,13; 15,22). In Röm 15,19-20 deklariert er, das Evangelium von Jerusalem aus bis nach Illyrien verkündigen zu wollen. Was die Interpretation dieser beiden Verse hinsichtlich der geografischen Ausbreitung des Evangeliums anbelangt, diskutiert Rabens verschiedene Ansätze, die diese Verse mit alttestamentlichen Traditionen verbinden (Jes 66,19 oder Gen 10). ${ }^{217}$ Diese bringt er ins Gespräch mit der These, dass Paulus sich an einem römischen Paradigma von Territorialität orientiere. ${ }^{218}$ Das Konzept von Territorialität beinhaltet das Zusammenspiel der drei Komponenten nature, meaning und social relations, also die Natur im Sinne der physischen Welt, Sinn sowie soziale Beziehungen. ${ }^{219}$ Diese drei Komponenten beeinflussen sich wechselseitig. Pointiert geäussert hat sich in jüngerer Zeit Ksenija Magda:

Jerusalem aus und rings umher ...' (Röm. 15,19): Die paulinische Missionsstrategie im Dickicht der Städte“, in: von Bendemann, Das frühe Christentum und die Stadt.

214 Vgl. Rodney Stark, Cities of God: The Real Story of How Christianity Became an Urban Movement and Conquered Rome (San Francisco 2006), 132.

215 Vgl. Volker Rabens, „Paul's Mission Strategy in the Urban Landscape of the First-Century Roman Empire“, in: Walton, Trebilco und Gill, The Urban World and the First Christians, 101, mit Verweis auf Stark, Cities of God, 81 .

216 Dies im Gegensatz zur Darstellung in der Apostelgeschichte, in der sich Paulus vom Heiligen Geist leiten lässt (z. B. Apg 16,6-10; 21,4) bzw. sich jeweils neu orientiert, wenn es zu Konflikten kommt (z. B. Apg 14,19-20; 16,39-40; 20,1-3).

217 Vgl. zum geografischen Rahmen der paulinischen Mission und zur Lektüre von Röm 15,16-28 auf dem Hintergrund von Jes 66,18-21 insbesondere Riesner, Die Frühzeit des Apostels Paulus, 213-227. Zu Gen 10 als Hintergrund vgl. James M. Scott, Paul and the Nations: The Old Testament and Jewish Background of Paul's Mission to the Nations with Special Reference to the Destination of Galatians, WUNT 84 (Tübingen 1995), Kap. 3.

218 Vgl. Volker Rabens, „Paul's Mission Strategy in the Urban Landscape of the First-Century Roman Empire", in: Walton, Trebilco und Gill, The Urban World and the First Christians, 105-112. Dazu schon früher Martin Hengel, „Der vorchristliche Paulus“, in: Heckel, Hengel und Schlatter, Paulus und das antike Judentum, 201-202.

219 Zur Definition von Territorialität vgl. Robert David Sack, Homo geographicus: A Framework for Action, Awareness, and Moral Concern (Baltimore 1997), Kap. 1; Robert David Sack, Human Territoriality: Its Theory and History, CSHG 7 (Cambridge 1986), 5 und 19. 
Within his Roman territoriality paradigm, Paul's call by Christ could bring about that serious change in theological understanding which was so difficult for Jerusalem-based apostles. Paul was a Roman citizen with a cosmopolitan feeling for all the nations, far more so than the other disciples of Jesus. In comparison with the territoriality of the other apostles, Paul's is broad enough to include other nations. Indeed, his place is broad enough to give him the freedom to claim that he can be all things to all people (l Cor 9:20)! His territoriality makes Paul aware of the need for salvation, which triggers a re-evaluation of his spiritual experience as well as his own Jewish traditions. ${ }^{220}$

Magda vertritt die These, dass die paulinische Mission unter den Völkern im römischen Territorialitätsparadigma liegt und für ihn der Grund war, eine Provinz nach der anderen zu bereisen.

Plausibel erscheint Rabens' Schluss, dass die römische Territorialität und die Gegebenheiten der römischen Städte einen günstigen Rahmen für Paulus' Reisen bieten. Diese würde er retrospektiv mit den prophetischen Worten von Jes 66 in Verbindung bringen. ${ }^{221}$ Die Umstände für Reisen sind zur Zeit des Paulus verhältnismässig günstig. Die Sicherheit während des Reisens ist unter derPaxAugusta relativ hoch und das Verkehrsaufkommen zunehmend. ${ }^{222}$ Grössere römische Städte sind in mancherlei Hinsicht geeignet für Paulus' Bestrebungen, das Evangelium zu verbreiten. ${ }^{223}$ In den Städten bewegen sich viele Händler, und die Infrastruktur ist gut ausgebaut, sodass es relativ einfach ist, mit anderen Menschen in Kontakt zu kommen. Ganz zentral für die Kommunikation ist natürlich die Koiné als Lingua franca.

Für Städte wie Korinth oder Ephesus dürfte Paulus sich aus mehreren Gründen entschieden haben. ${ }^{224}$ Neben den bereits genannten sowie den Möglichkeiten zur Ausübung von Erwerbstätigkeit und Missionsgelegenheiten daselbst weisen diese Städte eine heterogene Bevölkerung auf, zu der

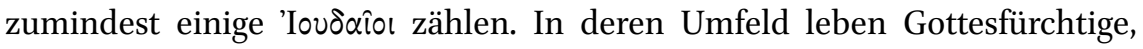
die für Paulus ein willkommenes Zielpublikum darstellen und umgekehrt wichtig werden für sein Wirken. ${ }^{225}$ Es kann kaum genug betont werden, dass es sich bei Paulus' Bemühungen um ein Beziehungsgeschehen handelt und damit um einen reziproken Prozess, bei dem er sich zusammen mit seinen

220 Ksenija Magda, Paul's Territoriality and Mission Strategy: Searching for the Geographical Awareness Paradigm behind Romans, WUNT II 266 (Tübingen 2009), 183.

221 Vgl. Volker Rabens, „Paul's Mission Strategy in the Urban Landscape of the First-Century Roman Empire“, in: Walton, Trebilco und Gill, The Urban World and the First Christians, 112.

222 Rabens weist mit Recht darauf hin, dass die Reisen des Paulus vielleicht treffender als Umzug bezeichnet werden könnten; vgl. ebd.

223 Vgl. ebd., 111-112.

224 Vgl. ebd., 122.

225 Vgl. ebd. 
Mitarbeitenden in eine Stadt hineinbegibt, mit den Menschen arbeitet, diskutiert, lebt und wirkt, was wiederum Einfluss auf sein Handeln hat.

\subsection{Zusammenfassung und Fazit}

Es hat sich gezeigt, dass sprachliche Aspekte für das Transfergeschehen eine ganz zentrale Rolle spielen: beim historischen Geschehen einerseits, aber insbesondere auch deshalb, weil die anderen mit Sicherheit zentralen Formen der Begegnung aus der historischen Distanz nicht mehr nachvollzogen werden können. Sämtliche uns überlieferten direkten Quellen von und über Paulus sind schriftlicher und damit sprachlicher Art. ${ }^{226}$ Dank seiner Herkunft aus dem Diasporajudentum verfügt Paulus über ein fehlerfreies Koiné-Griechisch und über eine grosse Vertrautheit mit der Septuaginta sowie über kulturelle Fertigkeiten und das Wissen um die Welt der Adressatinnen und Adressaten.

Paulus und seine Mitarbeitenden kommunizieren einerseits persönlich vor Ort, andererseits mittels in Koiné verfasster Briefe mit den christusgläubigen Gruppen im Mittelmeerraum. Die Briefe werden diktiert - sind also ursprünglich mündlich -, dann in schriftlicher Form übermittelt und am Empfängerende wiederum mündlich präsentiert. Den jeweiligen Überbringern der Briefe kommt eine nicht zu unterschätzende Funktion zu. Mit dem Brief als Medium der Korrespondenz partizipieren Paulus und seine Mitarbeitenden an einer in der hellenistischen Welt weitverbreiteten Art der Kommunikation. Diese Schreiben lassen sich als gemeindeleitende Briefe mit Aspekten des philophronetischen Briefes bezeichnen. Sie weisen eine grosse Nähe zu frühjüdischen Briefen dieses Genres auf, was angesichts der Herkunft und Sozialisierung des Paulus kaum verwunderlich ist. Paulus ist der erste christusgläubige Autor, von dem wir wissen, dass er Briefe zur Leitung einer Gruppe einsetzt und damit als Medium zur Vermittlung des Evangeliums unter den Menschen aus den Völkern als seiner Zielkultur. Paulus schreibt an Hausgemeinschaften in der hellenistischen Welt und damit an eine Öffentlichkeit. Sprachlich weisen schon bestimmte Formulierungen die Tendenz zur interkulturellen Vermittlung auf, indem Paulus beispielsweise nicht ausschliess-

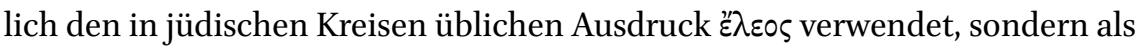

226 Dass wir nicht die eigentlichen von Paulus oder seinen Schreibern selbst physisch geschriebenen Briefe zur Verfügung haben, sondern lediglich Abschriften davon oder Abschriften von Abschriften, die möglicherweise sogar noch kompiliert sind, muss an dieser Stelle zwar festgehalten werden, ändert aber nichts. Entscheidend ist, dass die direktesten vorhandenen Quellen zu Paulus sprachlicher Art sind. 
Hinwendung zu den Menschen aus den Völkern den in pagan-griechischen Kreisen üblichen Gruss $\chi \alpha$ áı aufnimmt. In Verbindung mit dem wiederum jüdischen Friedensgruss entsteht durch die christologische Reinterpretation etwas Neues.

Alle Briefe sind situationsgebunden, und die meisten enthalten zahlreiche autobiografische Hinweise. Es lassen sich somit diverse Aspekte paulinischer Selbstbeschreibung zusammenstellen, die durch Angaben aus der Apostelgeschichte ergänzt werden können.

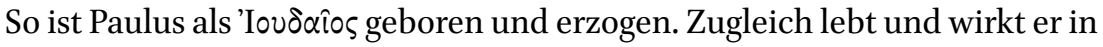
der Zeit des sogenannten Hellenismus, der alle und alles beeinflusst. Insofern

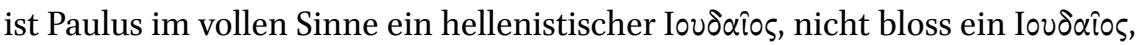
der zufälligerweise auf Griechisch schreibt. ${ }^{227}$ Zugleich zeigt sich Paulus' Zu-

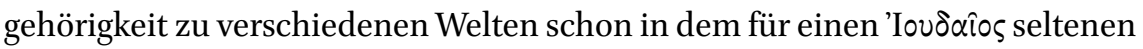
und daher auffälligen Namen П $\alpha \hat{\lambda}$ os. Jede der darüber hinaus und zur näheren Charakterisierung seiner Person verwendeten Herkunftsbeschreibungen betont Aspekte seiner übergeordneten Identität als (hellenistischer) 'Iovסaios: Mit 'Eßpaîos wird einerseits eine ethnische Zugehörigkeit angezeigt, anderer-

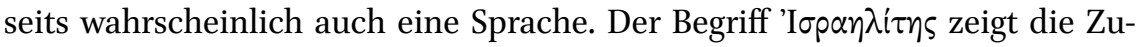
gehörigkeit zum auserwählten Gottesvolk und zu seiner Geschichte an. Als

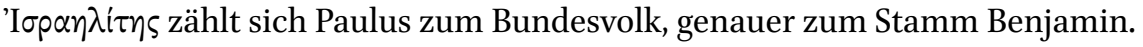
Die Formel $\sigma \pi \varepsilon \dot{p} \mu \alpha$ 'A $\beta p \alpha \alpha ́ \mu$ drückt die Kontinuität mit Abraham als dem Vater vieler Völker aus und zeugt von der Gewissheit, Träger dieser Verheissung zu sein. Paulus ist gemäss seiner eigenen Beschreibung ein Beschnittener, also äusserlich gekennzeichnet als Mitglied des Volkes Israel. Die Welt dieses Volkes und die Traditionen, die für es prägend sind, sind das Orientierungssystem, innerhalb dessen er sich sein Leben lang bewegt.

Paulus dürfte in der Diaspora, wahrscheinlich in Tarsus, geboren sein, ebendort einen Teil seiner Ausbildung durchlaufen haben und später nach Jerusalem gegangen sein. Entscheidender als die Frage, wo Paulus welche Elemente seiner Bildung erhalten hat, ist allerdings die Vorstellung von der Progression in Paulus' Bildung: von der literarischen Ausbildung in allgemein griechisch-hellenischer Form über die Progymnasmata, die philosophischen und rhetorischen Lehren, bis hin zur Beschäftigung mit dem Pharisäismus, innerhalb dessen er viele seiner Genossen an Eifer übertrifft und Andersgläubige verfolgt.

Die Vision vom auferstandenen Christus und die Hinwendung zu ihm

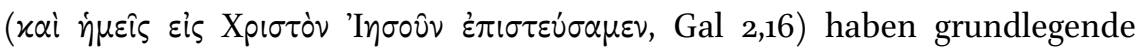
Konsequenzen: Paulus ist zum Apostel für die Völker berufen (Gal 1,16). Er

227 Vgl. du Toit, „Paulus Oecumenicus“, 121. 
adaptiert sein Verständnis vom jüdischen Orientierungssystem dahingehend, dass es permeabel wird für Aussenstehende. Über das zentrale kulturelle Artefakt, den Glauben an den auferstandenen Christus, können die Menschen aus den Völkern in dieses Orientierungssystem integriert und teilhaftig werden am Heil Israels. Mehr noch: Paulus erachtet sein Wirken unter den Völkern als Fortführung der ehrbaren Tradition der israelitischen Propheten, die selbst schon zum Dienst unter den Völkern berufen waren. ${ }^{228}$ Dies zeigt sich in seiner Anlehnung an die Berufungsgeschichten der Propheten Jesaja und Jeremia, wenn er von seiner eigenen Berufung schreibt (Gal 1,15-16). In alledem bleibt Paulus seiner Selbstdarstellung nach innerhalb der Grenzen des Judentums und somit innerhalb seines angestammten Orientierungssystems, auch wenn dieses eine beträchtliche Verschiebung erfahren hat. Den Glauben an Christus versteht Paulus nunmehr als zentralen Teil seines Glaubens an den Gott Israels.

Wichtig ist für Paulus' Selbstdarstellung als Apostel für die Völker seine Unabhängigkeit von den Jerusalemer Autoritäten, auf der er insistiert. Das Evangelium, das er verkündet, ist nicht menschlicher Art, denn er hat es nicht von Menschen empfangen, sondern direkt durch eine Offenbarung Jesu Christi (Gal 1,11-12). Paulus versteht sich als gewissermassen priesterlicher

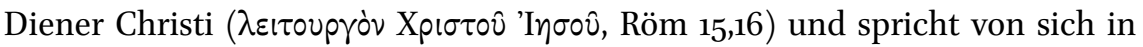
Anlehnung an den jesajanischen Gottesknecht (Röm 15,21). Entsprechend

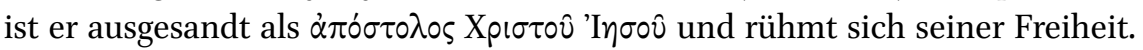
Um seine Subsistenz unter dieser Lebensaufgabe zu gewährleisten und den christusgläubigen Gruppen nicht zur Last zu fallen, betätigen sich Paulus und seine Mitarbeitenden auch auf Reisen als Handwerker. Diese Tätigkeit ist ein wesentlicher Aspekt seiner Freiheit und seines Verständnisses als Apostel, auf die er insbesondere in 1 Kor 9 eingeht.

Als Apostel für die Völker zählt Paulus auf einen umfassenden Stab von Mitarbeitenden: Mitautoren, Abgesandte, Begleiter und Mitarbeitende vor Ort. Er wirkt hier zusammen mit anderen an einem sich ausbreitenden und dynamischen Geflecht von Beziehungen mit. Insofern ist es ein Stück weit eine Verkürzung, von Paulus alleine als interkulturellem Vermittler zu sprechen, denn er ist bei näherer Betrachtung Teil eines wachsenden Netzes von Mitarbeitenden, also einer von vielen. Angesichts seiner zentralen Funktion und treibenden Kraft im Geschehen ist allerdings die Rede von Paulus als interkulturellem Vermittler gleichwohl angemessen. Die andere Dimension darf allerdings nicht ausgeblendet, sondern muss mitgedacht werden.

228 Vgl. Johnson Hodge, If Sons, then Heirs, 120. 